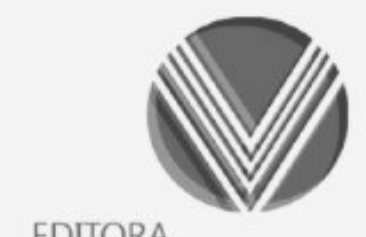

IN VIVO 
MEDICINA E BEM-ESTAR DE ANIMAIS SILVESTRES E EXÓTICOS

VOLUME 1

AKSA INGRID VIEIRA BATISTA

VICTOR FERNANDO SANTANA LIMA

(Organizadores)

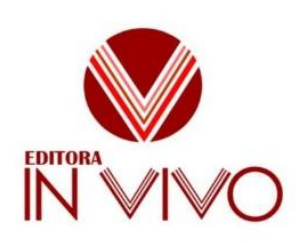

2021 


\author{
2021 by Editora In Vivo \\ Copyright (C) Editora In Vivo \\ Copyright do Texto (C) $2021 \mathrm{O}$ autor \\ Copyright da Edição (C) 2021 Editora In Vivo
}

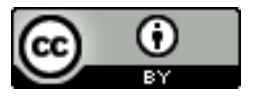

Esta obra está licenciada com uma Licença Creative Commons Atribuição 4.0 Internacional (CC BY 4.0).

\begin{abstract}
O conteúdo desta obra e seus dados em sua forma, correção e confiabilidade são de responsabilidade exclusiva dos autores. Permitido o download da obra e o compartilhamento desde que sejam atribuídos créditos aos autores, permitindo-se uso para fins comerciais.
\end{abstract}

\section{Colégio de Ciências da Vida 1.1 Ciências Agrárias}

Dr. Aderson Martins Viana Neto Dra. Ana Paula Bezerra de Araújo MSc. Edson Rômulo de Sousa Santos Dr. Fágner Cavalcante P. dos Santos MSc. Filomena Nádia Rodrigues Bezerra Dra. Lina Raquel Santos Araújo Dr. Luis de França Camboim Neto MSc. Maria Emília Bezerra de Araújo MSc. Yuri Lopes Silva

\subsection{Ciências Biológicas}

Dra. Antonia Moemia Lúcia Rodrigues Portela 1.3 Ciências da Saúde

Dra. Ana Luiza M. Cazaux de Souza Velho

Dr. Isaac Neto Goes Silva

Dra. Maria Verônyca Coelho Melo

MSc. Paulo Abílio Varella Lisboa

Dra. Vanessa Porto Machado

Dr. Victor Hugo Vieira Rodrigues

\section{Editor Chefe}

Dr. Everton Nogueira Silva

\section{Conselho Editorial}

\section{Colégio de Humanidades} 2.1 Ciências Humanas

Dra. Alexsandra Maria Sousa Silva

MSc. Francisco Brandão Aguiar

MSc. Julyana Alves Sales

2.2 Ciências Sociais Aplicadas

MSc. Cícero Francisco de Lima

MSc. Erivelton de Souza Nunes

Dra. Maria de Jesus Gomes de Lima

MSc. Maria Rosa Dionísio Almeida

MSc. Marisa Guilherme da Frota

MSc. Tássia Roberta Mota da Silva Castro

3 Colégio de Ciências Exatas, Tecnológica

\section{e Multidisciplinar}

3.1 Ciências Exatas e da Terra

MSc. Francisco Odécio Sales

Dra. Irvila Ricarte de Oliveira Maia

3.2 Engenharias

MSc. Amâncio da Cruz Filgueira Filho

MSc. Gilberto Alves da Silva Neto

MSc. Henrique Nogueira Silva

Dr. João Marcus Pereira Lima e Silva

MSc. Ricardo Leandro Santos Araújo

Dados Internacionais de Catalogação na Publicação - CIP

B333m Batista, Aksa Ingrid Vieira.

Medicina e bem-estar de animais silvestres e exóticos [livro eletrônico]. /

Organizadores: Aksa Ingrid Vieira Batista e Victor Fernando Santana Lima. Fortaleza:

Editora In Vivo, 2021.

$106 \mathrm{p}$.

V. 01

Bibliografia.

ISBN: 978-65-995500-2-7

DOI: $10.47242 / 978-65-995500-2-7$

1. Animais silvestres e exóticos. 2. Medicina e bem-estar animal. I. Título. II. Organizadores. 


\begin{abstract}
APRESENTAÇÃO
A medicina de animais silvestres e exóticos é uma área que está em constante crescimento. Isso se deve não só pela maior aquisição desses animais como pets, do crescimento estrutural e científico de zoológicos e centros de manejo, e do aumento da preocupação das pessoas para com os animais, mas infelizmente também pelo tráfico de animais silvestres e por desastres naturais e/ou causados pelo ser humano. Apesar do Brasil ser um dos países com maior biodiversidade do mundo, a fauna tem sofrido com a pressão decorrente do aumento de atividades antrópicas, o que coloca em risco muitas espécies de animais silvestres. Para redução dos danos à fauna, os profissionais da biologia e medicina da conservação do país e também de outras partes do mundo têm buscado implantar técnicas para a conservação desses indivíduos.

Dessa forma, cada vez mais se faz necessário atualizações que contribuam para o bem-estar e conservação da fauna, em cativeiro e em vida livre. Pensando nisso, pode-se dizer que o primeiro volume da obra "Medicina e bem-estar de animais silvestres e exóticos" representa uma fração do mundo em que essa área se encontra. Este livro digital está composto por diversos temas como clínica, cirurgia, parasitologia, patologia, saúde única, conservação, epidemiologia e manejo, assim como outras subáreas correlatas.

Os trabalhos aqui publicados referem-se a relatos de caso, pesquisas científicas e revisões de literatura que mostram a importância da medicina de animais silvestres e exóticos como uma ferramenta para promover o bem-estar e a conservação. E claro, a saúde, não só da fauna silvestre, mas dos seres humanos também. Esperamos que a leitura seja proveitosa e que possamos aprender juntos sobre os assuntos abordados aqui.
\end{abstract}

Boa leitura!

Aksa Ingrid Vieira Batista

Victor Fernando Santana Lima 


\section{SUMÁRIO}

Capítulo 1 - DOI: 10.47242/978-65-995500-2-7-1

NOVAS TECNOLOGIAS NO TRATAMENTO E RESTAURAÇÃO DE CARAPAÇAS EM QUELÔNIOS. 06

Capítulo 2 - DOI: 10.47242/978-65-995500-2-7-2

OCORRÊNCIA DE ECTOPARASITISMO POR LARVAS DE Philomis sp. MEINERT, 1890 (DIPTERA: MUSCIDAE) EM Pitangus sulphuratus LINNAEUS, 1766 (PASSERIFORMES: TYRANNIDAE) EM JOÃO PESSOA, PARAÍBA, BRASIL. 18

Capítulo 3 - DOI: 10.47242/978-65-995500-2-7-3

PARASITISMO POR Bertiella spp. EM BUGIO-PRETO (Alouatta caraya, Humboldt, 1812) DE CATIVEIRO EM JOÃO PESSOA, PB. 26

Capítulo 4 - DOI: 10.47242/978-65-995500-2-7-4

CAPILARIOSE EM ARARA-AZUL-GRANDE (Anodorhynchus hyacinthinus, LATHAM, 1790) CATIVA DO PARQUE ZOOBOTÂNICO ARRUDA CÂMARA, JOÃO PESSOA, PARAÍ́BA, BRASIL: RELATO DE CASO. 33

Capítulo 5 - DOI: 10.47242/978-65-995500-2-7-5

LEISHMANIOSE VISCERAL EM CACHORRO-DO-MATO (Cerdocyon thous LINNAEUS, 1766). . .42

Capítulo 6 - DOI: 10.47242/978-65-995500-2-7-6

ANIMAIS SILVESTRES E PETS NÃO CONVENCIONAIS ATENDIDOS NO HOSPITAL VETERINÁRIO UNIVERSITÁRIO PROFESSOR IVON MACÊDO TABOSA DA UFCG EM 2018 E 2019. .56

Capítulo 7 - DOI: 10.47242/978-65-995500-2-7-7

PROLAPSO DE CÓLON E ENFISEMA SUBCUTÂNEO DECORRENTE DE RUPTURA TRAQUEAL TRAUMÁTICA EM IGUANA-VERDE (Iguana iguana, Linnaeus, 1758) 64

Capítulo 8 - DOI: 10.47242/978-65-995500-2-7-8

IMPACTAÇÃO DO DIVERTÍCULO DO VESTÍBULO ORAL EM Phodopus campbelli- RELATO DE CASO. 71 
Capítulo 9 - DOI: 10.47242/10.47242/978-65-995500-2-7-9

MANEJO, REABILITAÇÃO E SOLTURA DE ANIMAIS SILVESTRES..............77

Capítulo 10 - DOI: 10.47242/10.47242/978-65-995500-2-7-10

ATROPELAMENTO DE FAUNA SILVESTRE EM RODOVIAS

Capítulo 11 - DOI: 10.47242/10.47242/978-65-995500-2-7-10

ENXERTIA CUTÂNEA EM CROCODILIANO .96

SOBRE OS ORGANIZADORES. 105

ÍNDICE REMISSIVO .106 


\section{Capítulo 1}

\section{NOVAS TECNOLOGIAS NO TRATAMENTO E RESTAURAÇÃO DE CARAPAÇAS EM QUELÔNIOS}

\section{Victor Fernando Santana Lima}

Universidade Federal de Sergipe, Núcleo de Medicina Veterinária, Nossa Senhora da Glória - SE ORCID: https://orcid.org/0000-0002-7255-0664

Lattes: http://lattes.cnpq.br/7265386741392623

\section{Weslania Souza Inacio da Silva}

Universidade Federal de Sergipe, Núcleo de Medicina Veterinária, Nossa Senhora da Glória - SE Lattes: http://lattes.cnpq.br/2096023399078864

\section{Igo Gonçalves dos Santos}

Universidade Federal de Sergipe, Núcleo de Medicina Veterinária, Nossa Senhora da Glória - SE Lattes: http://lattes.cnpq.br/3048876638161878

\section{Manuel Benicio Oliveira Neto}

Universidade Federal de Sergipe, Núcleo de Medicina Veterinária, Nossa Senhora da Glória - SE Lattes: http://lattes.cnpq.br/6372287958265880

\section{Camenas Vieira Barata}

Universidade Federal de Sergipe, Núcleo de Medicina Veterinária, Nossa Senhora da Glória - SE Lattes: http://lattes.cnpq.br/3753872871256727

\section{Danilo Santos de Jesus}

Universidade Federal de Sergipe, Núcleo de Medicina Veterinária, Nossa Senhora da Glória - SE Lattes: http://lattes.cnpq.br/0030697599240620

\section{Allan Costa Gomes}

Universidade Federal de Sergipe, Núcleo de Medicina Veterinária, Nossa Senhora da Glória - SE Lattes: http://lattes.cnpq.br/6542226186166115

\section{Lorena Maciel Santos Silva}

Universidade Federal de Sergipe, Núcleo de Medicina Veterinária, Nossa Senhora da Glória - SE Lattes: http://lattes.cnpq.br/0766419381359796

\section{Maria Flaviane Almeida Silva}

Universidade Federal de Sergipe, Núcleo de Medicina Veterinária, Nossa Senhora da Glória - SE Lattes: http://lattes.cnpq.br/7276739267506207

\section{Taynara Alessandra de Matos Santos}

Universidade Federal de Sergipe, Núcleo de Medicina Veterinária, Nossa Senhora da Glória - SE Lattes: http://lattes.cnpq.br/4807858146979413

\section{Matheus Resende Oliveira}

Universidade Federal de Sergipe, Núcleo de Medicina Veterinária, Nossa Senhora da Glória - SE Lattes: http://lattes.cnpq.br/3822150058285111 


Informações sobre o
artigo:
Recebido em:
17/08/2021
Aceito em:
02/09/2021
Data de publicação:
19/10/2021

Palavras-chave:

Inovação

Medicina de quelônios

Tratamento

\section{RESUMO}

Nos últimos anos é perceptível a preocupação de como será o tratamento e a qualidade de vida de muitos animais silvestres vítimas de traumas e mutilações. Com os avanços e inovações tecnológicas, novas alternativas começaram a serem aplicadas a saúde desses animais. Pensando na importância da integridade e arquitetura da carapaça na bioproteção dos testudíneos, o trabalho a seguir traz novas alternativas tecnológicas no tratamento e restauração de carapaças em quelônios. Para esse estudo, 281 animais foram avaliados individualmente para triagem de cágados, jabutis e tartarugas com lesões ativas em carapaça. Os animais selecionados passaram por uma avaliação biomecânica computadorizada para fotogrametria e definição de formas, dimensões e posições da carapaça em computação gráfica tridimensional. Em seguida, curativos e enxertos sintéticos a base de lâminas de cera de abelha, parafina e resina acrílica cianoacrilato, além de fixadores externos, foram as tecnológicas utilizadas no tratamento e restauração das carapaças lesionadas. Após o procedimento, os pacientes foram avaliados e monitorados até o $60^{\circ}$ dia. Todos os dados estatísticos foram analisados utilizando o software InStat GraphPad, com nível de significância de $p<0,05$. Como resultados, foi observado que 18,86\% ( $p<0.0001)$ dos quelônios apresentaram alterações de carapaça, no qual jabutis e cágados foram os mais acometidos por lesões de origem traumática $(16,98 \%)$ e não-traumática $(83,02 \%)(p<0.0001)$. Nestes casos as lâminas de cera e a resina acrílica foram utilizadas como enxerto sintético das placas córneas $(50,00 \%)$ e curativo das placas ósseas $(33,33 \%)(p<0.0001)$. Enquanto os fixadores externos metálicos foram utilizados em $57,14 \%$ dos casos. Ao $15^{\circ}$ dia pós-restauração os animais apresentaram melhora clínica, e ao $60^{\circ}$ dia já era perceptível a formação de tecido de cicatrização queratinizado nos animais com fratura. Demonstrando a efetividade dessas novas alternativas tecnológicas no tratamento e restauração de carapaças em quelônios.

\section{NEW TECHNOLOGIES IN THE TREATMENT AND RESTORATION OF CARAPACE IN CHEELONS}

\section{ABSTRACT}

In recent years, the concern about how the treatment and quality of life of many wild animals victims of trauma and mutilation will be noticeable. With advances and technological innovations, new alternatives began to be applied to the health of these animals. Considering the importance of the integrity and architecture of the carapace in the bioprotection of testudines, the work that follows brings new technological alternatives in the treatment and restoration of shells in turtles. For this study, 281 animals were 
Keywords:

Innovation

Chelon Medicine

Treatment individually evaluated for screening of turtles with active lesions on their carapace. The selected animals underwent a computerized biomechanical evaluation for photogrammetry and definition of shapes, dimensions and positions of the carapace in threedimensional computer graphics. Then, dressings and synthetic grafts based on sheets of beeswax, paraffin and acrylic resin cyanoacrylate, in addition to external fixators, were the technologies used in the treatment and restoration of the injured carapaces. After the procedure, patients were evaluated and monitored until the 60th day. All statistical data were analyzed using the InStat GraphPad software, with a significance level of $p$ $<0.05$. As a result, it was observed that $18.86 \%(p<0.0001)$ of turtles had carapace alterations, in which tortoises and tortoises were the most affected by traumatic $(16.98 \%)$ and non-traumatic injuries $(83.02 \%)(p<0.0001)$. In these cases, the wax sheets and acrylic resin were used as a synthetic graft from the corneal plates $(50.00 \%)$ and as a dressing for the bone plates (33.33\%) $(p<0.0001)$. While metallic external fixators were used in $57.14 \%$ of cases. On the 15th day after restoration, the animals showed clinical improvement, and on the 60th day, the formation of keratinized scar tissue was already noticeable in the animals with fracture. Demonstrating the effectiveness of these new technological alternatives in the treatment and restoration of turtle shells.

\section{INTRODUÇÃO}

Desde o surgimento da primeira escola de Medicina Veterinária em Lyon, na França, é perceptível a evolução das práticas e métodos de curar animais (SCHWABE, 1984; PFUETZENREITER et al., 2004). Durante muitos anos, as práticas veterinárias estavam voltadas aos aspectos populacionais e combate preventivos de enfermidades, entretanto, nos últimos anos com o surgimento de novas áreas da Medicina Veterinária, aspectos como bemestar e reabilitação começaram a ganhar maior destaque (FOWLER, 1986; CUBAS et al., 2006; PEÑUELA-GÓMEZ et al., 2012).

Atualmente, as inovações tecnológicas têm contribuído diretamente no campo da Medicina de Animais Silvestres, principalmente, nas áreas de diagnóstico, tratamento e cuidados em saúde (GRANBERG et al., 2016; BAI et al., 2018; EL-SAYED e KAMEL, 2020; SOUZA et al., 2020). A prova disso, são os sistemas de computadores (softwares) e Inteligência Artificial que auxiliam os profissionais, fornecendo informações diagnósticas, o que acaba favorecendo tomadas de decisões em menor espaço de tempo (MAALOUF et al., 2018). Além disso, essas ferramentas são capazes de reduzir futuras chances de erros e riscos 
durante a rotina clínica, o que acaba tornando os procedimentos veterinários mais seguros e benefícos para a saúde do animal a ser tratado (GAMBLE, 2007; LE et al., 2018).

$\mathrm{Na}$ Medicina de Quelônios, a tecnologia vem fornecendo novas soluções para problemas antigos, a exemplo do tratamento de animais com lesões de carapaça (MAUTINO e PAGE, 1993; CLABAUGH et al., 2005). Recentemente, várias aplicações da tecnologia começaram a ser utilizadas no desenvolvimento de curativos, próteses, e até novos cascos para animais vítimas de traumatismo e queimadura (XIE et al., 2019; CARVALHO et al., 2020; SANTOS et al., 2020).

No entanto, é possível notar uma certa limitação de materiais disponíveis no mercado para o tratamento restaurador de carapaças de quelônios, o que acaba, com isso, criando-se uma lacuna, a qual pode ser preenchida a partir do desenvolvimento de novos produtos e técnicas, como proposto por nosso trabalho (SHELEF e BAR-ON, 2017; SPADOLA e MORICI, 2017). Dessa forma, pensando-se na importância da integridade e arquitetura da carapaça na bioproteção dos animais, e pautada nos avanços tecnológicos da Medicina de Animais Silvestres, nosso trabalho apresenta novas alternativas tecnológicas que podem ser aplicadas no tratamento e restauração de carapaças de quelônios.

\section{METODOLOGIA}

Para esse estudo foi utilizado a casuística de 281 quelônios pertencentes as espécies, Chelonoidis carbonaria ( $\mathrm{n}=271)$, Chelonoidis denticulata $(\mathrm{n}=3)$, Chelydra serpentina $(\mathrm{n}=1)$, Mesoclemmys tuberculata $(\mathrm{n}=4)$ e Trachemys dorbigni $(\mathrm{n}=2)$, atendidos no Centro de Aprendizagem e Manejo de Animais Silvestres da Universidade Federal de Sergipe, campus do Sertão. Todos os dados clínicos foram registrados em fichas individuais. Além disso, as alterações de carapaças foram observadas, fotografadas, mensuradas e caracterizadas, respectivamente.

Após a caracterização das lesões, todos os quelônios foram submetidos a Avaliação Biomecânica Computadorizada para Fotogrametria nas projeções Látero-Lateral, MédioLateral, Látero-Medial e Dorso-Ventral, utilizando-se o Software SOLIDWORKS® de CAD 3D (Computer-Aided Design) para obtenção da formas, dimensões e posições das carapaças em computação gráfica tridimensional.

Utilizando como base os resultados da fotogrametria, foi realizado o planejamento e seleção da técnica de restauração. A tecnologia e tipo de material escolhido foram lâminas 
a base de cera de abelha e parafina associada a resina acrílica cianoacrilato, agindo como curativo e/ou enxerto sintético nos quelônios vítimas de queimaduras e traumatismo. Já os animais que apresentaram áreas de fraturas na carapaça, foram tratados com o método de redução e realinhamento da área com o auxílio de fixadores externos (bráquetes metálicos e parafusos $4.0 \times 16 \mathrm{~mm}$ ) unidos por Elástico Intraoral Látex (EIL).

A aplicação das técnicas de curativo e enxerto sintético foi realizada de acordo com o seguinte protocolo: 1) sobreposição de uma camada de $1,7 \mathrm{~mm}$ de lâminas utilizando resina acrílica cianoacrilato; 2) período de moldagem, secagem por 15 minutos e endurecimento a temperatura ambiente; 3) sobreposição de uma segunda camada das lâminas; 4) segundo ciclo de moldagem, secagem e endurecimento; 5) lapidação e ajustes pós-enxerto das lâminas e 6) lavagem com água e sabão neutro. Já a técnica de redução e realinhamento de fratura de carapaça foi realizada a partir da: 1) limpeza e secagem da área lesionada com soluções antissépticas; 2) adição de pomadas cicatrizantes no interior da lesão; 3) fixação externa de bráquetes metálicos e/ou parafusos 4.0 × $16 \mathrm{~mm}$ com resina acrílica cianoacrilato; 4) período de secagem por 10 minutos e 5) fixação dos EIL.

Após o procedimento, todos os curativos e enxertos sintéticos instalados foram avaliados quanto a sua resistência e impermeabilidade a água. Os pacientes foram monitorados até o $60^{\circ}$ dia, onde foram removidos os fixadores externos e avaliado a cicatrização da carapaça. Todos os dados foram analisados utilizando o software InStat (GraphPad Software), com nível de significância estabelecido de $p<0,05$.

\section{RESULTADOS E DISCUSSÃO}

Em nosso estudo 18,86\% (53/281) dos quelônios apresentaram alterações de carapaças, no qual o grupo dos jabutis $(98,11 \%)$ e cágados $(1,89 \%)$ foram os mais acometidos $(p<0.0001)$. Isso pode está relacionado ao fato destes animais serem répteis facilmente comercializados ilegalmente em feiras brasileiras, ou, ao grande número de animais criados de forma ilegal em residências na região Nordeste do Brasil (FREITAS et al., 2015; SALDANHA e PEIXOTO, 2021).

Quanto à classificação das alterações de carapaças, 16,98\% e 83,02\% (p<0.0001) foram de origem traumática (queimaduras por incêndio 7,55\%; fratura de placas ósseas 5,66\% e mordedura por cão 3,77\%) e não-traumática (piramidismo 77,36\% e má formação de placas córneas 5,66\%) (Figura 1), o que acaba reforçando os impactos da criação ilegal e do manejo inadequado na saúde da carapaça desses répteis (MARTINEZ-JIMENEZ et al., 2007; PARÉS-CASANOVA et al., 2020). Além disso, vale lembrar que muitos répteis 
acabam se tornando vítimas de atropelamento por veículos automobilísticos e queimados em incêndios, em virtude de apresentarem deslocamento lento ao tentarem realizar travessias entre matas e rodovias (RAMOS-ABRANTES et al., 2018; DURIGAN et al., 2020).

Figura 1 - Alterações de carapaças observadas em quelônios. A - Nota-se casco piramidal. B - Nota-se deformidade parcial e escoriações. C - Nota-se o afundamento e descolamento de placas córneas e ósseas. D - Nota-se fratura e sangramento em carapaça. E - Nota-se alteração na coloração de placas córneas e ósseas. F - Nota-se exposição de placas ósseas após perda generalizada de placas córneas.

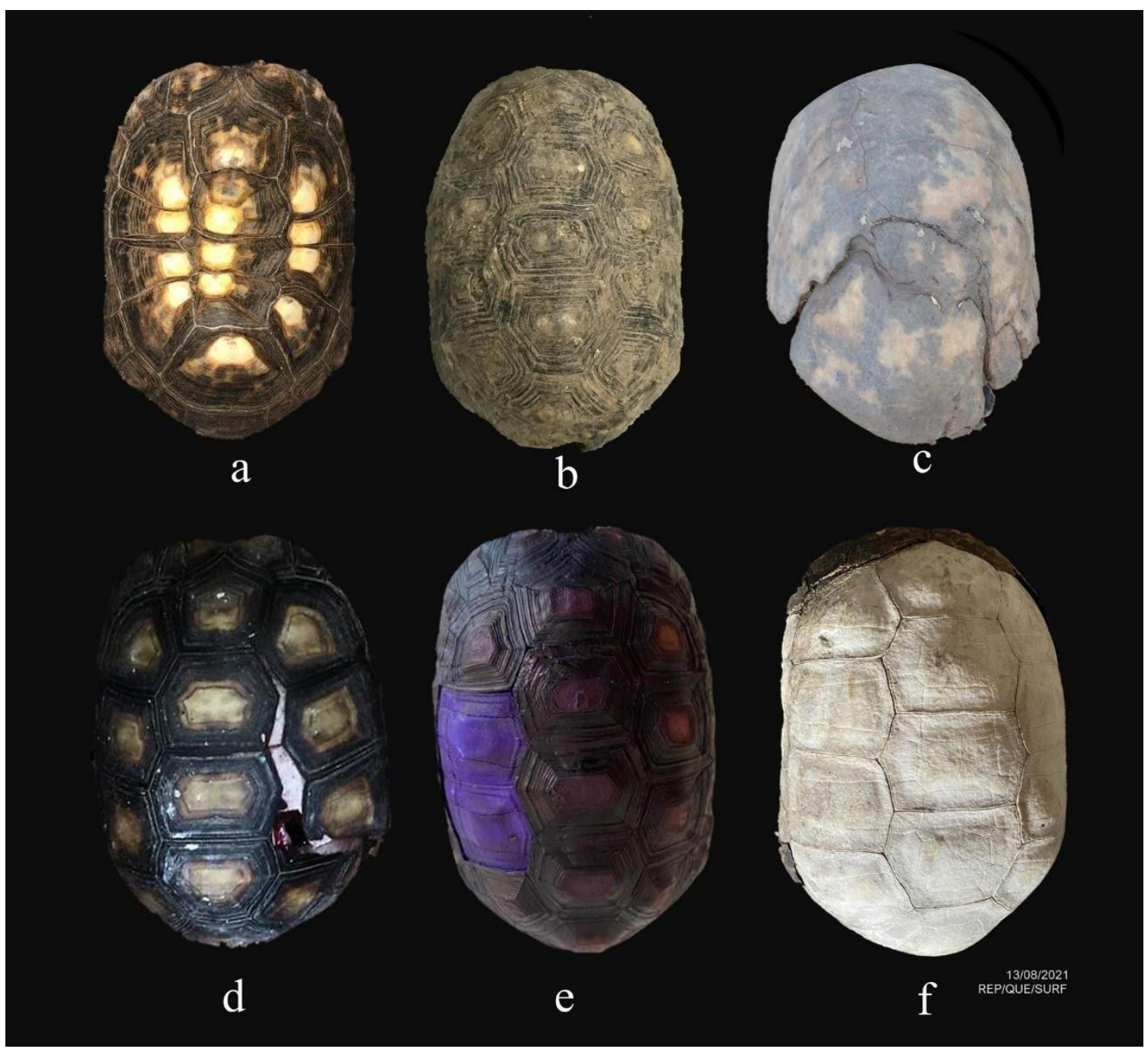

Fonte: Autores, 2021. 
A maioria das emergências de quelônios é resultado de lesões de carapaças em animais atropelados por automóveis, atacados por cães e gatos, ou traumas induzidos por humanos (SCHENK e SOUZA, 2014). Por esse motivo, as técnicas clínicas de restauração utilizadas em nosso estudo foram realizadas em jabutis $(85,71 \% ; p<0.0001)$ e cágados $(14,29 \% ; p<0.0001)$ vítimas de traumatismo por automóveis $(57,14 \%$ ) (Figura 2) e queimaduras em incêndios (42,86\%). Dentre as alternativas de tratamento para quelônios com lesões ativas em placas córneas e ósseas, as técnicas de restauração são excelentes opções a serem adotadas, pois além de uma recuperação mais rápida, essas tecnologias proporcionam melhores condições de vida para os pacientes (CUBO et al., 2016).

Figura 2 - Jabuti-piranga (C. carbonaria) vítima de atropelamento por veículo automobilístico. Nota-se em $\mathbf{A}$ e $\mathbf{B}$ fratura difusa entre as placas córneas e ósseas (seta). C e $\mathbf{D}$ uso de bráquetes metálicos associado a lâmina de cera. $\mathbf{E}$ e $\mathbf{F}$ fratura cicatrizada após o tratamento.

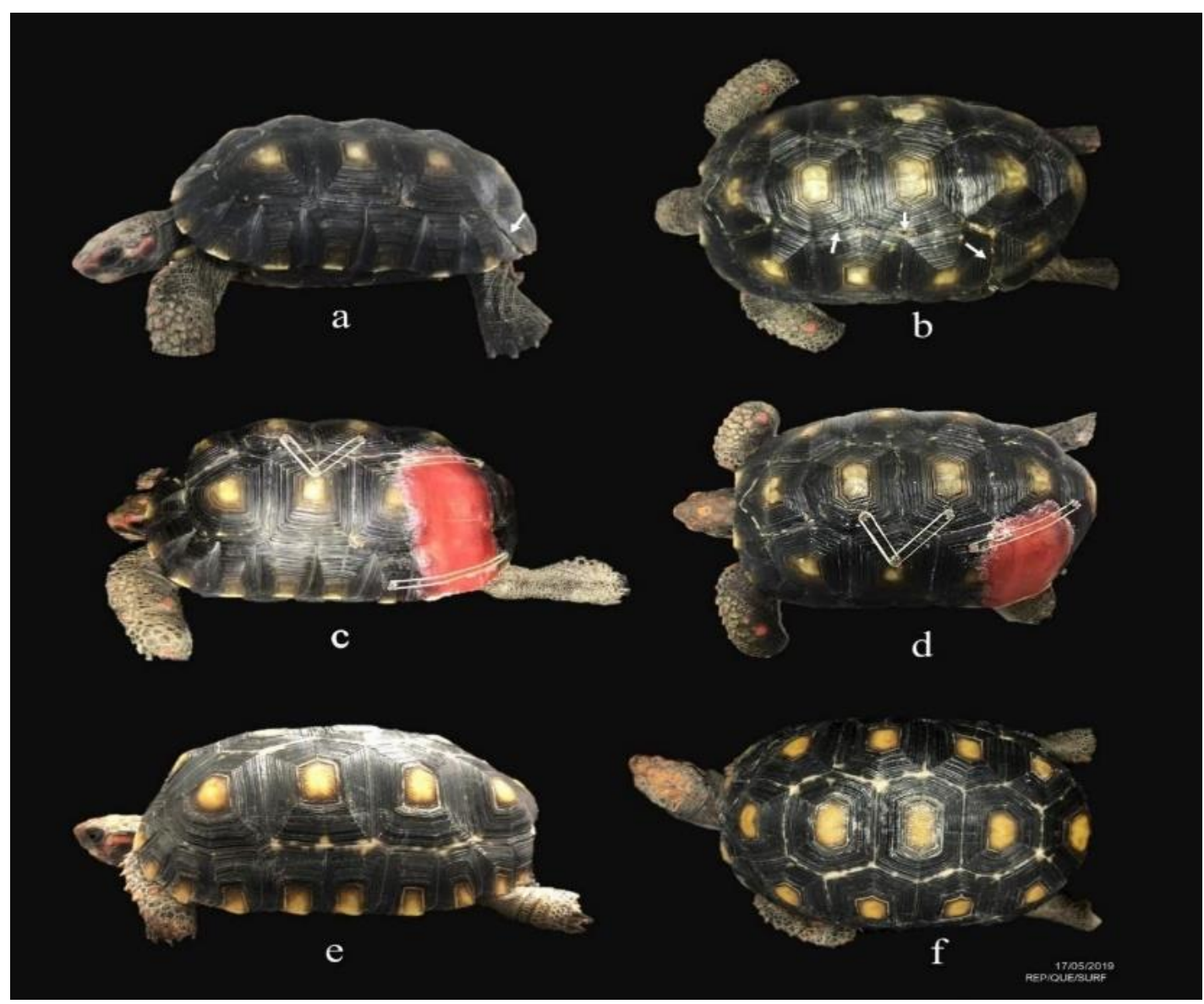

Fonte: Autores, 2021.

Para se obter êxito na restauração da carapaça, etapas como o planejamento e a seleção das técnicas, são etapas primordiais que devem ser adotadas. Além destas, os usos de 
programas de computação gráfica são excelentes alternativas, pois a partir da digitalização das lesões é possível obter formas, dimensões e posições da carapaça do paciente (BORTOLINI et al., 2012; MARCHIORI et al., 2015).

As lâminas de cera e a resina acrílica foram utilizadas em conjunto como enxerto sintético $(50,00 \%)$ nos procedimentos de restauração das placas córneas (Figura 3), e como curativo $(33,33 \%)$, nos casos de fraturas de placas ósseas, e em casos mais complexos, simultaneamente (16,67\%). Essa tecnologia já é muito difundida na Odontologia, e a mesma tem demostrado ser uma excelente aliada no tratamento de lesões ativas de carapaças em jabutis, pois, além de ser um material barato, acessível, resistente, biodegradável e passível de biomimetização, promove benefícios para a saúde dos animais acometidos por lesões traumáticas e ocasionadas por incêndios (GOIATO et al., 2014; JESUS et al., 2019).

Figura 3 - Jabutis-piranga (C. carbonaria) vítimas de queimaduras após o procedimento de enxertia sintética como substituto das placas córneas

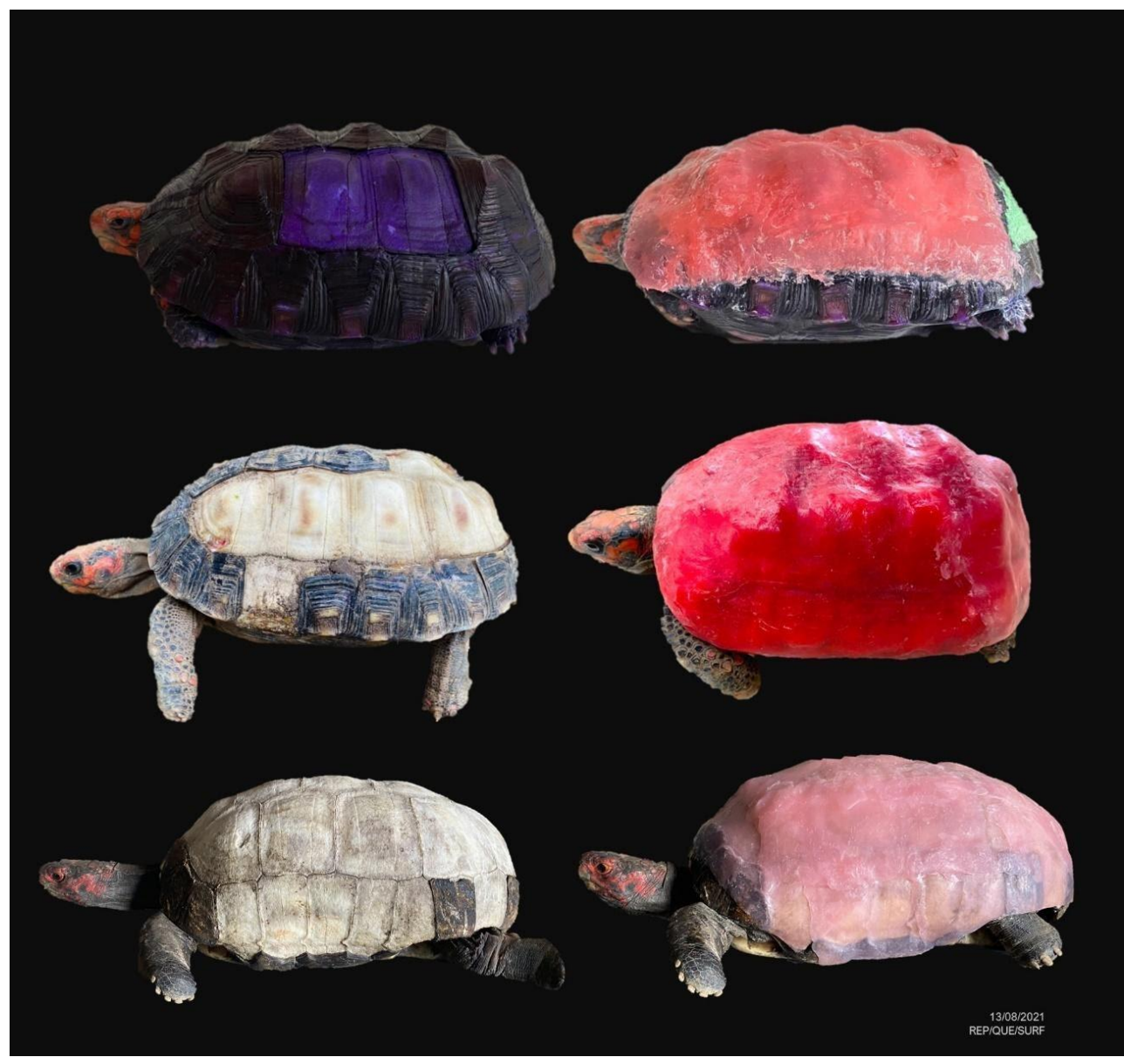

Fonte: Autores, 2021. 
Nos casos em que existe o acidente envolvendo veículos e quelônios, fraturas de placas ósseas e córneas podem estar presentes, sendo necessário, a utilização de fixadores externos para reduzir a área da lesão (CRESPO-PICAZO et al., 2013). Em nossos pacientes, por exemplo, os fixadores externos foram utilizados em 57,14\% $(p<0.0001)$ dos casos, sendo optado pelo uso de bráquetes metálicos $(75 \%)$ ou parafusos $(25 \%)$.

Apesar da complexidade no que tange a anatomia, fisiologia e a cicatrização da carapaça (HOROWITZ et al., 2015; MOUSTAKAS-VERHO et al., 2015; MOUSTAKASVERHO et al., 2017), as opções de tratamento apresentadas nesse estudo, proporcionaram melhora clínica 24 horas pós-restauração em 85,71\% (95\%; $p<0.0001)$, com recuperação do apetite e mobilidade dos pacientes. No $15^{\circ}$ dia, todos os animais voltaram a interagir com outros testudíneos e a expressar seu comportamento reprodutivo. No $30^{\circ}$ dia, foi observado uma diminuição nas bordas das fraturas, ausência de secreção, presença de tecido de granulação e formação de película de regeneração. Já no $60^{\circ}$ dia, foi realizada a remoção dos fixadores externos, sendo observado a formação de tecido queratinizado semelhante à carapaça hígida, demostrando assim, efetividade dos materiais e técnicas utilizadas (CRESPO-PICAZO et al., 2013; HIRASAWA et al., 2015).

Ademais, é importante destacar que a utilização de novos recursos e tecnologias, como as descrita nesse estudo, permite a disseminação de metodologias mais efetivas e duradouras, reduzindo assim, a necessidade de técnicas invasivas, bem como materiais que pdem trazer riscos a vida do paciente (PRAZERES et al., 2013).

\section{CONCLUSÃO}

O uso de novas tecnologias como as descritas nesse estudo, apresentaram efeitos benéficos e desejados para a restauração de carapaças de quelônios vítimas de traumatismos e queimaduras. Assim, a importância dessa tecnologia, possui elevado potencial inovador na Medicina Veterinária de Animais Silvestres, propiciando, desta forma, uma boa qualidade de vida, saúde e bem-estar na vida de quelônios.

\section{REFERÊNCIAS}

BAI, D. P.; LIN, X. Y.; HUANG, Y. F.; ZHANG, X. F. Theranostics Aspects of Various Nanoparticles in Veterinary Medicine. International Journal of Molecular Sciences, v.19, n.11, 3299, 1-32, 2018. 
BORTOLINI, Z.; LEHMKUHL, R. C.; OZEKI, L. M.; TRANQUILIM, M. V.; SESOKO, N. F.; TEIXEIRA, C. R.; VULCANO, L. C. Association of 3D reconstruction and conventional radiography for the description of the appendicular skeleton of Chelonoidis carbonaria (Spix, 1824). Anatomia, Histologia, Embryologia, v. 41, n. 6, p. 445-452, 2012.

CARVAlHO, S. G.; ARAUjO, V. H. S.; DOS SANTOS, A. M.; DUARTE, J. L.; SILVESTRE, A. L. P.; FONSECA-SANTOS, B.; VILLANOVA, J. C. O.; GREMIÃO, M. P. D.; CHORILLI, M. Advances and challenges in nanocarriers and nanomedicines for veterinary application. International Journal of Pharmaceutics, v.580, p. 119214, 2020.

CLABAUGH, K.; HAAG, K. M.; HANLEY, C. S.; LATIMER, K. S.; HERNANDEZDIVERS, S. J. Undifferentiated sarcoma resolved by forelimb amputation and prosthesis in a radiated tortoise (Geochelone radiata). Journal of Zoo and Wildlife Medicine, v.31, n.1, p.117-120, 2005.

CRESPO-PICAZO, J. L.; MARTÍNEZ, V.; MARTINS, S.; ABELLA E.; LÓPEZ, P.; GARCÍA-PÁRRAGA, D.; MARCO, A. Surgical repair of a large shell injury in a loggerhead sea turtle Caretta caretta and the need for a wildlife recovery centre in the Cape Verde Islands. Zoologia Caboverdiana, v. 4, n. 2, p. 25-30, 2013.

CUBAS, Z. S.; SILVA, J. C. R.; CATÃO-DIAS, J. L. Tratado de animais selvegens. Medicina veterinária. 1a ed. São Pauo, SP: Editora Roca Ltda, 2006.

CUBO, N.; GARCIA, M.; DEL CAÑIZO, J. F.; VELASCO, D.; JORCANO, J. L. 3D bioprinting of functional human skin: production and in vivo analysis. Biofabrication, v. 9, n. 1, p. 1-3, 2016.

DURIGAN, G.; PILON, N. A. L.; ABREU, R. C. R.; HOFFMANN, W. A.; MARTINS, M.; FIORILLO, B. F.; ANTUNES, A. Z.; CARMIGNOTTO, A. P.; MARAVALHAS, J. B.; VIEIRA, J.; VASCONCELOS, H. L. No Net Loss of Species Diversity After Prescribed Fires in the Brazilian Savanna. Frontiers in Forests and Global Change, v.3, n.13, p.1-13, 2020.

EL-SAYED, A.; KAMEL, M. Advanced applications of nanotechnology in veterinary medicine. Environmental Science and Pollution Research. v.27, n.16, p.19073-19086, 2020.

FOWLER, M. E. Stress. In: Zoo \& wild animal medicine. 2 ed. Philadelphia: Saunders Company, 1986. p.33-35.

FREITAS, A. C. P.; OVIEDO-PASTRANA, M. E.; VILELA, D. A. R.; PEREIRA, P. L. L.; LOUREIRO, L. O. C.; HADDAD, J. P.; MARTINS, N. R. S.; SOARES, D. F. M. Diagnóstico de animais ilegais recebidos no centro de triagem de animais silvestres de Belo Horizonte, Estado de Minas Gerais, no ano de 2011. Ciência Rural, v.45, n.1, p.163-170, 2015.

GAMBLE, K. C. Internal anatomy of the hornbill casque described by radiography, contrast radiography, and computed tomography. Journal of Avian Medicine and Surgery, v. 21, n.1, p.38-49, 2007. 
GOIATO, M. C.; NOBREGA, A. S.; GENNARI FILHO, H.; SANTOS, D. M. PROVA ESTÉTICA E FUNCIONAL - UMA DECISÃO EM CONJUNTO. Revista Odontológica de Araçatuba, v.35, n.2, p. 09-14, 2014.

GRANBERG, F.; BÁLINT, Á.; BELÁK, S. Novel technologies applied to the nucleotide sequencing and comparative sequence analysis of the genomes of infectious agents in veterinary medicine. Revue scientifique et technique, v.35, n.1, p.25-42, 2016.

HIRASAWA, T.; PASCUAL-ANAYA, J.; KAMEZAKI, N.; TANIGUCHI, M.; MINE, K.; KURATANI, S. The evolutionary origin of the turtle shell and its dependence on the axial arrest of the embryonic rib cage. Journal of Experimental Zoology Part B: Molecular and Developmental Evolution, v.324, n.3, p.194-207, 2015.

HOROWITZ, I. H.; YANCO, E.; TOPAZ, M. TopClosure System Adapted to Chelonian Shell Repair. Journal of Exotic Pet Medicine, v. 24, n.1, p. 65-70, 2015.

JESUS, Y. M. B.; OLIVEIRA, I. G. S.; ARAGÃO, N. S.; DELFINO, N. S. C.; SANTOS, V. B. P.; LIMA V. F. S. uso de lâminas de hidrocarboneto associado a cianoacrilato na reparação de fraturas de carapaça em chelonoidis carbonaria (Spix, 1824) (Reptilia: Testunidae). In: Anais da Semana de Medicina Veterinária da UFAL - SEMVET, 2., 2019, Viçosa. Resumos [...]. Viçosa: UFAL, 2019. p.1-2.

LE, D.; LE, C. V.; TROMP, J. G.; NGUYEN, G. N. Emerging Technologies for Health and Medicine. Hoboken: Scrivener Publishing LLC, 2018. 31p.

MAALOUF, N.; SIDAOUI, A.; ELHAJJ, I. H.; ASMAR, D. Robotics in Nursing: A Scoping Review. Journal of Nursing Scholarship, v. 50, n.6, p.590-600, 2018.

MARTINEZ-JIMENEZ, D.; HERNANDEZ-DIVERS, S. J. Emergency care of reptiles. Veterinary Clinics of North America: Exotic Animal Practice, v.10, n.2, p.557-585, 2007.

MARCHIORI, A.; DA SILVA, I. C.; DE ALBUQUERQUE BONELLI, M.; ALBUQUERQUE ZANOT'TI, L. C.; SIQUEIRA, D. B.; ZANOTTI, A. P.; COSTA, F. S. Use of computed tomography for investigation of hepatic lipidosis in captive Chelonoidis carbonaria (Spix, 1824). Journal of Zoo and Wildlife Medicine, v. 46, n. 2, p.320-324, 2015.

MAUTINO, M.; PAGE, C. D. Biology and medicine of turtles and tortoises. Veterinary Clinics of North America: Small Animal Practice, v. 23, n. 6, p.1251-1270, 1993.

MOUSTAKAS-VERHO, J. E.; CHEREPANOV, G. O. The integumental appendages of the turtle shell: an evo-devo perspective. Journal of Experimental Zoology Part B: Molecular and Developmental Evolution, v. 324, n.3, p.221-229, 2015.

PARÉS-CASANOVA, P. M.; BRANDO, P.; CAVIEDES, D.; SALAMANCA-CARREÑO, A. Scutation asymmetries in red-footed tortoise Chelonoidis carbonaria Spix, 1824 (Testudines: Testudinidae). Papéis Avulsos de Zoologia, v.60, p.1-6, 2020.

PEÑUELA-GÓMEZ, S. M.; PÉREZ-TOBAR, J. M.; SOLER-TOVAR, D.; VARELAARIAS, N. Conocimiento y Gestión de las Enfermedades de los Animales Silvestres 
en Colombia. 1.ed. Bogotá: Asociación de Veterinarios de Vida Silvestre (VVS), 2012. 220 p.

PFUETZENREITER, M. R.; ZYLBERSZTAJN, A.; AVILA-PIRES, F. D. Evolução histórica da medicina veterinária preventiva e saúde pública. Ciência Rural, v.34, n.5, p.1661-1668, 2004.

PRAZERES, R.F.; FIEBIG, W.J.; FECCHIO, R.S.; BIASI, C.; CASTRO, M.F.S.; GIOSO, M.A.; PACHALY, J.R. Technical reconstitution in beak birds - review article. Journal of the Health Sciences Institute, v.31 n.4 p. 441-447, 2013.

RAMOS-ABRANTES, M. M.; CARREIRO, A. N.; ARAÚJO, D. V. F.; SOUZA, J. G.; LIMA, J. P. R.; CEZAR, H. R. A.; LEITE, L. S.; ABRANTES, S. H. F. Vertebrados silvestres atropelados na rodovia BR-230, Paraíba, Brasil. PUBVET. v.12, n.1, p. 1-7, 2018.

SALDANHA, P. O.; PEIXOTO, R. S. Análise bibliográfica do tráfico de animais silvestres no Nordeste do Brasil na última década. Revista Multidisciplinar do Núcleo de Pesquisa e Extensão (RevNUPE), v. 1, n. 1, p.1-23, 2021.

SANTOS, I. G.; OLIVEIRA NETO, M. B.; OLIVEIRA, M. R.; SCHETTINO, S. C.; LIMA, V. F. S. Prótese Parcial Removível de Carapaça na Reabilitação de Jabuti-Piranga (Chelonoidis carbonaria Spix, 1824): Relato de Caso. Enciclopédia Biosfera, Centro Científico Conhecer, v. 17, n. 34, p. 417-428, 2020.

SCHENK, A. N.; SOUZA, M. J. Major anthropogenic causes for and outcomes of wild animal presentation to a wildlife clinic in East Tennessee, USA, 2000-2011. PLoS One, v.9, n.3, p. 1-3, 2014.

SCHWABE, C. W. Veterinary medicine and human health 3.ed. Baltimore: Williams \& Wilkins, 1984. 680p.

SHELEF, Y.; BAR-ON, B. Surface protection in bio-shields via a functional soft skin layer: Lessons from the turtle shell. Journal of the Mechanical Behavior of Biomedical Materials, v. 73, p.68-75, 2017.

SOUZA, G. V.; HESPANHA, A. C. V.; PAZ, B. F.; SÁ, M. A. R.; CARNEIRO, R. K.; GUAITA, S. A. M.; MAGALHÃES, T. V.; MINTO, B. W.; DIAS, L. G. G. G. Impact of the internet on veterinary surgery. Veterinary and Animal Science. v.14, n.11, p.1-8, 2020.

SPADOLA, F.; MORICI, M. The use of silver amalgam for treatment of shell ulcerations in turtles: 60 cases. Journal of Small Animal Practice, v. 58, n.12, p.720-723, 2017.

XIE, S.; CAI, B.; RASIDI, E.; YEN, C. C.; HSU, C. D.; CHOW, W. T.; DE BUSSCHER, V.; HSU, L. C. The use of a 3D-printed prosthesis in a Great Hornbill (Buceros bicornis) with squamous cell carcinoma of the casque. PLoS One, v.14, n.8, p.1-13, 2019. 


\title{
OCORRÊNCIA DE ECTOPARASITISMO POR LARVAS DE Philornis sp. MEINERT, 1890 (DIPTERA: MUSCIDAE) EM Pitangus sulphuratus LINNAEUS, 1766 (PASSERIFORMES: TYRANNIDAE) EM JOÃO PESSOA, PARAÍBA, BRASIL
}

\author{
Aksa Ingrid Vieira Batista \\ Universidade Federal Rural do Semi-Árido (UFERSA), Mossoró - RN \\ ORCID: https://orcid.org/0000-0003-0696-7194 \\ Lattes: http:/ / lattes.cnpq.br/6614624885083003 \\ Gabriel Vinícius Carvalho de Lucena \\ Universidade Federal de Campina Grande (UFCG), Patos - PB \\ ORCID: https://orcid.org/00000001-9789-6066

\section{Mariana Fernandes Lopes} \\ Espaço Pet Clínica Veterinária, João Pessoa - PB \\ ORCID: https://orcid.org/0000-0002-3572-2332 \\ Jéssica Azevedo Costeira \\ Espaço Pet Clínica Veterinária, João Pessoa - PB \\ ORCID: https://orcid.org/0000-0002-1252-5512
}

Roberto Citelli de Farias

Espaço Pet Clínica Veterinária, João Pessoa - PB ORCID: https://orcid.org/0000-0002-7837-2803

\section{Caio Shibuya Pessoa}

Espaço Pet Clínica Veterinária, João Pessoa - PB ORCID: https://orcid.org/0000-0001-5056-7441

\section{Lígia Vanessa Leandro Gomes}

Universidade Federal Rural do Semi-Árido (UFERSA), Mossoró - RN ORCID: https://orcid.org/0000-0001-7914-1356

\section{Felipe José da Costa Andrade}

Universidade Federal do Piauí (UFPI), Bom Jesus - PI

ORCID: https://orcid.org/0000-0001-7932-2536

\section{Maria Heloísa Pontes de Souza}

Universidade Federal Rural do Semi-Árido (UFERSA), Mossoró - RN ORCID: https://orcid.org/0000-0001-5924-1018

Juliane Nayra Dantas Silva

Universidade Federal Rural do Semi-Árido (UFERSA), Mossoró - RN ORCID: https://orcid.org/0000-0001-8226-4285

Fernando Lucas Monteiro Medeiros

Universidade Federal Rural do Semi-Árido (UFERSA), Mossoró - RN ORCID: https://orcid.org/0000-0003-1978-8224

Josivania Soares Pereira

Universidade Federal Rural do Semi-Árido (UFERSA), Mossoró - RN ORCID: https://orcid.org/0000-0002-2407-9417 


\begin{tabular}{|c|c|}
\hline $\begin{array}{l}\text { Recebido em: } \\
25 / 08 / 2021 \\
\text { Aceito em: } \\
02 / 09 / 2021 \\
\text { Data de publicação: } \\
\text { 19/10/2021 } \\
\text { Palavras-chave: } \\
\text { Aves } \\
\text { Ectoparasitos } \\
\text { Moscas } \\
\text { Parasitilogia }\end{array}$ & $\begin{array}{l}\text { RESUMO } \\
\text { O bem-te-vi (Pitangus sulphuratus LINNAEUS, 1766) é um } \\
\text { representante da ordem Passeriformes e família Tyrannidae, sendo } \\
\text { um dos pássaros mais comuns e populares do Brasil. As } \\
\text { ectoparasitoses estão entre os principais agravos que acometem } \\
\text { aves silvestres, e estas podem causar anemia e diminuir o sucesso } \\
\text { reprodutivo das mesmas, podendo interferir ainda em taxas de } \\
\text { natalidade e mortalidade. Dentre os Diptera que podem causar } \\
\text { mí́ases, o gênero Philornis MEINERT, 1890 é o único } \\
\text { representante no Novo Mundo e da família Muscidae que é } \\
\text { obrigatoriamente associado à classe Aves. Considerando que no } \\
\text { Brasil e em especial para a região Nordeste deste país, os registros } \\
\text { de ocorrência deste Diptera são escassos e espaçados, o presente } \\
\text { trabalho tem como objetivo relatar a primeira ocorrência de } \\
\text { Philornis sp. em P. sulphuratus no Município de João Pessoa, no } \\
\text { Estado da Paraíba (PB). }\end{array}$ \\
\hline $\begin{array}{l}\text { Keywords: } \\
\text { Birds } \\
\text { Ectoparasites } \\
\text { Flies } \\
\text { Parasitology }\end{array}$ & $\begin{array}{l}\text { OCCURRENCE OF ECTOPARASITISM BY LARVES OF Philornis sp. } \\
\text { MEINERT, } 1890 \text { (DIPTERA: MUSCIDAE) IN Pitangus sulphuratus } \\
\text { LINNAEUS, } 1766 \text { (PASSERIFORMES: TYRANNIDAE) IN JOÃO } \\
\text { PESSOA, PARAÍBA, BRAZIL } \\
\text { ABSTRACT } \\
\text { The great kiskadee (Pitangus sulphuratus LINNAEUS, 1766) is a } \\
\text { representative of the order Passeriformes and family Tyrannidae, } \\
\text { being one of the most common and popular birds in Brazil. } \\
\text { Ectoparasitosis are among the main diseases that affect wild birds, } \\
\text { and they can cause anemia and reduce their reproductive success, } \\
\text { and can also interfere with birth and mortality rates. Among the } \\
\text { Diptera that can cause myiasis, the genus Philomis MEINERT, } \\
1890 \text { is the only representative in the New World and the Muscidae } \\
\text { family that is mandatorily associated with the class Aves. } \\
\text { Considering that in Brazil and especially for the Northeast region } \\
\text { of this country, the occurrence records of this Diptera are sparse } \\
\text { and spaced, the present work aims to report the first occurrence of } \\
\text { Philornis sp. in P. sulphuratus in the Municipality of João Pessoa, in } \\
\text { the State of Paraíba (PB). }\end{array}$ \\
\hline
\end{tabular}

\section{INTRODUÇÃO}

O bem-te-vi (Pitangus sulphuratus LINNAEUS, 1766) é uma ave da ordem Passeriformes e família Tyrannidae, sendo um dos pássaros mais ordinários que residem em 
território brasileiro. Esta espécie ocorre em bordas e clareiras de florestas, sendo identificado também em cidades, matas ou até mesmo em locais próximos a rios e lagos. Por apresentar um comportamento generalista, esta ave possui hábito onívoro, geralmente se alimentando tanto de insetos, aracnídeos, peixes, lagartos, girinos, filhotes de aves, como também de frutos, sementes e até mesmo de carniça e lixo. É uma ave típica da América Latina, com uma distribuição ampla que se estende dos Estados Unidos da América à Argentina. O seu canto trissilábico característico lembra as sílabas "bem-te-vi", que dão o nome popular à espécie no Brasil (RODRIGUES, 2017).

As ectoparasitoses estão entre as principais afecções que acometem aves silvestres, e dentre os Diptera causadores de miíases, o gênero Philornis MEINERT, 1890 é o único representante do Novo Mundo e da família Muscidae, que é associado a aves obrigatoriamente. Os ectoparasitos podem afetar os hospedeiros quanto a sua morfologia, comportamento e na fisiologia dos animais, podendo causar anemia nas aves e diminuir o sucesso reprodutivo das mesmas, interferindo assim em suas taxas de natalidade e mortalidade, o que é um empecilho para a conservação. Ressalta-se que a taxa mortalidade de filhotes, devido ao acometimento por larvas de Philornis, pode atingir até 100\% em uma ninhada (O'CONNOR et al. 2010; LUZ et al., 2013).

As larvas deste gênero podem ter três tipos de associações com as aves, que variam de acordo com os diferentes hábitos alimentares dessas espécies dípteras. Elas podem estar livres nos ninhos, podendo ser coprófagas e alimentando-se de fezes ou restos orgânicos como penas e cascas de ovos, ou semi-hematófagas, escarificando a pele dos filhotes causando sangramentos; e larvas que são propriamente ditas como parasitárias, que se localizam no subcutâneo/derme e possuem hábito hematófago. Apesar da relação intrínseca entre o gênero Philornis e as aves, sabe-se pouco sobre a biologia destes parasitos, como também sobre sua distribuição geográfica e seus hospedeiros (HIGGINGS et al., 2005; COURI; TAVARES; STENZEL, 2006; COURI et al., 2018; MONJE et al., 2013).

Considerando que no Brasil e em especial para a região Nordeste deste país, os registros de ocorrência deste Diptera são escassos e espaçados, o presente trabalho tem como objetivo relatar a primeira ocorrência de Philornis sp. em P. sulphuratus no Município de João Pessoa, no Estado da Paraíba (PB). 


\section{METODOLOGIA}

No dia 11 de fevereiro de 2021, deu entrada na Clínica Veterinária Espaço Pet um bem-te-vi (Pitangus sulphuratus Linnaeus, 1766) jovem e macho de vida livre, apresentando míase. O animal possuía escore corporal 3 (na escala onde 1 representa caquexia e 5 representa obesidade), mucosas normocoradas, e apresentava-se assintomático. Para atendimento clínico da referida ave, a mesma foi contida e na ocasião, com o auxílio de pinças anatômicas, dez larvas dípteras foram recuperadas. Destas, sete foram eutanasiadas em água morna e transferidas para frascos contendo álcool $70^{\circ}$, e três foram separadas com intuito de que estas evoluíssem até adultas. As larvas separadas foram transferidas para frasco coletor plástico contendo papel umedecido e furos na tampa que o recobria. Estas foram mantidas a temperatura ambiente por 10 dias. Assim, as mesmas passaram pelo estágio pulpário e após 10 dias evoluíram para moscas adultas. Estas foram conservadas em álcool $70^{\circ}$ até sua identificação. Ressalta-se que o animal hospedeiro permaneceu no internamento alimentado com sementes e papa específica para passeriformes a cada 5 horas, por cerca de 5 dias, quando veio à óbito.

As larvas e moscas adultas foram encaminhadas ao Laboratório de Parasitologia Animal da Universidade Federal Rural do Semi-Árido (LPA-UFERSA) para análise. Para montagem dos mesmos, realizou-se clareamento em solução de potassa a 30\%; series de hidratações e desidratações e diafanização em fenol. Por fim, estas foram montadas em meio de Hoyer. A identificação foi realizada com o auxílio de estereomicroscópio e microscopia óptica usando-se as chaves taxonômicas de Garcia (1952), Dodgen e Aitken (1968) e Couri (1989). 


\section{RESULTADOS E DISCUSSÃO}

Da análise realizada nos espécimes, identificou-se os mesmos como sendo machos adultos e larvas de Philornis sp., (Figura 1).

Figura 1 - Espécime adulto macho de Philornis sp. (A, B, C, D, E e F) Obj.5.6x. Larva em estádio 3 (G, H, I) Obj.20x. A - Dorso do espécime; B - olhos; C - aparato bucal; D abdômen; E - asas; F - caliptra; G - larva; H - Esqueleto cefalofaríngeo; I - Placas estigmáticas e estigmas respiratórios.

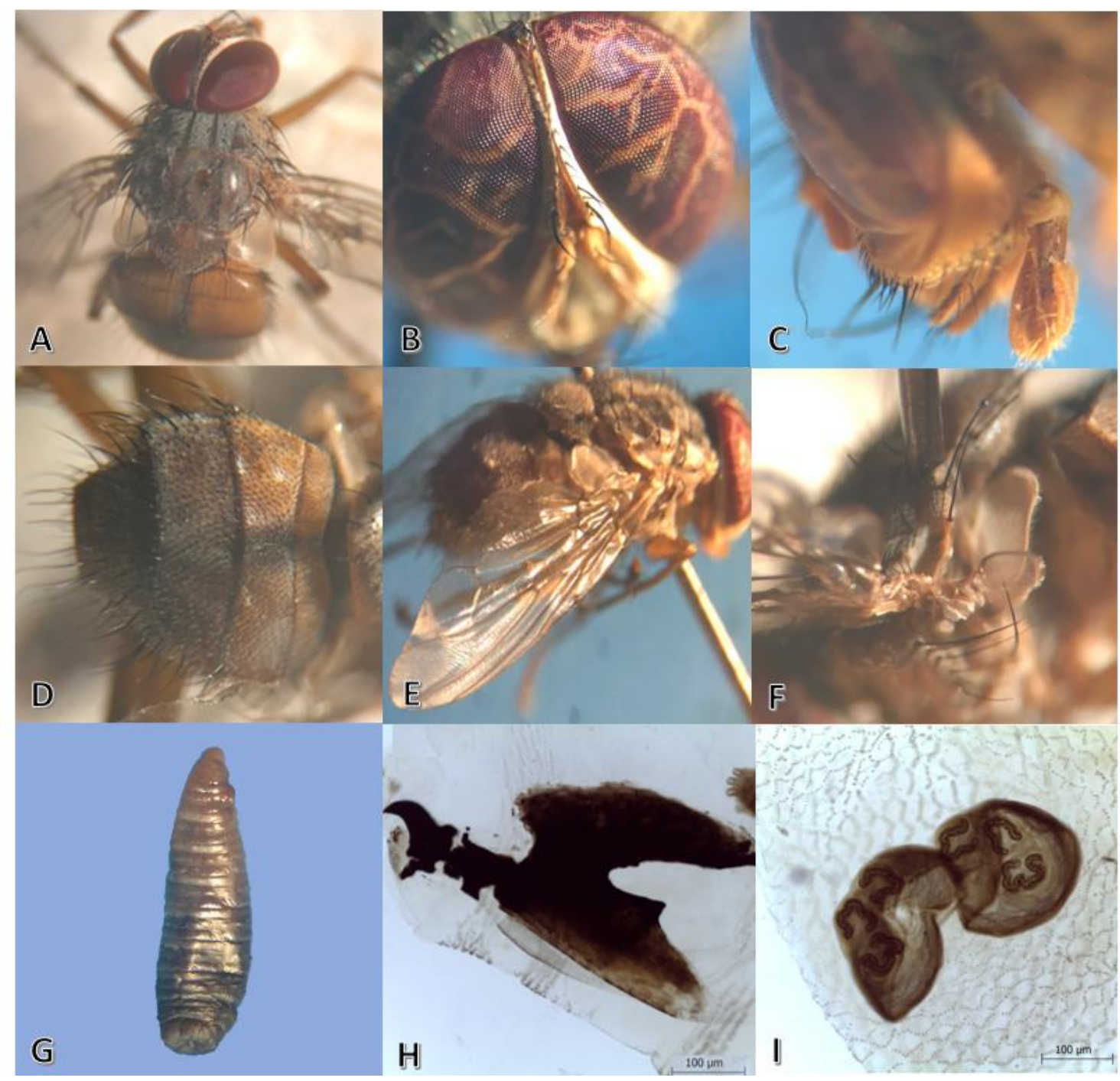

Fonte: Autores, 2021.

Dentre as espécies de Diptera: Muscidae que podem acometer aves, Passeromyia Rodhain e Villeneuve, 1915 e Philornis Meinert, 1890 são os únicos gêneros que já foram 
relatados nessas espécies. O gênero Philornis é atualmente composto por 50 espécies descritas, das quais 39 ocorrem no Brasil, havendo relatos de parasitismo por esse gênero para 130 espécies de aves (COURI; CARVALHO et al., 2003; CARVALHO et al., 2005; COURI et al., 2018).

No Brasil, as primeiras menções aparentes a associação de Philornis em Passeriformes no Brasil datam do século 17. Primeiro em 1618 por Brandão em Cacicus cela Linnaeus, 1758 (Icteridae) em Pernambuco e depois em 1648 por Marcgrave, também no Nordeste do Brasil (TEIXEIRA, 1999). Além dessas, a maioria das ocorrências desse parasito foram relatados no Sudeste e mais especificamente no Rio de Janeiro como Philornis sp. em Thalurania glaucopis Gmelin, 1788 (Trochilidae) (LUZ et al., 2010 b); P. deceptiva Dodge; Aitken, 1968 em Thraupis sayaca Linnaeus, 1766, em Xolmis cinerea Vieillot, 1816 e em Lepidocolaptes angustirostris Vieillot, 1918 (LUZ; FERREIRA; COURI, 2007; 2008; LUZ et al., 2010); e P. bella Couri, 1984 em Tyrannus melancholicus Vieillot, 1819 (LUZ et al., 2011). Porém, essa associação também foi vista em outros estados como P. torquatus em Phacellodomus rufifrons Wied, 1821 (Furnariidae) em Minas Gerais; Philornis sp. (DUCA et al., 2009) e P. torquans Nielsen, 1913 (COURI et al., 2018) em Neothraupis fasciata Lichtenstein, 1823 (Thraupidae) no Distrito Federal.

Esse gênero também foi relatado para aves passeriformes da família Tyrannidae como P. angustifrons Lowel, 1861 e P. deceptivus Dodge; Aitken, 1968 em ninhos de Suiriri affinis Burmester, 1856 e S. islerorum Zimmer; Whittaker; Oren no Distrito Federal (HIGGINS et al., 2005). Porém, apesar de ser uma espécie de ave muito comum no Brasil, só há apenas um relato de milase causada por Philornis sp. em Pitangus sulphuratus, sendo esta no estado do Rio de Janeiro (LUZ et al., 2013). Neste estudo, (LUZ et al., 2013), notou-se que as aves apresentaram um retardo no desenvolvimento, tanto em massa corporal como comprimento total, principalmente quando há grau muito alto de parasitismo.

\section{CONCLUSÃO}

Logo, destacando a importância desse agravo para a conservação, e considerando que os relatos para essa espécie são escassos e espaçados, o presente trabalho registra a ocorrência de Philornis sp. em P. sulphuratus pela primeira vez em João Pessoa, Paraíba, e representa um novo dado referente aos Diptera que ocorrem nessa espécie, no Nordeste e no Brasil. Esta pesquisa contribui para ampliação dos dados ecológicos, assim como para a 
conservação desta e de outras aves que podem ser acometidas. A partir do presente relato, será possível que pesquisas futuras sejam realizadas com o objetivo de compreender o comportamento desses ectoparasitos em passeriformes, apurar as consequências que as populações desses animais podem sofrer em vida livre e como a relação desse parasito em $P$. sulphuratus interfere no bem-estar da espécie hospedeira.

\section{REFERÊNCIAS}

CARVALHO, C. J. B. et al. A catalogue of the Muscidae (Diptera) of the Neotropical Region. Zootaxa, v. 860, n. 1, p. 1-282, 2005.

COURI, Márcia Souto. Philornis Meinert, 1890: key to adults (Diptera, Muscidae, Reinwardtinae). Revista Brasileira de Zoologia, v. 6, n. 3, p. 569-576, 1989.

COURI, M. S.; CARVALHO, C. J. B. Systematic relations among Philornis Meinert, Passeromyia Rodhain \& Villeneuve and allied genera (Diptera, Muscidae). Brazilian Journal of Biology, v. 63, n. 2, p. 223-232, 2003.

COURI, M. S.; TAVARES, M. T.; STENZEL, R. R. Parasitoidism of Chalcidid wasps (Hymenoptera, Chalcididae) on Philornis sp. (Diptera, Muscidae). Brazilian Journal of Biology, v. 66, n. 2A, p. 553-557, 2006.

COURI, M. S. et al. A new host for Philornis torquans (Diptera, Muscidae) from the Brazilian Cerrado. Papéis Avulsos de Zoologia, v. 58, 2018.

DODGE, H. R.; AITKEN, T. H. G. Philomis flies from Trinidad (Diptera: Muscidae). Journal of the Kansas Entomological Society, p. 134-154, 1968.

DUCA, C. et al. Cost-efficient conservation for the white-banded tanager (Neothraupisfasciata) in the Cerrado, central Brazil. Biological Conservation, v. 142, n. 3, p. 563-574, 2009.

GARCÍA, M. Las especies argentinas del género Philornis Mein., con descripción de especies nuevas (Dipt. Anthom.). Revista de la Sociedad entomológica Argentina, v. 15, n. 4, 1952.

HIGGINS, B. F. et al. Sobre a ocorrência de Philornis angustifrons e P. deceptiva (Diptera, Muscidae) em ninhos de Suiriri affinis e S. islerorum (Aves, Tyrannidae), no Cerrado do Distrito Federal, Brasil. Entomología y Vectores, v. 12, n. 1, p. 127-131, 2005.

LUZ, H. R.; FERREIRA, I.; COURI, M. S. Ocorrência de larvas de Philornis deceptiva (Dodge \& Aitken, 1968) (Diptera: Muscidae) na Maria-branca, Xolmis cinerea (Vieillot, 1816) (Aves: Tyrannidae), no município Seropédica, Rio de Janeiro, Brasil. Lundiana: International Journal of Biodiversity, v. 8, n. 2, p. 153-154, 2007.

LUZ, H. R.; FERREIRA, I.; COURI, M. S. Larvas de Philornis deceptiva Dodge \& Aitken (Diptera, Muscidae) no Sanhaçu-cinzento Thraupis sayaca (Linnaeus 1766) (Thraupidae) no município de Seropédica, Rio de Janeiro, Brasil. Biota Neotropica, v. 8, n. 2, p. 0-0, 2008.

LUZ, H. R. et al. Novo hospedeiro de Philornis deceptivus (Dodge e Aitken, 1968) (Insecta, Diptera, Muscidae) em Dendrocolaptidae (Aves, Passeriformes). Biotemas, v. 23, n. 1, p. 97-100, 2010 . 
LUZ, H. R. et al. First record of Philornis glaucinis Dodge \& Aitken, 1968 (Diptera: Muscidae) in Thalurania glaucopis Gmelin, 1788 (Aves: Trochilidae). Biotemas, v. 23, n. 3, p. 227-229, $2010^{\mathrm{b}}$.

LUZ, H. R. et al. Occurrence of Philornis bella Couri in nestlings of Tyrannus melancholicus Vieillot (Tyranninae) in the municipal district of Seropédica, Rio de Janeiro. Biotemas, v. 24, n. 3, p. 69-72, 2011.

MONJE, L, D. et al. Sequence analysis of the internal transcribed spacer 2 (ITS2) from Philornis seguyi (García, 1952) and Philornis torquans (Nielsen, 1913) (Diptera: Muscidae). Systematic parasitology, v. 86, n. 1, p. 43-51, 2013.

O'CONNOR, J. A. et al. Philornis downsi parasitism is the primary cause of nestling mortality in the critically endangered Darwin's medium tree finch (Camarbynchus pauper). Biodiversity and Conservation, v. 19, n. 3, p. 853-866, 2010.

RODRIGUES, F. G. Análise do repertório vocal de Pitangus sulphuratus (Linnaeus, 1766) (Aves: Passeriformes: Tyrannidae) em diferentes regiões do Brasil. Dissertação (Mestrado em Ciências Biológicas) - Universidade Estadual Paulista, Botucatu, 2017.

TEIXEIRA, D.M. Myiasis caused by obligatory parasites. General observations on the biology of species of the genus Philornis Meinert, 1890 (Diptera, Muscidae). In: Guimarães, J.H. \& Papavero, N. Myiasis in man and animals in the Neotropical region. Plêiade/FAPESP, p. 71-96, 1999. 


\section{PARASITISMO POR Bertiella spp. EM BUGIO-PRETO (Alouatta caraya, Humboldt, 1812) DE CATIVEIRO EM JOÃO PESSOA, PB}

\section{Aksa Ingrid Vieira Batista}

Universidade Federal Rural do Semi-Árido (UFERSA), Mossoró - RN ORCID: https://orcid.org/0000-0003-0696-7194

Lattes: http:/ / lattes.cnpq.br/6614624885083003

\section{Gabriel Vinícius Carvalho de Lucena}

Universidade Federal de Campina Grande (UFCG), Patos - PB

ORCID: https://orcid.org/00000001-9789-6066

\section{Audisio Alves da Costa Filho}

Centro Universitário de João Pessoa (UNIPÊ), João Pessoa - PB

ORCID: https://orcid.org/0000-0003-4125-0359

\section{Everaldo Henrique Souza do Vale}

Universidade Federal do Oeste da Bahia (UFOB), Barreiras - BA

ORCID: https://orcid.org/0000-0002-8171-4245

\section{Thiago Ferreira Lopes Nery}

Parque Zoobotânico Arruda Câmara, João Pessoa - PB

ORCID: https://orcid.org/0000-0002-4051-428X

\section{Nathalia Caroline Souza da Silva}

Parque Zoobotânico Arruda Câmara, João Pessoa - PB

ORCID: https://orcid.org/0000-0003-1043-5713

\section{Roberta da Silva Simas}

Universidade Federal da Paraíba (UFPB), João Pessoa - PB

ORCID: https://orcid.org/0000-0002-6668-5108

\section{Igor Espínola Winkeler}

Universidade Federal da Paraíba (UFPB), João Pessoa - PB

ORCID: https://orcid.org/0000-0003-1861-9509

\section{João Victor Fernandes da Silva}

Universidade Federal da Paraíba (UFPB), João Pessoa - PB

ORCID: https://orcid.org/0000-0001-7628-5151

\section{Vanessa Maria de Sales Duarte}

Universidade Federal Rural do Semi-Árido (UFERSA), Mossoró - RN ORCID: https://orcid.org/0000-0003-0872-5295

\section{Maria Heloísa Pontes de Souza}

Universidade Federal Rural do Semi-Árido (UFERSA), Mossoró - RN ORCID: https://orcid.org/0000-0001-5924-1018

\section{Josivania Soares Pereira}

Universidade Federal Rural do Semi-Árido (UFERSA), Mossoró - RN ORCID: https://orcid.org/0000-0002-2407-9417 


\begin{tabular}{|c|c|}
\hline $\begin{array}{l}\text { Informações sobre o } \\
\text { artigo: } \\
\text { Recebido em: } \\
25 / 08 / 2021 \\
\text { Aceito em: } \\
02 / 09 / 2021 \\
\text { Data de publicação: } \\
\text { 19/10/2021 } \\
\text { Palavras-chave: } \\
\text { Bertielose } \\
\text { Cestoda } \\
\text { Primatas } \\
\text { Zoológico }\end{array}$ & $\begin{array}{l}\text { RESUMO } \\
\text { Dentre os parasitos que podem acometer os bugios-pretos } \\
\text { (Alouatta caraya, Humboldt, 1812), os Anoplocephalidae do gênero } \\
\text { Bertiella ganham destaque devido a sua grande prevalência nesses } \\
\text { animais. Apesar de na maioria dos casos a doença ser } \\
\text { assintomática, estes endoparasitos podem influenciar nas taxas de } \\
\text { mortalidade e natalidade de seu hospedeiro definitivo, o que se } \\
\text { torna um obstáculo para a conservação desses animais. Além disso, } \\
\text { a infecção parasitária por Bertiella spp. é uma zoonose de } \\
\text { importância no mundo, já que seres humanos são hospedeiros } \\
\text { acidentais. A fim de favorecer dados ecológicos da relação parasito- } \\
\text { hospedeiro demonstrado através deste estudo, o objetivo do } \\
\text { presente trabalho é relatar a primeira ocorrência de Bertiella spp. em } \\
\text { A. caraya cativo do Parque Zoobotânico Arruda Câmara, João } \\
\text { Pessoa-PB. }\end{array}$ \\
\hline $\begin{array}{l}\text { Keywords: } \\
\text { Berthiellosis } \\
\text { Basket } \\
\text { Primates } \\
\text { Zoo }\end{array}$ & $\begin{array}{l}\text { PARASITISM BY Bertiella spp. IN A BLACK-AND-GOLD HOWLER } \\
\text { MONKEY (Alouatta caraya, HUMBOLDT, 1812) OF CAPTIVITY IN } \\
\text { JOÃO PESSOA, PB } \\
\text { ABSTRACT } \\
\text { Among the parasites that can affect black howler monkeys } \\
\text { (Alouatta caraya, Humboldt, 1812), the Anoplocephalidae of the } \\
\text { genus Bertiella are highlighted due to their high prevalence in these } \\
\text { animals. Although in most cases the disease is asymptomatic, these } \\
\text { endoparasites can influence the mortality and birth rates of their } \\
\text { definitive host, which becomes an obstacle for the conservation of } \\
\text { these animals. Furthermore, the parasitic infection by Bertiella spp. } \\
\text { it is a zoonosis of importance in the world, as human beings are } \\
\text { accidental hosts. In order to favor ecological data of the host- } \\
\text { parasite relationship demonstrated through this study, the aim of } \\
\text { the present work is to report the first occurrence of Bertiella spp. in } \\
\text { A. caraya captive of the Arruda Câmara Zoobotanical Park, João } \\
\text { Pessoa-PB. }\end{array}$ \\
\hline
\end{tabular}

\section{INTRODUÇÃO}

O bugio-preto (Alonatta caraya, Humboldt, 1812) é uma espécie de primata do Novo Mundo da família Atelidae que habita florestas tropicais do Brasil e outros países da América do Sul (GREDORIN, 2006). Esses animais possuem uma dieta herbívora, sendo acidental o consumo de alimentos de origem animal (DE OLIVEIRA et al. 2011). A. caraya não é 
considerada em risco de extinção no Brasil, mas é "vulnerável” em alguns estados do país (COSTA et al. 2005).

Uma das principais afecções em animais silvestres são as endoparasitoses, e em nível populacional, as espécies parasitas podem influenciar a reprodução e a sobrevivência do hospedeiro, influenciando em suas taxas de mortalidade e natalidade, o que é um obstáculo para a preservação. Além disso, esses animais podem ser importantes carreadores de zoonoses, inclusive parasitárias (DE OLIVEIRA et al. 2011).

Dentre os parasitos que podem acometer essa espécie, estão os cestoda Anoplocephalidae do gênero Bertiella spp., com aproximadamente 40 espécies, sendo que apenas dez delas infectam primatas (SERVIAN et al. 2020). Dessa forma, o diagnóstico de endoparasitos se faz necessário para prevenir doenças mais graves que venham acometer esses indivíduos, que podem inclusive comprometer todo o plantel. Dentre as técnicas de diagnóstico coproparasitológico, o Mini-FLOTAC permite o diagnóstico tanto de ovos/larvas de helmintos como de oocistos/cistos de protozoários, oferecendo uma vantagem sobre outras técnicas coproparasitológicas por ser um método rápido, eficaz e de baixo custo, servindo como técnica tanto qualitativa, quanto quantitativa para a contagem de formas parasitárias (Cringoli et al., 2017).

A fim de favorecer dados ecológicos da relação parasito-hospedeiro demonstrado através deste estudo, o objetivo do presente trabalho é relatar a primeira ocorrência de Bertiella spp. em A. caraya cativo do Parque Zoobotânico Arruda Câmara, João Pessoa-PB.

\section{METODOLOGIA}

O projeto de pesquisa foi foi submetido à Comissão de Ética no uso de animais em pesquisa da Universidade Federal Rural do Semi-Árido (UFERSA) (CEUA-UFERSA) e aprovado $\left(\mathrm{N}^{\circ}\right.$ de parecer $\left.11 / 2020\right)$. Todos os procedimentos de manipulação que os animais foram submetidos durante esta pesquisa seguiram as diretrizes especificas do Colégio Brasileiro de Experimentação Animal. O zoológico (CNPJ; 08.806.721/0001-03) encontrase cadastrado no Instituto Brasileiro do Meio Ambiente e dos Recursos Naturais Renováveis sob Registro n²36567. O Parque Zoobotânico Arruda Câmara, vulgarmente conhecido como Bica, está localizado entre as coordenadas $292670 \mathrm{mE}$ e $293330 \mathrm{mE}$ e entre as coordenadas $9213107 \mathrm{mN}$ e $9214100 \mathrm{mN}$, localizando-se em um fragmento de Mata Atlântica. 
Realizou-se coleta de fezes para exames coproparasitológicos de rotina, em 14 de março de 2020, de um bugio-preto (Alonatta caraya, HUMBOLT, 1812), macho, adulto, cativo de um recinto no Parque Zoobotânico Arruda Câmara, João Pessoa-PB (Figura 1). As fezes foram coletadas do chão do recinto com o auxílio de palitos de madeira e frascos coletores. A amostra biológica obtida foi adicionada de formalina $5 \%$. $\mathrm{Na}$ ocasião da coleta, percebeu-se fragmento móvel sugestivo de proglótide que se projetava do ânus do animal. Este foi também coletado e acondicionado em frascos contendo álcool $70^{\circ}$ para posterior análise.

Figura 1- Bugio-preto (Alonatta caraya) macho adulto cativo do Parque Zoobotânico Arruda Câmara, João Pessoa, Paraíba, Brasil

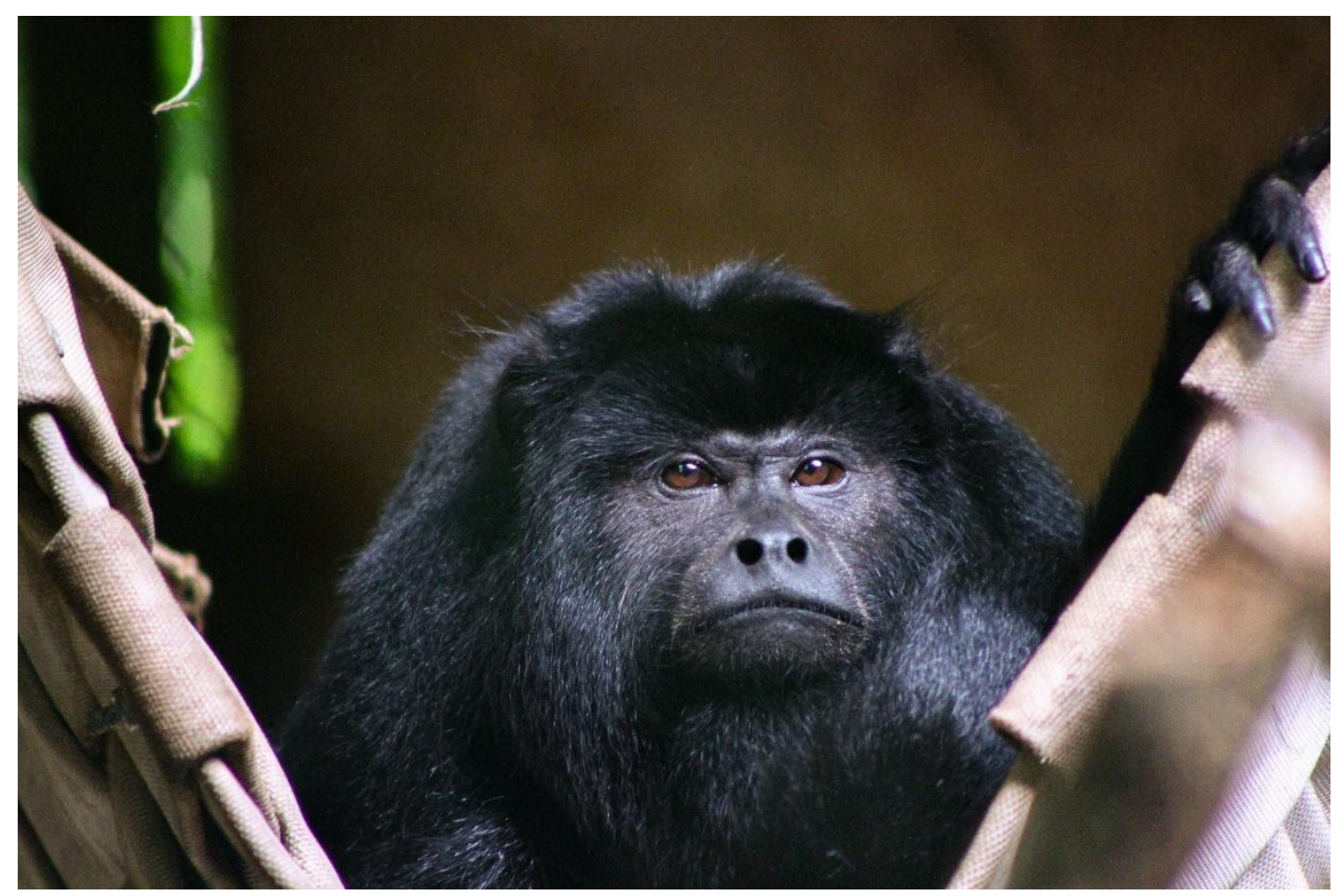

Fonte: Autores, 2021.

Todas as amostras biológicas coletadas foram encaminhadas ao Laboratório de Parasitologia Animal da Universidade Federal Rural do Semi-Árido (LPA-UFERSA) para diagnóstico. Para a análise das fezes, utilizou-se o método direto (HOFFMAN, 1987); de sedimentação simples (HOFFMAN et al. 1934); flutuação em solução hipersaturada de sulfato de zinco (WILLIS, 1921) e flutuação pelo método de Mini-FLOTAC (CRINGOLI 
et al. 2017; CAPASSO et al. 2019). Para o Mini-FLOTAC foi utilizado 10 como o fator de conversão.

Dessa maneira, a identificação dos ovos encontrados nas fezes e do fragmento móvel da região anal do animal foi realizada através da morfologia utilizando-se literatura específica (SERVIAN et al. 2020) auxiliado por microscopia óptica de luz e estereomicroscopia.

\section{RESULTADOS E DISCUSSÃO}

Da análise realizada nas fezes e através das três técnicas empregadas foram recuperados ovos do gênero Bertiella. Já o fragmento móvel da região anal do animal foi confirmado que se tratava de uma proglótide do referido Cestoda (Figura 2). Na câmara de Mini-FLOTAC foram contados onze ovos, totalizando 110 ovos por grama de fezes (OPG).

Figura 2 - Bertiella spp. em bugio-preto (Alouatta caraya). A - Ovo encontrado em fezes na técnica de flutuação pelo método de Mini-FLOTAC (CRINGOLI et al., 2017), objetiva de 40x. B - Proglótide liberada de forma espontânea pelo animal.

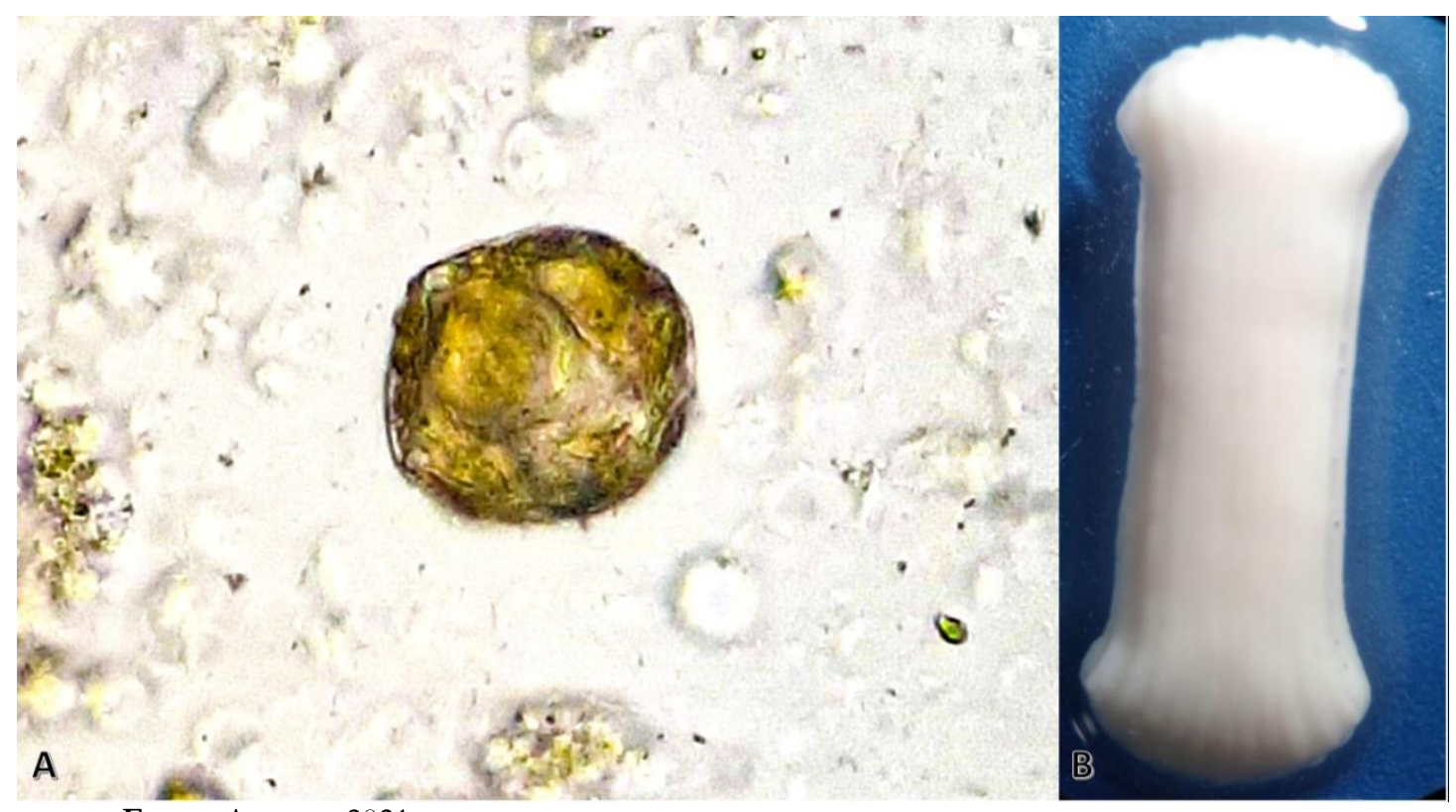

Fonte: Autores, 2021

De Oliveira et al. (2011) afirmaram que houve uma prevalência significativa desse parasito em bugios-pretos de vida livre no estado do Rio Grande do Sul, Brasil. Por estes indivíduos viverem em bandos, geralmente há uma alta densidade de animais, o que favorece a prevalência da parasitose visto que esses animais defecam no local e acabam ingerindo folhas contendo os ácaros contaminados. Porém, no referido trabalho apesar de não se ter 
observado grande densidade populacional no recinto, visto que existia no máximo dois animais por recinto, sugerimos que a referida infecção pode ter ocorrido devido a contaminação do alimento, ou dos próprios animais já que vieram de um mantenedouro de fauna da região.

Para que não haja o aparecimento desta parasitose em cativeiro, é necessário que haja higiene constante do recinto, o que evita o acúmulo de fezes e a prevenção de artrópodes no local. Além disso, deve-se realizar uma higienização dos vegetais oferecidos a esses primatas e evitar a alta densidade populacional dentro dos recintos, evitando a transmissão da doença, assim como a diminuição do estresse em cativeiro, que levará a queda da imunidade.

Já foi demonstrado também a importância dessa zoonose, que pode ocorrer principalmente em pacientes com contato direto ou indireto com esses animais. Dessa forma, essa doença já foi registrada em humanos nos estados de Goiás (POÇÁ, 2003), Pará (FURTADO et al. 2012) e Minas Gerais (LOPES et al. 2015). Isso pode ocorrer onde há coexistência de populações de primatas humanos e não humanos no mesmo local; na utilização dos mesmos como animais de estimação; ou na manutenção destes animais sob cuidados humanos. Embora a infecção em primatas não humanos e humanos seja frequentemente assintomática, pode causar desconforto abdominal, diarreia, gastroenterite e anorexia (SERVIAN et al. 2020).

Quanto às técnicas coproparasitológicas empregadas no presente estudo, Servian et al. (2020) e Jesus (2013) demonstraram a eficácia para realização do diagnóstico de Bertiella spp. utilizando técnicas de sedimentação e flutuação. Da mesma maneira, observou-se que a técnica de sedimentação simples (método de Holfman) e as de flutuação (método de WillisMollay e Mini-FLOTAC) utilizadas nesse estudo foram eficazes na recuperação dos ovos de Bertiella spp.

\section{CONCLUSÃO}

A ocorrência de Bertiella spp. em $A$. caraya é relatada pela primeira vez em João Pessoa, Paraíba e constitui um novo dado aplicável aos endoparasitos que ocorrem nessa espécie e no nordeste do Brasil. Fato este que contribui para ampliação referente aos dados ecológicos, bem como preservação desta referida espécie. A partir desse estudo, será possível que pesquisas futuras sejam realizadas com a finalidade de compreender a dinâmica desses 
parasitos em bugios-pretos e assim investigar as consequências que a população desses hospedeiros pode sofrer e como essa relação de Bertiella spp. em $A$. caraya interfere no bemestar desta espécie hospedeira.

\section{REFERÊNCIAS}

CAPASSO M. et al. Use of mini-FLOTAC and Fill-FLOTAC for rapidly diagnosing parasitic infections in zoo mammals. Revista Brasileira de Parasitologia Veterinária, 2019.

COSTA, L.P. Conservação de mamíferos no Brasil. Megadiversidade, 2005.

CRINGOLI, G. et al. The Mini-FLOTAC technique for the diagnosis of helminth and protozoan infections in humans and animals. Nature protocols, 2017.

DE OLIVEIRA, S.G. et al. Prevalência de Bertiella sp. em um grupo de bugios-pretos, Alouatta caraya (Humbolt, 1812). A Primatologia no Brasil, 2011.

DE SOUZA JÚNIOR, J.C. et al. Bertiellosis in brazilian non-human primates: natural infection in Alouatta guariba clamitans (Cabrera, 1940) (Primates: Atelidae) in Santa Catarina State, Brazil. Revista de Patologia Tropical, 2008.

FURTADO, Adriano P. Human Bertielliasis in Amazonia: Case Report and Challenging Diagnosis. Neglected Tropical Diseases, 2012.

HOFFMANN, R. P. Diagnóstico de parasitismo veterinário. Sulina, 1987.

HOFFMANN, W. A.; PONS, J. A.; JANER, J. L. The sedimentation concentration method in Schistosomiasis mansoni. Journal of Tropical Medicine and Public Health, 1934.

JESUS, A.S. Composição da dieta e intensidade de infecção parasitária em bugiospretos (Alouatta caraya): buscando evidências de automedicação. Dissertação (Mestrado) - Curso de Zoologia, Pontifícia Universidade Católica do Rio Grande do Sul, 2013.

LOPES, V.V. et al. First case of human infection by Bertiella studeri (Blanchard, 1891) Stunkard,1940 (Cestoda; Anoplocephalidae) IN BRAZIL. Revista do Instituto de Medicina Tropical de São Paulo, 2015.

PAÇÔ, Julieta M et al. Human bertiellosis in Goiás, Brazil: a case report on human infection by Bertiella sp. (Cestoda: Anoplocephalidae). Revista do Instituto de Medicina Tropical de São Paulo, 2003.

SERVIÁN, A. et al. Morphological and molecular characterization of Bertiella sp. (Cestoda, Anoplocephalidae) infection in a human and howler monkeys in Argentina. Parasitology Research, 2020.

WILLIS, H. H. A simple levitation method for the detection of wookworm ova. Medicine Journal of Australia, 1921. 


\section{Capítulo 4}

\section{CAPILARIOSE EM ARARA-AZUL-GRANDE (Anodorhynchus hyacinthinus, LATHAM, 1790) CATIVA DO PARQUE ZOOBOTÂNICO ARRUDA CÂMARA, JOÃO PESSOA, PARAIÍBA, BRASIL: RELATO DE CASO}

Gabriel Vinícius Carvalho de Lucena

Universidade Federal de Campina Grande (UFCG), Patos - PB

ORCID: https://orcid.org/00000001-9789-6066

\section{Aksa Ingrid Vieira Batista}

Universidade Federal Rural do Semi-Árido (UFERSA), Mossoró - RN ORCID: https://orcid.org/0000-0003-0696-7194

Lattes: http:/ /lattes.cnpq.br/6614624885083003

\section{Audisio Alves da Costa Filho}

Centro Universitário de João Pessoa (UNIPÊ), João Pessoa - PB

ORCID: https://orcid.org/0000-0003-4125-0359

\section{Thiago Ferreira Lopes Nery}

Parque Zoobotânico Arruda Câmara, João Pessoa - PB

ORCID: https:/ /orcid.org/0000-0002-4051-428X

Nathalia Caroline Souza da Silva

Parque Zoobotânico Arruda Câmara, João Pessoa - PB

ORCID: https://orcid.org/0000-0003-1043-5713

\section{Cintia Cleub Neves Batista}

Parque Zoobotânico Arruda Câmara, João Pessoa - PB ORCID: https://orcid.org/0000-0001-5363-7863

\section{Marília Gabriela Maia}

Parque Zoobotânico Arruda Câmara, João Pessoa - PB

ORCID: https://orcid.org/0000-0003-3113-2738

Helze Melo de Freitas Lins

Parque Zoobotânico Arruda Câmara, João Pessoa - PB

ORCID: https://orcid.org/0000-0001-7731-2668

\section{Paola de Cassia Gonçalves}

Parque Zoobotânico Arruda Câmara, João Pessoa - PB

ORCID: https://orcid.org/0000-0001-5372-3104

\section{Igor Espínola Winkeler}

Universidade Federal da Paraíba (UFPB), João Pessoa - PB

ORCID: https://orcid.org/0000-0003-1861-9509

\section{João Victor Fernandes da Silva}

Universidade Federal da Paraíba (UFPB), João Pessoa - PB

ORCID: https://orcid.org/0000-0001-7628-5151

Josivania Soares Pereira

Universidade Federal Rural do Semi-Árido (UFERSA), Mossoró - RN ORCID: https://orcid.org/0000-0002-2407-9417 
Informações sobre o artigo:

Recebido em:

26/08/2021

Aceito em:

02/09/2021

Data de publicação:

$19 / 10 / 2021$

Palavras-chave:

Capilariose

Parasitologia

Psitacídeos

Zoológico

\section{RESUMO}

A arara-azul-grande (Anodorbynchus hyacinthinus, Latham, 1790) é um psitacídeo endêmico do Brasil, sendo considerado o maior do mundo. Dentre as principais afecções que acometem aves silvestres e que são um obstáculo para a conservação ex situ desses animais, as endoparasitoses se destacam devido à alta prevalência. Os Nematoda do gênero Capillaria podem acometer esses indivíduos de forma aguda ou crônica, promovendo danos significativos às mucosas intestinais ocasionando má absorção de nutrientes e consequente perda de peso, diarreia e complicações neuromusculares, podendo levar ao óbito. Uma arara-azul-grande deu entrada no ambulatório do Parque Zoobotânico Arruda Câmara e apresentava perda de peso, escore corporal 1 (em uma escala de 1 a 5 , sendo $1=$ caquético e $5=$ obeso), penas arrepiadas e sem brilho, diarreia, retrizes sujas de fezes e dificuldade de se manter em estação. Realizou-se a coleta de fezes que foram posteriormente analisadas por método direto (HOFFMANN, 1987), flutuação com sulfato de zinco (WILLIS, 1921) e sedimentação espontânea (HOFFMANN et al., 1934), havendo positividade para Capillaria sp. O animal foi tratado utilizando-se Mebendazol, e suporte nutricional adequado. Após dois exames negativos para o referido parasito, o animal foi considerado livre de infecção parasitária. A fim de favorecer dados ecológicos da relação parasito-hospedeiro demonstrado neste estudo, o objetivo do presente trabalho é relatar a primeira ocorrência de Capillaria sp. em $A$. byacinthinus cativa do Parque Zoobotânico Arruda Câmara, João Pessoa-PB, assim como o protocolo terapêutico utilizado.

CAPILLARIASIS IN HYACINTH MACAW (Anodorhynchus hyacinthinus, LATHAM, 1790) CAPTIVE OF THE ARRUDA CÂMARA ZOOBOTANICAL PARK, JOÃO PESSOA, PARAÍBA, BRAZIL: CASE REPORT

\section{ABSTRACT}

The hyacinth macaw (Anodorbynchus byacintbinus, Latham, 1790) is an endemic parrot in Brazil, being considered the largest in the world. Among the main diseases that affect wild birds and that are an obstacle to the ex situ conservation of these animals, endoparasitosis stand out due to their high prevalence. Capillaria Nematodes can affect these individuals acutely or chronically, causing significant damage to the intestinal mucosa, causing poor absorption of nutrients and consequent weight loss, diarrhea and neuromuscular complications, which can lead to death. A hyacinth macaw was admitted to the outpatient clinic of the Arruda Câmara Zoo and Botanical Park and presented weight loss, body score 1 (on a scale of 1 to $5,1=$ cachectic and $5=$ obese), ruffled feathers and dull, diarrhea, dirty feces retrictions and difficulty in keeping in season. Feces were collected and analyzed by direct method 
Keywords:

Capillariasis

Parasitology

Parrots

Zoo
(HOFFMANN, 1987), fluctuation with zinc sulfate (WILLIS, 1921) and spontaneous sedimentation (HOFFMANN et al., 1934), with positivity for Capillaria sp. The animal was treated using Mebendazole, and adequate nutritional support. After two negative tests for that parasite, the animal was considered free from parasitic infection. In order to favor ecological data on the host-parasite relationship demonstrated in this study, the aim of the present work is to report the first occurrence of Capillaria sp. in $A$. byacinthinus captive from the Arruda Câmara Zoo-Botanical Park, João Pessoa-PB, as well as the therapeutic protocol used.

\section{INTRODUÇÃO}

Os Psittaciformes possuem características marcantes como o formato curvo do bico, os pés zigodáctilos e as inúmeras variações de cores. O Brasil é considerado o país mais rico em representantes da família Psittacidae, ocorrendo 85 das 375 espécies reconhecidas (CUBAS et al. 2014). Dentre essas, a arara-azul-grande (Anodorbynchus hyacinthinus, Latham, 1790) atinge cerca de 1 metro da ponta do bico à ponta da cauda e pesa por volta de $1,3 \mathrm{~kg}$, sendo considerada como o maior psitacídeo do mundo. Essa ave possui penas de cor azul cobalto com a região em torno dos olhos e da ranfoteca de cor amarela (PRESTI et al. 2016).

Uma das principais infecções em animais silvestres são as endoparasitoses, e em nível populacional, os endoparasitos podem diminuir a aptidão na reprodução e a sobrevivência do hospedeiro, influenciando também em suas taxas de mortalidade e natalidade, o que é um obstáculo para a preservação (DE OLIVEIRA et al., 2011). Dentre as principais infecções parasitárias que ocorrem em aves, a capilariose possui grande relevância, podendo trazer diversos danos ao animal como a caquexia, diarreia, penas arrepiadas e sem brilho, além de massas inflamatórias, placas diftéricas na cavidade oral e também lesões hemorrágicas na comissura do bico, tendo assim uma elevada taxa de mortalidade em psitacídeos (CUBAS \& GODOY, 2004; MARQUES et al, 2018).

A fim de favorecer dados ecológicos da relação parasito-hospedeiro demonstrado neste estudo, o objetivo do presente trabalho é relatar a primeira ocorrência de Capillaria sp. em $A$. byacinthinus cativa do Parque Zoobotânico Arruda Câmara, João Pessoa-PB, assim como o protocolo terapêutico utilizado. 


\section{METODOLOGIA}

O projeto foi submetido à Comissão de Ética no uso de animais em pesquisa da Universidade Federal Rural do Semi-Árido (UFERSA) (CEUA-UFERSA) e aprovado $\left(\mathbb{N}^{\circ}\right.$ de parecer 11/2020). Todos os procedimentos de manipulação que os animais foram submetidos durante esta pesquisa seguiram as diretrizes especificas do Colégio Brasileiro de Experimentação Animal. O referido zoológico (CNPJ; 08.806.721/0001-03) apresenta-se cadastrado no Instituto Brasileiro do Meio Ambiente e dos Recursos Naturais Renováveis sob Registro nº236567.

O Parque Zoobotânico Arruda Câmara é popularmente conhecido como Bica, e está localizado entre as coordenadas $292670 \mathrm{mE}$ e $293330 \mathrm{mE}$ e entre as coordenadas $9213107 \mathrm{mN}$ e $9214100 \mathrm{mN}$, mais precisamente na porção norte do município de João Pessoa, e encontra-se em um fragmento de Mata Atlântica. O presente relato refere-se a um espécime de arara-azul-grande (Anodorbynchus, byacinthinus, Latham, 1790) adulta e fêmea. Esse animal foi apreendido do tráfico de animais silvestres há 2 anos e direcionado para um recinto comunitário com aves de diferentes espécies no Parque Zoobotânico Arruda Câmara, João pessoa-PB.

Esse animal deu entrada no ambulatório do zoológico e apresentava como sinais clínicos a perda de peso, penas arrepiadas e sem brilho, diarreia, retrizes sujas de fezes e dificuldade de se manter em estação. Ao exame físico, o animal apresentava-se com escore corporal 1 (em uma escala de 1 a 5 , sendo 1 = caquético e 5 = obeso) (Figura 1). 
Figura 1 - Arara-azul-grande (Anodorbynchus hyacintbinus). A, B - Pode-se notar animal com plumagem em mau aspecto e sem brilho característico; C - Escore 1 (na escala onde 1 representa caquexia e 5, obesidade). $\mathbf{D}$ - Plumagem quebrada e em mau aspecto, penas sujas de fezes sugerindo diarreia.

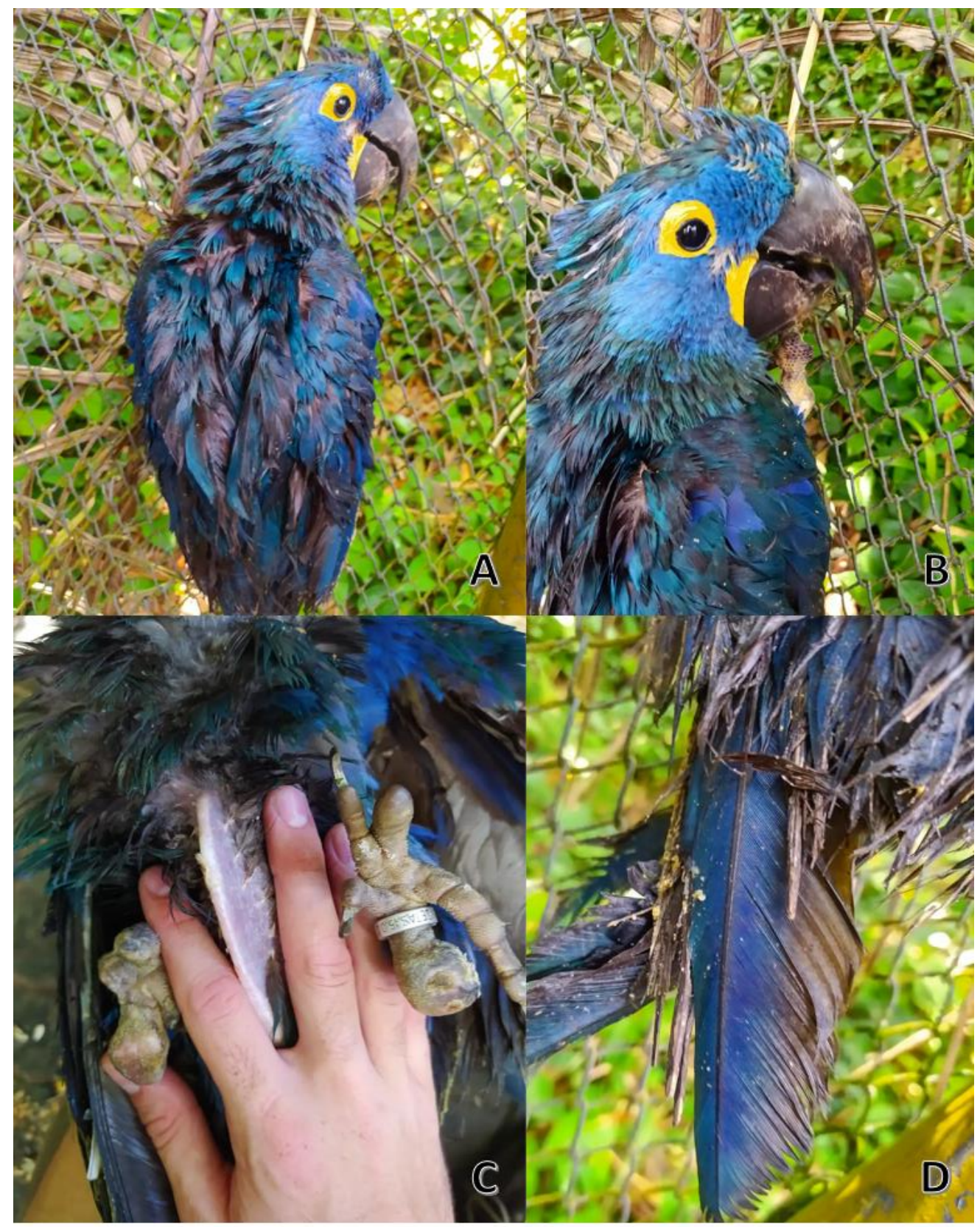

Fonte: Autores, 2021.

Devido à suspeita de endoparasitose, no dia 28 de fevereiro de 2020 realizou-se a coleta de fezes que foram posteriormente analisadas por método direto (HOFFMANN, 1987), flutuação com sulfato de zinco (WILLIS, 1921), sedimentação espontânea (HOFFMANN et al., 1934). A identificação dos ovos encontrados nas fezes do animal foi 
realizada através da morfologia utilizando-se literatura específica (TAMARU et al. 2015). Após confirmação do diagnóstico, o referido paciente foi transferido para o ambulatório do zoológico onde ocorria higienização constante. Assim, foi estabelecido tratamento e ao término do mesmo, foram realizados exames clínicos e coproparasitológicos para confirmação da recuperação do animal.

\section{RESULTADOS E DISCUSSÃO}

Dos exames coproparasitológicos realizados, obteve-se a recuperação de ovos de Capillaria sp. (Figura 2). Ao animal, foi administrado um tratamento segundo Carpenter (2018) com o fármaco mebendazol (25mg/kg) por via oral, a cada 24 horas e com duração de 5 dias. Além disso, o animal recebeu suporte alimentar necessário com ração extrusada e papinha específica para psitacídeos, além de mistura de sementes selecionadas.

Figura 2 - Ovos de Capillaria sp. em fezes de arara-azul-grande (Anodorbynchus hyacinthinus), na técnica de flutuação com sulfato de zinco (WILLIS, 1921), objetiva de 40x

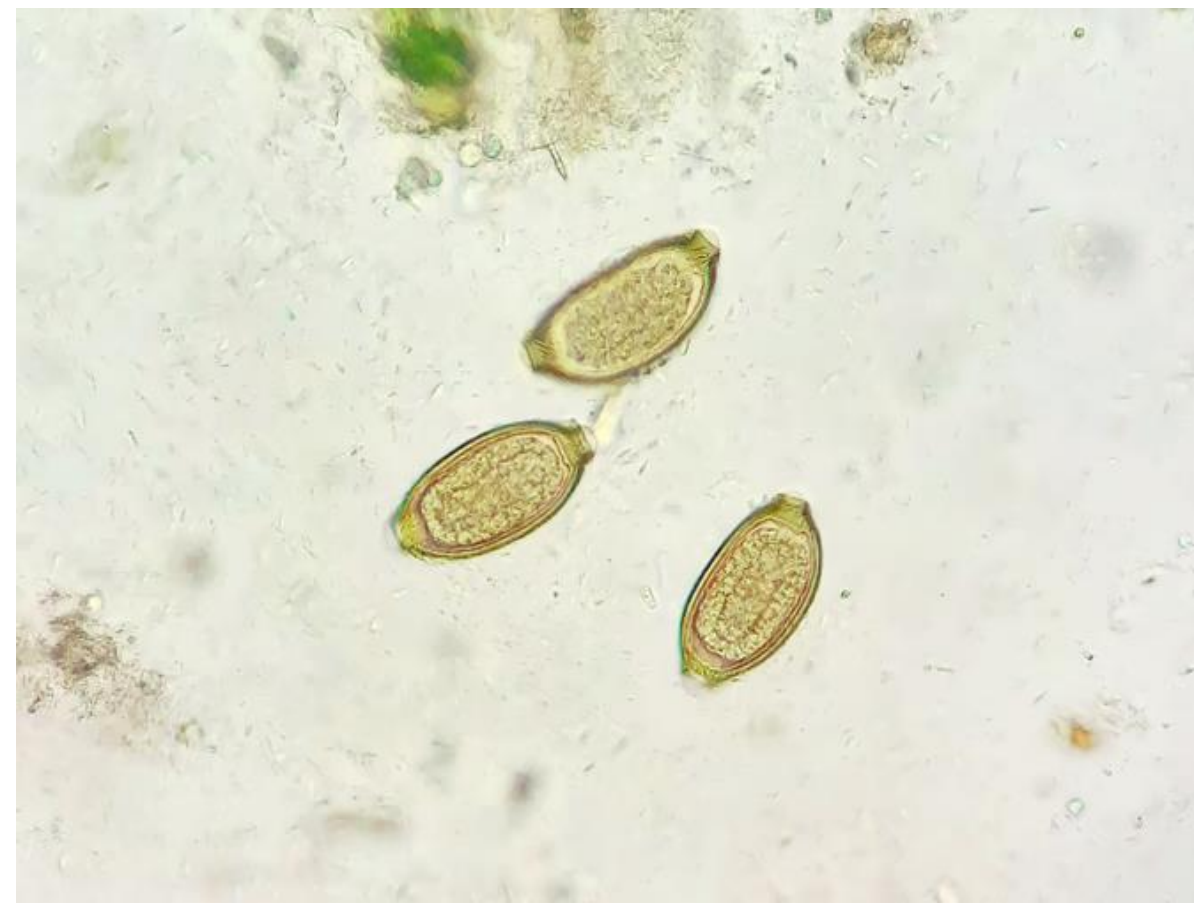

Fonte: Autores, 2021.

Após uma semana do término do tratamento e realização de novos exames, confirmou-se a recuperação do animal que apresentou resultados coproparasitologicos 
negativos. Depois de cerca de 5 meses, o animal já se encontrava com as penas com aspecto, cor e brilho característicos, com escore 2,5, sem diarreia e totalmente sadio (Figura 3).

Figura 3 - Arara-azul-grande (Anodorbynchus byacinthinus) recuperada

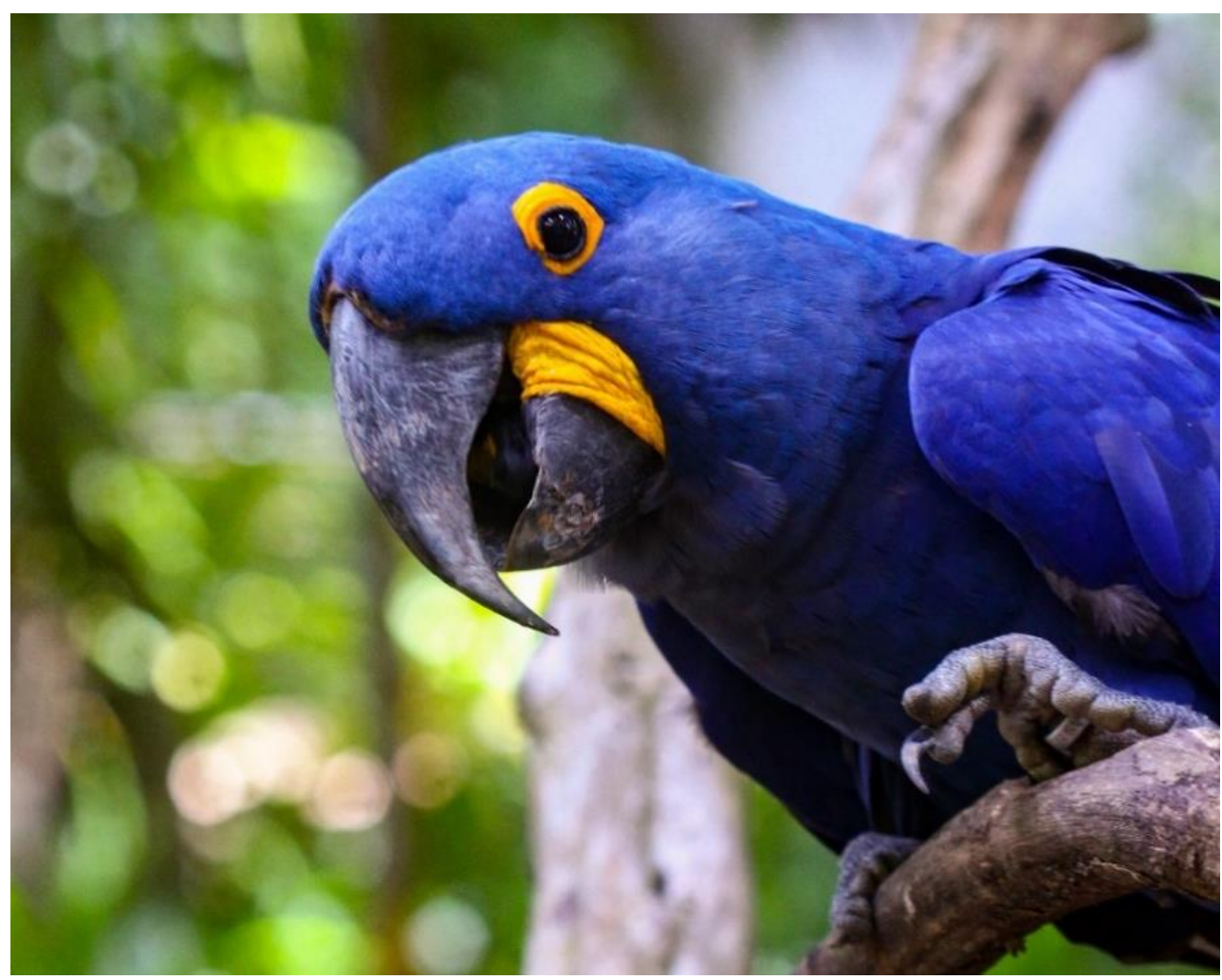

Fonte: Autores, 2021.

Os parasitos do gênero Capillaria podem ser encontrados no intestino, orofaringe ou inglúvio das aves. A doença é marcada por causar baixo desenvolvimento, perda de peso, diarreia, massas inflamatórias, placas diftéricas na cavidade oral, lesões hemorrágicas na comissura do bico, e por ter elevada mortalidade em psitacídeos (HOFSTATTER \& GUARALDO, 2014; SANTOS et al, 2015; MELO et al, 2019; MATIAZZO, 2020).

Capillaria sp. possui alta patogenicidade podendo infectar diversas ordens de aves, porém com mais relatos em passeriformes, psitaciformes, columbiformes e galliformes. A prevalência destes capilarídeos é alta em psitacídeos silvestres cativos de zoológicos, tendo um índice de mortalidade elevada. No entanto, a literatura para a ocorrência desse parasito em Anodorbynchus byacinthinus, no Brasil, é escassa, sendo relatada na cidade de Recife, Pernambuco e Americana, São Paulo (HOFSTATTER \& GUARALDO, 2014; SANTOS et al, 2015; MELO et al, 2019; MATIAZZO, 2020). 
As infecções parasitárias representam uma grande prevalência em animais cativos, já que há alta contaminação ambiental devido a manutenção de animais em áreas confinadas. A capilariose é uma afecção de difícil controle, sendo necessário promover a higiene diária dos recintos, o que evita o acúmulo de fezes e consequentemente a doença parasitária. Para evitar a reinfecção dos animais, deve-se realizar uma desinfecção total do ambiente, já que os Nematoda do gênero Capillaria possuem ovos resistentes que podem ficar viáveis por muito tempo. Além disso, é importante impedir a alta densidade populacional dentro dos viveiros, pois caso isso não ocorra, o estresse pode aumentar, o que leva a queda da imunidade, e consequentemente a predisposição a parasitoses (BENEZ, 2004; CUBAS \& GODOY, 2004; FAGIOLINI, M. et al., 2010; ALVES, 2018).

\section{CONCLUSÃO}

A ocorrência de Capillaria sp. em Anodorbynchus byacinthinus (Latham, 1790) é relatada pela primeira vez em João Pessoa, Paraíba e constitui um novo dado aplicável aos endoparasitos que ocorrem nessa espécie e no nordeste do Brasil. Fato este que contribui para ampliação referente aos dados ecológicos e tratamento, bem como preservação desta referida espécie. A partir desse estudo, será possível que pesquisas futuras sejam realizadas com a finalidade de compreender a dinâmica desses parasitos em araras-azul-grandes e assim investigar as consequências que a população desses hospedeiros pode sofrer e como essa relação de Capillaria sp. em $A$. byacinthinus interfere no bem-estar desta espécie hospedeira.

\section{REFERÊNCIAS}

ALVES, E.N.N. Parasitas gastrointestinais dos animais no centro de estudos e recuperação de animais silvestres (CERAS, Castelo Branco). Dissertação (Mestrado) Instituto de Ciências Biomédicas Abel Salazar, 2018.

BENEZ, S.M. Aves: criação, clínica, teoria, prática: silvestres, ornamentais, avinhados. 4 ed. Ribeirão Preto - SP. Editora: Tecmedd. 2004.

CARPENTER, J. Exotic Animal Formulary. 5 ed. Missouri: Elsevier, 2018.

CUBAS, Z. S.; GODOY, S. N. Algumas doenças de aves ornamentais. Departamento de Meio Ambiente. Foz do Iguaçu - PR, 2004.

CUBAS, Z. S.; SILVA, J. C. R.; CATÃO, D, J. L. Tratado de animais selvagens: Medicina Veterinária. 2 ed. São Paulo: GEN/Roca, 2014. 
DE OLIVEIRA, S.G. et al. Prevalência de Bertiella sp. em um grupo de bugios-pretos, Alouatta caraya (Humbolt, 1812). A Primatologia no Brasil, 2011.

FAGIOLINI, M. et al. Gastrointestinal parasites in mammals of two italian zoological gardens. Journal of Zoo and Wildlife Medicine, v. 23, p. 219-221, 2010.

FREITAS, M. F. L. et al. Parásitos gastrointestinales aves silvestres en cautiverio en el estado de Pernambuco, Brasil. Parasitología al Día, 2002.

HOFFMANN, R. P. Diagnóstico de parasitismo veterinário. Sulina, 1987.

HOFFMANN, W. A.; PONS, J. A.; JANER, J. L. The sedimentation concentration method in Schistosomiasis mansoni. Journal of Tropical Medicine and Public Health, 1934.

HOFSTATTER, G.; GUARALDO, A. M. A. Levantamento parasitológico em aves de alguns zoológicos brasileiros Paulo. Brazilian Journal of Veterinary Parasitology, 2015.

MARQUES, T. M. S. et al. Capilariose em savacu (Nycticorax nycticorax). Neotropical Helminthology, 2018.

MATIAZZO, M. F. et al. Prevalência de endoparasitas em Progne chalybea no dormitório em Chapecó, Santa Catarina, Brasil. Pubvet, 2020.

MELO, Y. J. O. et al. Ovos de helmintos encontrados em fezes de aves silvestres. Enciclopédia biosfera, 2019.

PRESTI, T. F. et al. Arara Azul Carajás. Belo Horizonte: ICMBio - Instituto Chico Mendes de Conservação da Biodiversidade, 2016.

SANTOS, P. M. S. et al. Parasitos de aves e mamíferos silvestres em cativeiro no estado de Pernambuco. Pesquisa Veterinária Brasileira, 2015.

TAMARU, M. et al. Morphological and molecular genetic characterization of three Capillaria spp. (Capillaria anatis, Capillaria pudendotecta, and Capillaria madseni) and Baruscapillaria obsignata (Nematoda: Trichuridae: Capillariinae) in avians. Parasitological Research, 2015.

WILLIS, H. H. A simple levitation method for the detection of wookworm ova. Medicine Journal of Australia, 1921. 


\section{LEISHMANIOSE VISCERAL EM CACHORRO-DO-MATO (Cerdocyon thous LINNAEUS, 1766)}

\section{Mylena Adriele Dias da Silva}

Universidade Federal de Sergipe, São Cristóvão - SE

ORCID: https://orcid.org/0000-0002-8286-3963

\section{Washington Santos Antunes}

Universidade Federal da Bahia, Salvador - BA

Lattes: http://lattes.cnpq.br/9120739395070560

\section{Karine Fernandes Camacho}

Universidade Federal da Integração Latino-Americana, Foz do Iguaçu - PR

Lattes: http://lattes.cnpq.br/7201388477956454

\section{Matheus Resende Oliveira}

Universidade Federal de Sergipe, Núcleo de Medicina Veterinária, Nossa Senhora da Glória - SE Lattes: http://lattes.cnpq.br/3822150058285111

\section{Igo Gonçalves dos Santos}

Universidade Federal de Sergipe, Núcleo de Medicina Veterinária, Nossa Senhora da Glória - SE Lattes: http://lattes.cnpq.br/3048876638161878

\section{Manuel Benicio Oliveira Neto}

Universidade Federal de Sergipe, Núcleo de Medicina Veterinária, Nossa Senhora da Glória - SE Lattes: http://lattes.cnpq.br/6372287958265880

\section{Weslania Souza Inacio da Silva}

Universidade Federal de Sergipe, Núcleo de Medicina Veterinária, Nossa Senhora da Glória - SE Lattes: http://lattes.cnpq.br/2096023399078864

\section{Lorena Maciel Santos Silva}

Universidade Federal de Sergipe, Núcleo de Medicina Veterinária, Nossa Senhora da Glória - SE Lattes: http://lattes.cnpq.br/0766419381359796

\section{Camenas Vieira Barata}

Universidade Federal de Sergipe, Núcleo de Medicina Veterinária, Nossa Senhora da Glória - SE Lattes: http://lattes.cnpq.br/3753872871256727

\section{Danilo Santos de Jesus}

Universidade Federal de Sergipe, Núcleo de Medicina Veterinária, Nossa Senhora da Glória - SE Lattes: http://lattes.cnpq.br/0030697599240620

\section{Maria Flaviane Almeida Silva}

Universidade Federal de Sergipe, Núcleo de Medicina Veterinária, Nossa Senhora da Glória- SE Lattes: http://lattes.cnpq.br/7276739267506207

\section{Victor Fernando Santana Lima}

Universidade Federal de Sergipe, Nossa Senhora da Glória - SE

Lattes: http://lattes.cnpq.br/7265386741392623 


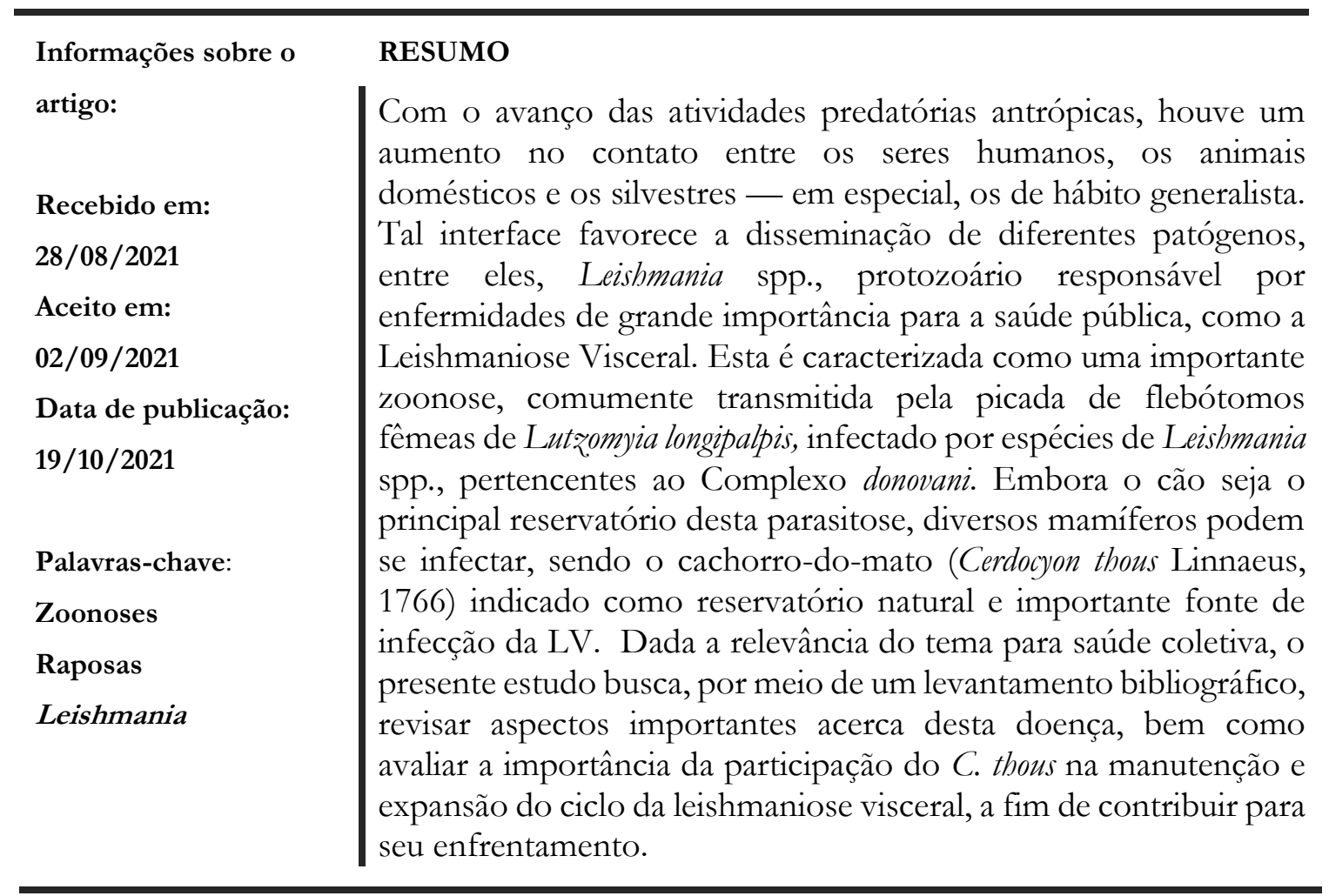

VISCERAL LEISHMANIASIS IN CRAB-EATING-FOX (Cerdocyon thous LINNAEUS, 1766)

\section{ABSTRACT}

With the advance of anthropic predatory activities, there has been an increase in contact between humans, domestic animals and wild animals - especially those of generalist habit. This interface favors the dissemination of different pathogens, including Leishmania sp., a protozoan responsible for diseases of great importance to public health, such as Visceral Leishmaniasis. This is characterized as an important zoonosis, commonly transmitted by the bite of Lutzomyia longipalpis female sand fly, infected by species of Leishmania spp. belonging to the donovani complex. Although the dog is the main reservoir of this parasitosis, several mammals can become infected, and the bush $\operatorname{dog}$ (Cerdocyon thous Linnaeus, 1766) is indicated as a natural reservoir and an important source of VL infection. Given the relevance of the issue for public health, this

Keywords:

Zoonosis

Foxes

Leishmania study seeks, through a literature survey, to review important aspects of this disease and assess the importance of the participation of $C$. thous in maintaining and expanding the cycle of visceral leishmaniasis in order to contribute to its confrontation. 


\section{INTRODUÇÃO}

As atividades agropecuárias têm sido uma das principais causas do desmatamento e destruição do habitat de diversos animais silvestres ao longo dos anos. Consequentemente, na busca por novos habitats, esses animais acabam adentrando o ambiente urbano (PATZ et al.,2000; CURI et al., 2006; BARBOSA et al, 2011).

Uma espécie que ilustra bem esse cenário é o cachorro-do-mato (C. thous Linnaeus, 1766) que, pelo hábito alimentar generalista e intensa fragmentação de seu habitat, transita entre zonas urbanas (COELHO et al., 2008; ROCHA et al., 2008; SANTOS, 2013). Assim, possibilitando o desenvolvimento de doenças comuns aos animais domésticos e de importância para a saúde pública, como a leishmaniose visceral (LV), devido suas altas taxas de incidência, letalidade e mortalidade (CATENACCI et al.; JORGE et al., 2010; CUBAS et al., 2014; WHO, 2020).

A contribuição do $C$. thous para a epidemiologia da LV não está totalmente esclarecida. Estudos atribuem a essa espécie, o papel de manter o ciclo no ambiente silvestre, sugerindo sua atuação como sentinela da doença (PEAKALL \& BOYD, 1987; COURTENAY et al., 2001; SOUZA et al., 2010).

Desta forma, considerando a importância dessa zoonose para a manutenção da saúde coletiva, o objetivo deste estudo é realizar um levantamento bibliográfico a respeito da Leishmaniose Visceral em $C$. thous, por sua relação sinantrópica e ampla distribuição em território brasileiro.

\section{REFERENCIAL TEÓRICO}

\subsection{Etiologia e epidemiologia}

A LV é causada por protozoários do gênero Leishmania presentes no Complexo donovani, sendo a espécie L. chagasi a mais relatada no Brasil (BOSSLER, 2012; BEDOR, 2013; CUBAS et al., 2014).

Alterações ambientais, o êxodo rural e a adaptação do vetor ao meio urbano contribuíram para que a LV se expandisse da área rural para as urbanas, conferindo a ela caráter reemergente (LAURENTI, 2010; BOSSLER, 2012; GONTIJO \& MELO, 2014; SILVA et al.,2017; TRIGO, 2018). Ademais, condições de desnutrição, restrição de recursos, 
habitações precárias e sistema imunológico debilitados são considerados fatores de risco a essa doença (RODRIGUES, 2013; OPAS/OMS, 2019; SANTOS et al., 2020).

Estima-se uma média de 30.000 novos casos de LV e 20.000 mortes por ano, no mundo (SANTOS, 2019; WHO, 2020). Dos 76 países endêmicos a esta doença, o Brasil se destaca com 96\% dos casos ocorridos no continente americano entre os anos de 2001 e 2017 , com maior incidência registrada na região Nordeste (AZEVEDO et al., 2019; OPAS/OMS, 2019; SANTOS et al., 2020).

\subsection{Vetores e reservatórios}

Os principais vetores da LV são fêmeas de flebotomíneos do gênero Lutromyia, sendo o Lu. Longipalpis, o principal vetor da doença. No entanto, Lu. cruð̨, Migonemyia migonei - usual vetor da L. braziliensis -, além de pulgas e carrapatos já foram descritos como potenciais vetores (CERQUEIRA et al., 2000; TEICHMANN et al., 2011; SANTOS, 2019).

No ambiente urbano, o principal reservatório é o cão doméstico (Canis familiaris), sendo fundamental para a transmissão em humanos e, ocupando, de tal forma, importante papel na epidemiologia da LV (MORENO \& ALVAR, 2002; DANTAS-TORRES, 2007; ALVAR et al., 2012).

No ambiente silvestre, marsupiais e raposas são indicados como responsáveis pela manutenção do ciclo do parasito (GONTIJO \& MELO, 2004). Estudos apontam o C. thous (Figura 1) como importante reservatório e fonte de infecção por LV para humanos (SILVEIRA et al., 1982; COURTENAY et al., 1994; COURTENAY et al., 2001; COURTENAY et al., 2002; JORGE et al., 2010). 
Figura 1 - Exemplar de Cerdocyon thous.

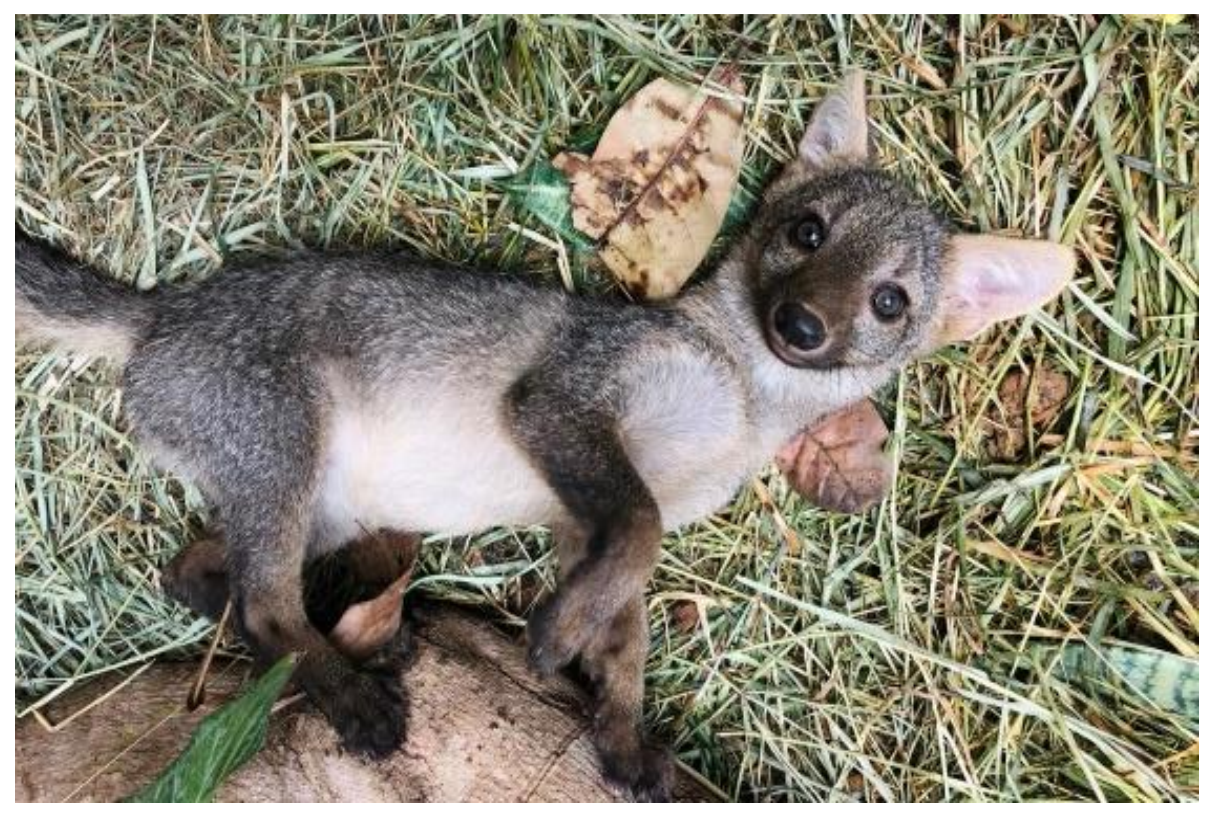

Fonte: Autores, 2021.

\subsection{Transmissão e ciclo biológico}

A transmissão vetorial é a forma mais comum de transmissão da LV no Brasil, porém, na literatura há relatos de transmissão venérea e vertical da doença (LUTZ e NEIVA, 1912; MANGABEIRA, 1938; CERQUEIRA et al., 2000; TEICHMANN et al., 2011).

Quanto ao ciclo biológico de Leishmania spp., há duas as formas infectantes: a promastigota metacíclicas e a amastigota. A primeira se aloja na probóscide do flebotomíneo e infecta o hospedeiro vertebrado durante o repasto sanguíneo. A partir desse momento, deslocam-se para os órgãos linfoides secundários, de forma a infectar células do sistema fagocítico mononuclear (SFM), como monócitos, histiócitos e macrófagos (REY, 2001).

Após o período de incubação - um mês a sete anos -, formas amastigotas começam a se desenvolver e se multiplicam por fissão binária até o rompimento da célula hospedeira e disseminação hematogênica e linfática, atraindo outros macrófagos através de uma reação inflamatória (SANTA-ROSA \& OLIVEIRA, 1997; COUTO et al., 1998; REY, 2001).

Ao se alimentar de um hospedeiro infectado, o vetor adquire a forma amastigota do protozoário, a qual é liberada em seu trato digestivo. Nele, diferencia-se em promastigota procíclica, multiplicando-se por divisão binária e diferenciando-se em formas metacíclicas, 
que migram para a probóscide do flebótomo, reiniciando o ciclo ao se alimentar de um novo hospedeiro (Figura 2) (SILVA, 2008).

Figura 2 - Representação do ciclo biológico da Leishmania spp. na transmissão da Leishmaniose Visceral.

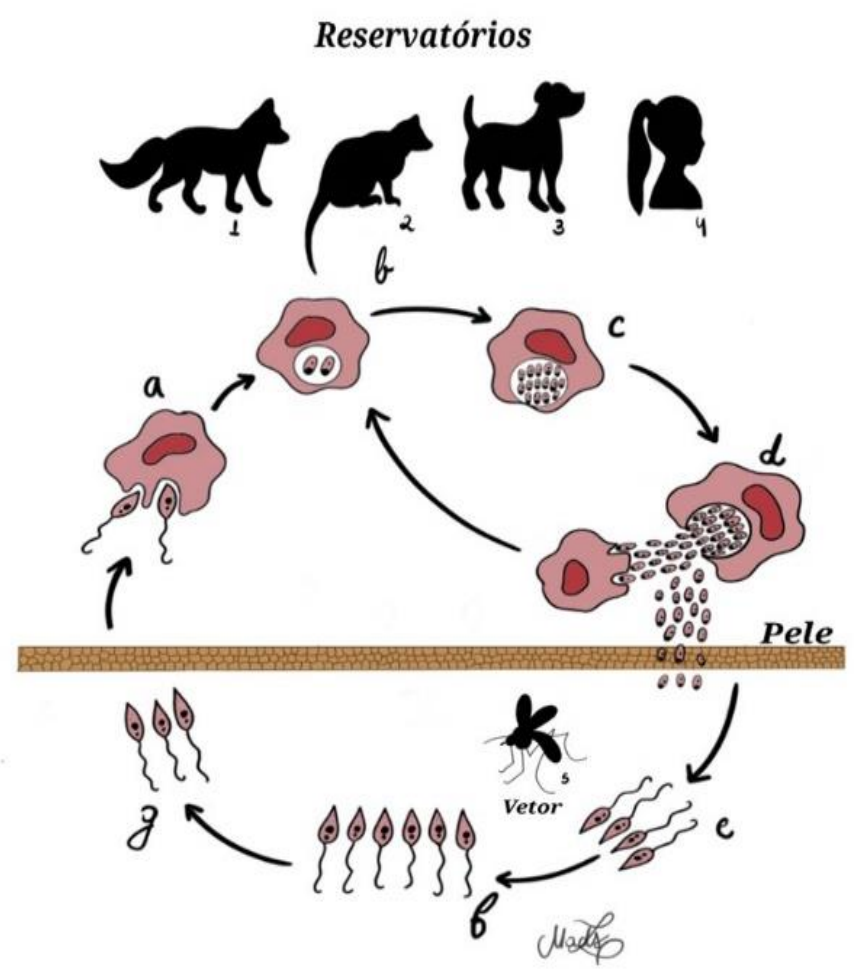

Fonte: Autores, 2021.

\subsection{Sinais clínicos}

O cachorro-do-mato, por vezes, apresenta-se como assintomático. (LUPPI et al., 2008; TUNON et al., 2015). Todavia, existem relatos de manifestações clínicas e quando presentes assemelham aos de cães domésticos, podendo desenvolver sintomas graves da doença e até mesmo vir a óbito, evidenciando o caráter inespecífico da doença (Tabela 1, Figura 2) (LUPPI et al., 2008; FORNAZARI \& LANGONI, 2014; ROQUE \& JANSEN, 2014). 
Tabela 1 - Sinais Clínicos encontrados em animais silvestres acometidos pela Leishmaniose Visceral, bem como os métodos diagnósticos utilizados

\begin{tabular}{|c|c|c|}
\hline Espécies & Sinais Clínicos & Referências \\
\hline $\begin{array}{l}\text { Speothos venaticus } \\
\text { (Cachorro-Vinagre) }\end{array}$ & $\begin{array}{l}\text { Anemia, vômito, diarreia, falência renal, } \\
\text { hemorragia, dermatite, alopecia, caquexia, } \\
\text { onicogrifose, óbito com sinais típicos da } \\
\text { doença }\end{array}$ & $\begin{array}{l}\text { Luppi et al. (2008); } \\
\text { Lima et al. (2009); Jusi } \\
\text { et al. (2011). }\end{array}$ \\
\hline $\begin{array}{l}\text { Cerdocyon thous } \\
\text { (Cachorro-do-mato) }\end{array}$ & $\begin{array}{l}\text { Onicogrifose, mucosas hipocoradas, } \\
\text { emagrecimento progressivo, alopecia, uveíte, } \\
\text { conjuntivite, escamação furfu-rácea, } \\
\text { hepatoesplenomegalia, dermatite seborreica, } \\
\text { lesões em boca, lábio e patas, óbito. }\end{array}$ & $\begin{array}{l}\text { Souza et al. (2010); Jusi } \\
\text { et al. (2011); Tenório et } \\
\text { al., 2011; Lima et al., } \\
\text { (2018). }\end{array}$ \\
\hline $\begin{array}{l}\text { Canis lupus } \\
\text { (Lobo-cinzento) }\end{array}$ & Sinais típicos, principalmente cutâneos. & Beck et al. (2008). \\
\hline $\begin{array}{l}\text { Lycalopex vetulus } \\
\text { (Raposa-do-campo) }\end{array}$ & Lesões cutâneas. & Luppi et al. (2008). \\
\hline $\begin{array}{l}\text { Chrysocyon brachyurus } \\
\text { (Lobo-Guará) }\end{array}$ & $\begin{array}{l}\text { Sinais típicos, incluindo onicogrifose e lesões } \\
\text { cutâneas. }\end{array}$ & $\begin{array}{l}\text { Luppi et al. (2008); Jusi } \\
\text { et al. (2011). }\end{array}$ \\
\hline
\end{tabular}

Fonte: Dados da pesquisa, 2021.

Figura 2 - Sinais clínicos apresentados por C. thous, dentre eles: conjuntivite (A), lesão em ponta de orelha (B) e onicogrifose (C).
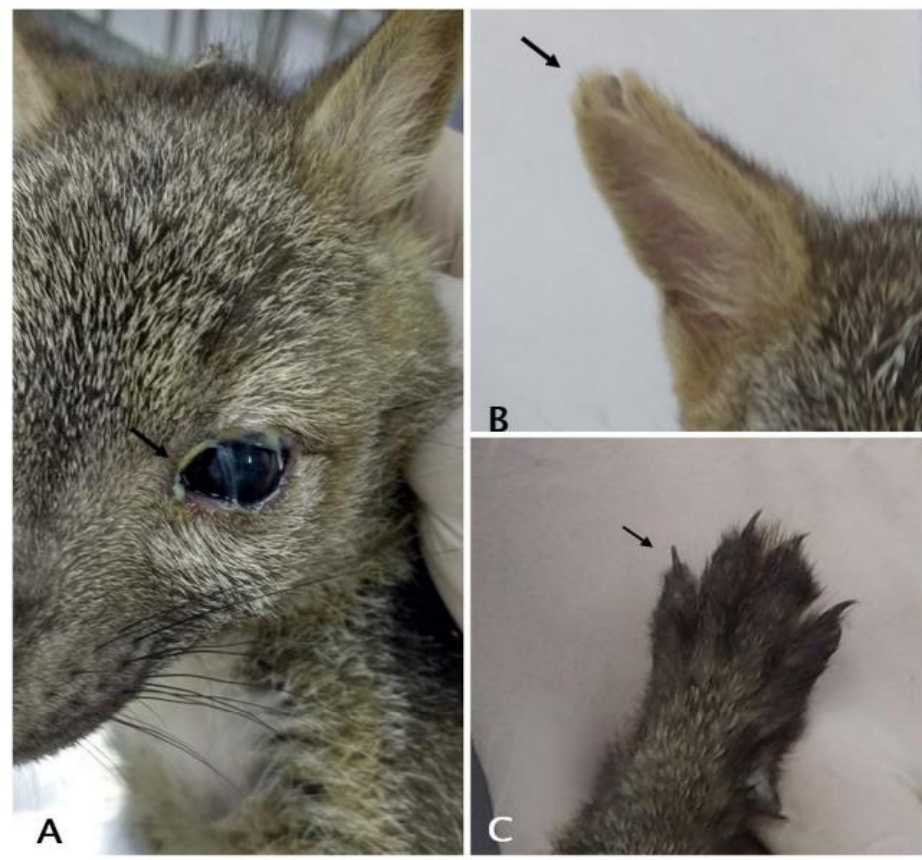

Fonte: Lima et al., 2021. 


\subsection{Diagnóstico, Tratamento e Controle}

Para o diagnóstico de qualquer doença o estado clínico do paciente deve ser priorizado. Animais silvestres em cativeiro mesmo quando assintomáticos, devem receber maior atenção, visto que suas condições podem levar ao estresse e consequentemente, a imunossupressão (CUBAS et al., 2014). No entanto, a inespecificidade e presença de reservatórios assintomáticos para LV, faz a clínica perder sua soberania, dando lugar a diagnósticos laboratoriais.

Dentre os métodos diagnósticos laboratoriais disponíveis, estão o parasitológico, consistindo na visualização direta de formas amastigotas do parasito; o sorológico, que baseia-se em técnicas de detecção do antígeno (direto) ou de anticorpos anti-Leishmania (indiretos), como ensaio de imunoabsorção enzimático indireto (ELISA); o imunológico molecular, que consiste na técnica de Reação em Cadeia da Polimerase (PCR), onde a identificação do agente consiste na amplificação de seu DNA através de algumas reações (IKEDA-GARCIA \& MARCONDES, 2007; CUBAS et al., 2014). Outro método é o xenodiagnóstico, que consiste na identificação do patógeno através do uso de vetores e na avaliação da capacidade de infectividade do hospedeiro a ele (CUBAS et al., 2014).

Não há normativa que regulamente o tratamento nesses animais, ficando a critério do médico veterinário o devido tratamento (CUBAS et al., 2014). No entanto, drogas como marbofloxacina, alopurinol e miltefosina já foram utilizadas nestes animais com resultados promissores (LIBERT et al., 2012).

Em animais silvestres mantidos em cativeiro, são indicadas a aplicação de telas adequada nos recintos, administração de repelentes nos animais acometidos e o uso de coleiras impregnadas com deltametrina, para fins de controle e prevenção da doença (LIBERT et al., 2012; CUBAS et al., 2014).

Para os animais de vida livre, o controle e prevenção da LV tornam-se mais complexos, embora possam incluir algumas alternativas, como: 1) Estabelecimento de zonas tampões ao redor de áreas protegidas, cuja presença de animais domésticos seria proibida; 2) Intensificação das medidas de controle em animais domésticos; 3) Tratamento dos infectados; 4) Vacinação e 5) Redução Populacional dos Reservatórios. No entanto, grande parte depende da adesão da população ou não são viáveis em termos financeiros ou ecológicos (COURTENAY et al., 2002; CROSS et al., 2007; JORGE et al., 2010; FORNAZARI e LANGONI, 2014). 


\subsection{Papel do Cerdocyon thous na epidemiologia da LV}

O cachorro-do-mato é mencionado por numerosos autores como importante fonte de infecção para a LV, sendo considerado um risco para a saúde de animais domésticos e humanos (ASHFORD, 1996; JORGE et al., 2010).

Além de ter contato com o ambiente, facilitando a disseminação de patógenos entre eles e os humanos e animais domésticos, outros fatores a serem considerados incluem a alta prevalência de infecção confirmada apresentada pela espécie, bem como a alta carga parasitária encontrada na pele desses animais e a alta taxa de contato com cães infectados e com o principal vetor da doença, o Lu. longipalpis (COURTENAY et al., 2001; JORGE et al., 2010 (JUAREZ \& MARINHO-FILHO, 2002; FIGUEIREDO et al., 2008; SANTOS, 2013).

Em contrapartida, existem autores que acreditam que esta espécie não é relevante para o ciclo de manutenção e expansão da Leishmaniose Visceral, pois possui baixa capacidade de infectar os vetores - como verificado por Courtenay et al. (2002) em experimentos utilizando flebótomos Lu. Longipalpis em cachorros-do-mato infectados, nos quais nenhum dos insetos vieram a se infectar. Uma vez que a transmissão se dá através da picada do vetor infectado com a Leishmania spp., se o reservatório não possuir essa capacidade de infectividade, o ciclo não se completará.

Apesar da contradição na literatura acerca do real papel desses animais no ciclo de transmissão da LV, acredita-se que essa parasitose é importante para a população de canídeos selvagens, em especial, para populações em declínio ou em risco de extinção (CUBAS et al., 2014). Dessa forma, estudos mais detalhados a respeito do potencial infectante desses hospedeiros aos vetores são extremamente relevantes, contribuindo, significativamente, para o desenvolvimento de medidas eficazes de controle a doença (JORGE et al., 2010).

\section{CONSIDERAÇÕES FINAIS}

Canídeos selvagens, em especial o Cerdocyon thous, indicados por numerosos autores como reservatórios primários ou naturais da Leishmaniose Visceral, ao que tudo indica, estão apresentando, com maior frequência e maior severidade, sinais clínicos desta zoonose. Em contrapartida, embora seja associado como importante fonte de infecção da LV, existem estudos que determinaram uma baixa capacidade dessa espécie em infectar o vetor.

Logo, o real papel desses animais na manutenção e expansão do ciclo da doença não estão bem esclarecidos, possivelmente sendo apenas mais uma das vítimas da ação antrópica. Assim, pensando no conceito de conservação das espécies, é imprescindível o 
desenvolvimento de mais estudos que avaliem o risco apresentado e sofrido por esses animais. Além disso, compreender o papel dessa espécie como reservatório é gerar conhecimento para o desenvolvimento de medidas efetivas de controle a doença, garantindo uma grande conquista em prol da saúde coletiva.

\section{REFERÊNCIAS}

ALVAR, J. et al., and WHO Leishmaniasis Control Team, 2012. Leishmaniasis worldwide and global estimates of its incidence. PLoS One, v. 7, n. 5, 2012.

ASHFORD, R. W. Leishmaniasis reservoir and their significance in control. Clinics in Dermatology, v. 14, p. 523-32, 1996.

AZEVEDO, T.S.; LORENZ, C.; CHIARAVALLOTI-NETO, F. Risk mapping of visceral leishmaniasis in Brazil. Rev. Soc. Bras. Med. Trop., Uberaba, v. 52, e20190240, 2019.

BARBOSA, A. D.; MARTINS, N. R. S.; MAGALHÃES, D. F. Zoonoses e Saúde Pública: Riscos da proximidade humana com a fauna silvestre. Ciênc. vet. tróp., Recife-PE, v. 14, n. 1/2/3, p. 1 - 9, 2011.

BEDOR, C.N.G. Sequenciamento e caracterização de genes identificados como codificantes para proteínas antigênicas de Leishmania chagasi. 2003. Dissertação (Mestrado em Genética) - Universidade Federal de Pernambuco, Recife, 2003.

BOSSLER, R.S. Diversidade de helmintos intestinais. Dissertação (Bacharelado) Medicina Veterinária - Faculdade Veterinária do Rio Grande do Sul, Porto Alegre, 2012.

CERQUEIRA, E. J. L. et al. Considerações sobre pulgas (Siphonaptera) da raposa Cerdocyon thous (Canidae) da área endêmica de leishmaniose visceral de Jacobina, Bahia, Brasil. Revista da Sociedade Brasileira de Medicina Tropical, Uberaba, v. 33, n. 1, p. 91-93, 2000.

COELHO, I.P.; KINDEL, A.; COELHO, A.V.P. Roadkills of vertebrate species on two highways through the Atlantic Forest Biosphere Reserve, southern Brazil. European of Journal Wildlife Research, n. 54, p. 689-699, 2008.

COURTENAY, O. et al. Epidemiology of canine leishmaniasis: a comparative serological study of dogs and foxes in Amazon Brazil. Parasitology, v. 109, p. 273-279, 1994.

COURTENAY, O.; QUINNELL, R.J.; CHALMERS, W.S.K. Contact rates between wild and domestic canids: no evidence of parvovirus or canine distemper virus in crabeating foxes. Veterinary microbiology, v. 81, p. 9-19, 2001. 
COURTENAY, O.; QUINNELL, R. J. et al. Low infectiousness of a wildlife host of Leishmania infantum: the crabeating fox is not important for transmission. Parasitology, v. 125, p. 407-414, 2002.

COUTO, C. G. et al. Doenças protozoárias polissistêmicas: medicina interna de pequenos animais. 2 ed. Rio de Janeiro: Guanabara Koogan, p. 1031-1040, 1998.

CROSS, M.L.; BUDDLE, B.M. \& ALDWELL, F.E. The potential of oral vaccines for disease control in wildlife species. The Veterinary Journal, v.174, p. 472-480, 2007.

CUBAS, Z. S.; SILVA, J. C. R.; CATÃO-DIAS, J. L. Tratado de animais selvagens: Medicina Veterinária. 2. ed. São Paulo: Editora GEN/Roca, 2014.

CURI, N.H.A.; MIRANDA, I.; TALAMONI, S.A. Serologic evidence of Leishmania infection in free-ranging wild and domestic canids around a Brazilian National Park. Mem Inst Oswaldo Cruz; v. 101, p. 99-101, 2006.

DANTAS-TORRES F. The role of dogs as reservoirs of Leishmania parasites with emphasis on Leishmania (Leishmania) infantum and Leishmania (Viannia) braziliensis. Vet Parasitol; v.149, p. 139-146, 2007.

FIGUEIREDO, F. B.; GREMIÃO, I. D. F.; PEREIRA, S. A. et al. First report of natural infection of a bush dog (Speothos venaticus) with Leishmania (Leishmania) chagasi in Brasil. Transactions of the Royal Society of Tropical Medicine and Hygiene, v. 102, n. 2, p. 200-201, 2008.

FORNAZARI, F.; LANGONI, H. Principais zoonoses em mamíferos selvagens. Vet. e Zootec, v. 21, n. 1, p. 10-24, 2014.

GONTIJO, C.M.F.; MELO, M.N. Leishmaniose visceral no Brasil: quadro atual, desafios e perspectivas. Rev Bras Epidemiol. v. 7, p. 338-349, 2004.

IKEDAGARCIA, F. A.; MARCONDES, M. Métodos de diagnóstico da leishmaniose visceral canina. Clínica Veterinária, n. 71, p. 3442, 2007.

JORGE, R. S. P.; ROCHA, F. L.; JÚNIOR, J. A. M.; et al. Ocorrência de patógenos em carnívoros selvagens brasileiros e suas implicações para a conservação e saúde pública. Oecologia Australis, v. 14, n. 3, p. 686-710, 2010.

JUAREZ, K.M. \& MARINHO-FILHO, J. Diet, habitat use, and home ranges of sympatric canids in Central Brazil. Journal of Mammalogy, v. 83, p. 925-933, 2002.

JUSI, M.M.G. et al. Molecular and serological detection of Leishmania spp. in captive wild animals from Ilha Solteira, SP, Brazil. Rev. Bras. Parasitol. Vet, v.20, n.3, p.219-222, 2011.

LAURENTI, M. D. Patologia e patogenia das leishmanioses. Tese (Professor LivreDocente) - Faculdade de Medicina Veterinária e Zootecnia da Universidade de São Paulo, São Paulo, p. 84, 2010. 
LIBERT, C. et al. Leishmania infantum infection in two captive barbary lions (Panthera leo leo). J. Zoo. Wildl. Med, v. 43, p. 685-688, 2012.

LIMA, E.S.; JORGE, R.S.P.; DALPONTE, J.C. Habitat use and diet of bush dogs, Speothos venaticus, in the Northern Pantanal, Mato Grosso, Brazil. Mammalia, v. 73, p. 13-19, 2009.

LIMA, V.F.S. Agentes parasitários em animais silvestres, sinantrópicos e domésticos: aspectos clínicos epidemiológicos e de saúde pública. Tese (Doutorado) -Programa de Pós-Graduação em Ciência Animal Tropical- Universidade Federal Rural de Pernambuco, Recife, 2018.

LIMA, V. F. S. et al. Zoonotic parasites in wild animals such as carnivores and primates that are traded illegally in Brazil. Brazilian Journal of Veterinary Medicine, v. 43, n. 1, 2021.

LUPPI, M.M. et al. Visceral leishmaniasis in captive wild canids in Brazil. Veterinary Parasitology, v. 155, p. 146-151, 2008.

LUTZ, A.; NEIVA, A. Contribuição para o conhecimento das espécies do gênero Phlebotomus existentes no Brasil. Mem Inst Oswaldo Cruz, v. 4, p. 84-95, 1912.

MANGABEIRA, O. Sobre duas novas especies de Flebotomus (Diptera: Psychodidae). Memórias do Instituto Oswaldo Cruz, v. 3, p. 349-56, 1938.

MORENO, J.; ALVAR, J. Canine leishmaniasis: epidemiological risk and the experimental model. Trends in Parasitol. v. 18, p. 399-405, 2002.

OPAS - Organização Pan-Americana da Saúde. Leishmanioses. Informe Epidemiológico das Américas, dezembro 2019. Disponível em http: https://iris.paho.org/handle/10665.2/51738. Acessado em 15/08/2020.

PATZ, J.A. et al. Effects of environmental change on emerging parasitic diseases. International Journal of Parasitology, n. 30, p. 1395-1405, 2000.

PEAKALL, D.B.; BOYD, H. Birds as bio-indicators of environmental conditions. In: The Value of Birds (Diamond, A.W., Filion, F.L. eds.), Cambridge, p. 113-119, 1987.

REY, L. O complexo “Leishmania donovani” e a Leishamaníase Visceral. In.: Parasitologia. parasitos e doenças parasitárias do homem nas Américas e na África. 3. ed. Rio de Janeiro: Guanabara Koogan, 2001.

ROCHA, V.J. et al. Feeding habits of the crab-eating fox, Cerdocyon thous (Carnivora: Canidae), in a mosaic area with native and exotic vegetation in Southern Brazil. Revista Brasileira de Zoologia, v. 25, p. 594-600, 2008.

RODRIGUES, A.P.D. Efeito in vitro e in vivo do 5-hidroxi-2-hidroximetil-gma-pirona durante a infecção por Leishmania (Leishmania) amazonensis. Tese (Doutorado) - 
Pós Graduação em Neurociências e Biologia Celular - Universidade Federal do Pará, BelémPará, 2013.

ROQUE, A. L. R.; JANSEN, A. M. Wild and synanthropic reservoirs of Leishmania species in the Americas. International Journal for Parasitology: Parasites and Wildlife, v. 3, n. 3, p. 251-262, 2014.

SANTA-ROSA, I. C. A; OLIVEIRA, I. C. S. Leishmaniose Visceral: uma zoonose reemergente. Clínica Veterinária-Saúde Pública, São Paulo, v. 2, n. 11, p. 24-28, 1997.

SANTOS, E.F.M. Bionomia de Migonemyia migonei (Diptera, Psychodidae, Phlebotominae) em condições experimentais. Dissertação (Mestrado) - Biologia da Interação Patógeno-Hospedeiro) - Instituto Leônidas e Maria Deane, 2019.

SANTOS, E.W et al. Abordagem da leishmaniose visceral canina (lvc) por médicos veterinários. (Preprint - Version 1). Scielo, Biological Sciences, 2020. Disponível em: < https://doi.org/10.1590/SciELOPreprints.1463 >; Acesso em 08 dez. 2020.

SANTOS, J.D.O. Diversidade de helmintos intestinais em cães domésticos (Canis familiaris Linnaeus, 1758) e de raposas (Cerdocyon thous Linnaeus, 1766) no semiárido do Nordeste do Brasil e implicações para a saúde. Dissertação (Mestrado em Saúde Pública) - Fundação Oswaldo Cruz, 201p. 2013.

SANTOS, S.O. et al. Incrimination of Lutzomyia cruzi as a vector of American Visceral Leishmaniasis. Med Vet Entomol; v. 12, p. 315-317, 1998.

SILVA, D.G. Padronização do cultivo de amastigotas axênicos e intracelulares de Leishmania spp. e análise da atividade leishmanicida de chalconas.2008.120 f. Dissertação (Mestrado em Biotecnologia) - Universidade de Santa Catarina, UFSC, Florianópolis, 2008.

SILVA, S.T.P. et al. Leishmaniose visceral humana: reflexões éticas e jurídicas acerca do controle do reservatório canino no Brasil. Rev Bio y Der, v. 39, p. 135-151; 2017.

SILVEIRA, F.T.; LAINSON, R., SHAW, J.J. \& POVOA, M.M. Leishmaniasis in Brazil: XVIII. Further evidence incriminating the fox Cerdocyon thous as a reservoir of Amazonian visceral leishmaniasis. Transactions of the Royal Society of Tropical Medicine and Hygiene, v. 76, p. 830-832, 1982.

SOUZA, N.P. et al. Leishmania (Leishmania) infantum chagasi em canídeos silvestres mantidos em cativeiro, no Estado de Mato Grosso. Revista da Sociedade Brasileira de Medicina Tropical, v. 43, n. 3, p. 333-335, 2010.

TEICHMANN, C.E. et al. Evidence of venereal and transplacental transmission of Canine Visceral Leishmaniasis in southern Brazil. Acta Scientiae Veterinariae, Porto Alegre, v. 39, n. 4, p. 1-4, 2011.

TENÓRIO, M.S. Avaliação visceral da técnica sorológica para Leishmaniose visceral e doença de Chagas em animais silvestres e identificação molecular. Tese (doutorado) - Universidade Estadual Paulista Júlio de Mesquita Filho, Faculdade de Medicina de Botucatu, 91 f., 2015. 
TRIGO, B.B. Diferenciação molecular de subgênero, complexo e espécies de Leishmania. Dissertação (Mestrado) - Ciência Animal - Unesp, Campus de Araçatuba, Araçatuba, 2018.

TUNON, G.I.L. et al. In vitro Infection by Leishmania infantum in the peripheral bloodmononuclear cell-derived macrophages from crab-eating foxes (Cerdocyonthous). Veterinary Parasitology v. 212, n. 3, 2015.

WHO - WORLD HEALTH ORGANIZATION. Leishmaniasis. 2020. Disponível em: <https://www.who.int/health-topics/leishmaniasis\#tab=tab_1>; Acesso em 09 dez. 2020. 


\section{Capítulo 6}

\section{ANIMAIS SILVESTRES E PETS NÃO CONVENCIONAIS ATENDIDOS NO HOSPITAL VETERINÁRIO UNIVERSITÁRIO PROFESSOR IVON MACÊDO TABOSA DA UFCG EM 2018 E 2019}

Joyce Galvão de Souza

Universidade Federal do Rio Grande do Norte (UFRN), Natal - RN

ORCID: https://orcid.org/0000-0001-5492-6317

Lattes: http://lattes.cnpq.br/2721275127997056

Gabriel Vinícius Carvalho de Lucena

Universidade Federal de Campina Grande (UFCG), Patos - PB

Lattes: http://lattes.cnpq.br/2795820000194401

\section{Aksa Ingrid Vieira Batista}

Universidade Federal Rural do Semi-Árido (UFERSA), Mossoró - RN

Lattes: http://lattes.cnpq.br/6614624885083003

\section{Artur da Nóbrega Carreiro}

Universidade Federal de Campina Grande (UFCG), Patos - PB

Lattes: http://lattes.cnpq.br/7750885373832284

\section{Luan Nascimento Batista}

Médico Veterinário Anestesista Volante, Recife - PE

Lattes: http://lattes.cnpq.br/3431992433963298

\section{Moana Barbosa dos Santos Figuerêdo}

Médica Veterinária na Clínica Vita 24h, Recife - PE

Lattes: http://lattes.cnpq.br/8807162730434058

\section{Brunna Muniz Rodrigues Falcão}

Universidade Federal de Campina Grande (UFCG), Patos - PB

Lattes: http://lattes.cnpq.br/8069283312084930

\section{Jhonatan Henrique Lima da Rocha}

Universidade Federal do Acre (UFAC), Rio Branco - AC

Lattes: http://lattes.cnpq.br/6281828730485974

\section{Andrea Moura de Camargo}

Universidade Estadual de Londrina (UEL), Londrina - PR

Lattes: http://lattes.cnpq.br/1882470339559969

\section{Amanda Moraes Silva}

Universidade Federal de Mato Grosso do Sul (UFMT), Campo Grande - MS Lattes: http://lattes.cnpq.br/1401528992814617

\section{Gilmara Miguel Souza}

Universidade Estadual Paulista (UNESP), Araçatuba - SP

Lattes: http://lattes.cnpq.br/7181429399410680

\section{Danilo José Ayres de Menezes}

Universidade Federal do Rio Grande do Norte (UFRN), Natal - RN

Lattes: http://lattes.cnpq.br/4003577127443065 


\begin{tabular}{|c|c|}
\hline $\begin{array}{l}\text { Informações sobre o } \\
\text { artigo: } \\
\text { Recebido em: } \\
\text { 30/08/2021 } \\
\text { Aceito em: } \\
\text { 02/09/2021 } \\
\text { Data de publicação: } \\
\text { 19/10/2021 } \\
\text { Palavras-chave: } \\
\text { Aves } \\
\text { Clínica } \\
\text { Mamíferos } \\
\text { Répteis }\end{array}$ & $\begin{array}{l}\text { RESUMO } \\
\text { A criação de pets não convencionais já existe há muito tempo e vem } \\
\text { crescendo cada vez mais, aumentando também a busca em clínicas } \\
\text { veterinárias por atendimento para estes animais, que inclui } \\
\text { principalmente aves, mamíferos e répteis. Este trabalho objetivou } \\
\text { relatar os atendimentos ocorridos no Hospital Veterinário } \\
\text { Universitário Professor Ivon Macêdo Tabosa da Universidade } \\
\text { Federal de Campina Grande, Patos, Paraíba, à animais silvestres e } \\
\text { pets não convencionais nos anos de } 2018 \text { e } 2019 \text {. De um total de } \\
185 \text { atendimentos, excluindo-se os retornos, } 98 \text { ( } 52,97 \%) \\
\text { atendimentos foram de aves, } 82(44,32 \%) \text { foram de mamíferos e } 5 \\
(2,7 \%) \text { de répteis. O levantamento mostrou que os animais } \\
\text { atendidos eram pets, oriundos de resgates pela polícia ambiental, } \\
\text { animais a serem utilizados em projetos da própria instituição ou } \\
\text { animais feridos encontrados por terceiros. A predominância de } \\
\text { atendimentos foi à animais pets, sendo os mais frequentes as } \\
\text { calopsitas e os hamsters. }\end{array}$ \\
\hline $\begin{array}{l}\text { Keywords: } \\
\text { Birds } \\
\text { Clinic } \\
\text { Mammals } \\
\text { Reptiles }\end{array}$ & $\begin{array}{l}\text { WILD ANIMALS AND NON-CONVENTIONAL PETS SERVED AT } \\
\text { THE UNIVERSITY VETERINARY HOSPITAL PROFESSOR IVON } \\
\text { MACEDD TABOSA DA UFCG IN } 2018 \text { AND } 2019 \\
\text { ABSTRACT } \\
\text { The creation of unconventional pets has been around for a long } \\
\text { time and has been growing more and more, also increasing the } \\
\text { search in veterinary clinics for care for these animals, which mainly } \\
\text { includes birds, mammals and reptiles. This study aimed to report } \\
\text { the consultations that took place at the Professor Ivon Macêdo } \\
\text { Tabosa University Veterinary Hospital of the Federal University of } \\
\text { Campina Grande, Patos, Paraíba, to wild animals and non- } \\
\text { conventional pets in } 2018 \text { and } 2019 \text {. From a total of } 185 \\
\text { consultations, excluding returns, } 98 \text { ( } 52,97 \%) \text { visits were from } \\
\text { birds, } 82 \text { (44,32\%) were from mammals and } 5(2,7 \%) \text { from reptiles. } \\
\text { The survey showed that the animals cared for were pets, from } \\
\text { rescues by the environmental police, animals to be used in the } \\
\text { institution's own projects or injured animals found by third parties. } \\
\text { The predominance of assistance was for pets, with cockatiels and } \\
\text { hamsters being the most frequent. }\end{array}$ \\
\hline
\end{tabular}




\section{INTRODUÇÃO}

O mercado de pets não convencionais vem crescendo e com ele aumenta a exigência de profissionais capacitados para atendê-los, o que demonstra a necessidade de avanços no que diz respeito aos conhecimentos sobre esses animais nas mais diversas áreas da medicina veterinária. As aves estão entre os animais mais criados como pets e, dentre essas, as pertencentes ao grupo dos Psittaciformes (GRESPAN; RASO, 2014) e dos Passeriformes (SANCHES; GODOY, 2014) são as mais frequentes nas clínicas especializadas. Além desses, algumas aves menos usuais também têm sido criadas como animais de companhia, alguns até então tidos como animais de produção, a exemplo de Galliformes (BATISTA, et al., 2019).

Os pequenos roedores exóticos, assim como outras muitas espécies diferentes das convencionais, também vêm sendo escolhidos como animais de companhia por apresentarem características interessantes, como pequeno porte, beleza e docilidade, sendo as espécies mais comuns os hamsters, os porquinhos-da-índia, chinchilas, ratos twister, camundongos e gerbilos (TEIXEIRA, 2014).

Este trabalho teve como objetivo fazer um levantamento dos atendimentos realizados à animais silvestres no Hospital Veterinário Universitário Professor Ivon Macêdo Tabosa da Universidade Federal de Campina Grande (UFCG), Patos, Paraíba (PB) e verificar a frequência de atendimentos de aves, mamíferos e répteis nos anos de 2018 e 2019.

\section{METODOLOGIA}

Realizou-se pesquisa através da consulta às fichas dos atendimentos clínicos a animais silvestres e exóticos ocorridos nos anos de 2018 e 2019 no Hospital Veterinário Universitário Professor Ivon Macêdo Tabosa da Universidade Federal de Campina Grande, localizado na cidade de Patos, Paraíba, afim de se conhecer o perfil dos pets não convencionais mais criados na região em que está localizado o hospital e dos animais silvestres resgatados.

Foram contabilizados todos os atendimentos, excluindo os retornos, porém no caso de um animal que veio para novo atendimento, com uma queixa diferente, foi contabilizado como novo atendimento. Todos os dados foram colocados em planilha eletrônica e em seguida transferidos para o programa estatístico SPSS (Statistical Page For Social Sciences) versão 23.0, para que fossem obtidos os valores de porcentagem. 


\section{RESULTADOS E DISCUSSÃO}

No ano de 2018 foram atendidos 62 casos e no ano de 2019 foram 123, totalizando 185 atendimentos. Destes, 98 (52,97\%) atendimentos foram de aves, 82 (44,32\%) de mamíferos e 5 (2,7\%) de répteis (Gráfico 1).

Gráfico 1 - Porcentagem dos Animais Silvestres e Exóticos atendidos no Hospital

Veterinário Universitário Professor Ivon Macêdo Tabosa em 2018 e 2019.

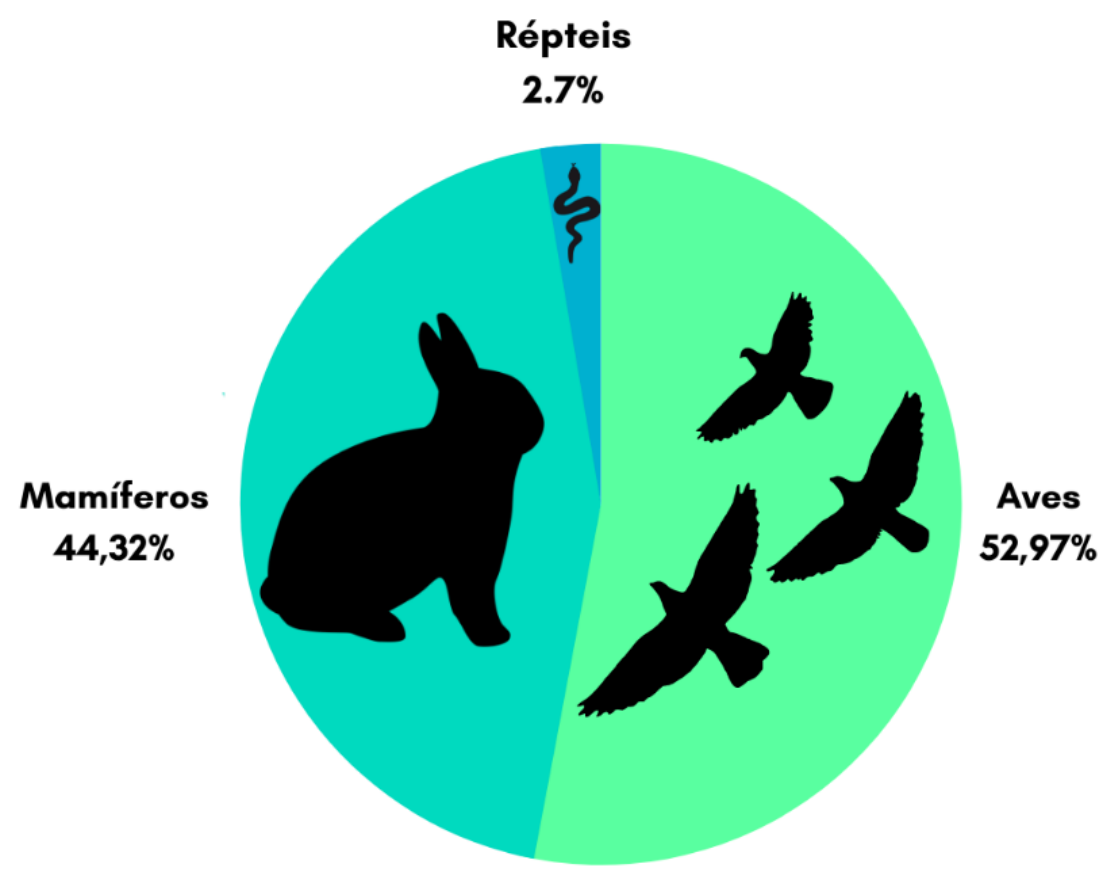

Fonte: Autores, 2021.

A busca por atendimento veterinário se deu por diferentes causas que incluíram: 1) Animais trazidos por seus tutores para consultas de rotina ou quando apresentavam algum processo patológico; 2) Animais resgatados trazidos pela Polícia Ambiental quando apresentavam alguma afecção; 3) Animais de vida livre acidentados que foram trazidos por pessoas que os encontraram e levaram para avaliação com a intenção de ajudá-los; 4) Animais que faziam parte de projetos de pesquisa dentro da instituição e precisavam passar por avaliação médica veterinária para atestar sua saúde. No caso de animais encontrados por pessoas que o trouxeram para atendimento, esses recebiam o primeiro atendimento e a Polícia Ambiental era acionada para que pudesse realizar a correta destinação dos animais. 
Entre os mamíferos atendidos, houveram representantes das ordens Rodentia, Lagomorpha, Primates, Didelphimorphia, Chiroptera e Carnivora. Sendo as espécies atendidas: hamsters (Mesocricetus auratus e Phodopus campbelli), coelho (Oryctolagus cuniculus), ratos (Rattus novergicus), porquinho-da-índia (Cavia porcellus), sagui-de-tufos-brancos (Callithrix jacchus), gambá-de-orelha-branca (Didelphis albiventris), gato-do-mato-pequeno (Leopardus tigrinus) e dois morcegos, que não tiveram a espécie identificada (Figura 1). O mais numeroso foi o grupo dos roedores com um total de 49 animais atendidos, que representou 59,7\% do total de mamíferos atendidos.

Figura 1 - Animais Silvestres e Exóticos atendidos no Hospital Veterinário Universitário Professor Ivon Macêdo Tabosa em 2018 e 2019. A - Corn Snake (Pantherophis guttatus); B Peru (Meleagris gallopavo); C - Sagui (Callithrix jacchus); D - Calopsita (Nymphicus hollandicus);

E - Galo-de-campina (Paroaria dominicana); F - Anão russo (Phodopus campbelli); G Periquito-da-caatinga (Eupsittula cactorum); H - Jabuti-piranga (Chelonoidis carbonaria).

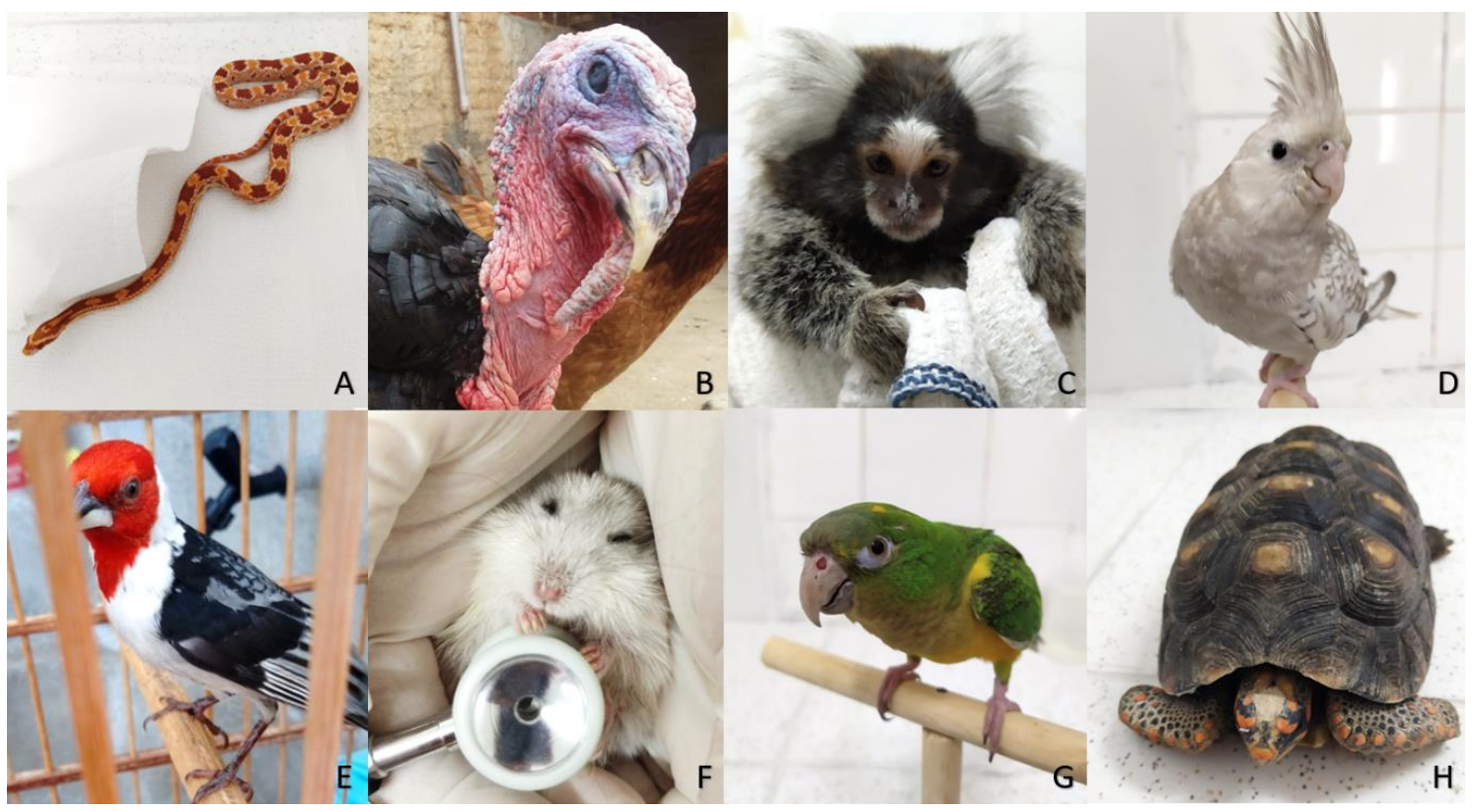

Fonte: Autores, 2021.

Os pequenos roedores têm se tornado pets muito populares, por apresentarem características como beleza, temperamento dócil e porte pequeno. Os mais comumente mantidos como pets são o Mus musculus, Rattus novergicus, Mesocricetus auratus, Meriones unguiculatus, Phodopus campbelli, Cavia porcelus e Chinchilla lanigera (TEIXEIRA, 2014). Deste grupo, foram registrados atendimentos de Mesocricetus auratus (Hamster Sírio), Phodopus campbelli (Hamster anão-russo), Rattus novergicus (Rato Twister) e Cavia porcellus (Porquinhoda-índia) (Figura 1). 
Entre os roedores atendidos, 43,8\% eram hamsters das espécies Mesocricetus auratus ou Phodopus campbelli. De acordo com Quesenberry e colaboradores (2021), este grupo de roedores não apresentam grande resistência às doenças recém-adquiridas ou causadas por estresse, que pode ser causado, por exemplo, por ambiente com temperatura elevada ou quando mantidos na mesma gaiola que outros da mesma espécie. Assim como citado, foram observados nos atendimentos casos relacionados à temperatura elevada e que estavam afetando a saúde dos animais, além de lesões causadas por brigas quando mantidos mais de um hamster na mesma gaiola.

O grupo de aves atendidas teve espécies pertencentes às ordens dos Psittaciformes, Galliformes, Passeriformes, Strigiformes, Anseriformes e Columbiformes. Sendo as espécies atendidas: Calopsitas (Nymphicus hollandicus), Periquito-da-caatinga (Eupsittula cactorum), Papagaio-verdadeiro (Amazona aestiva), Papagaio-do-mangue (Amazona amazonica), Periquitoaustraliano (Melopsittacus undulatus), Ring-neck (Psittacula krameri), Agapornis (Agapornis roseicollis), Galinha (Gallus gallus domesticus), Peru (Meleagris gallopavo), Galo-de-campina (Paroaria dominicana), Caboclinho-frade (Sporophila bouvreuil), Canário-do-reino (Serinus canaria), Azulão (Cyanocompsa brissonii), Tico-tico (Zonotrichia capensis), Ganso-doméstico (Anser domesticus), Burguesa (Streptopelia decaocto), Coruja suindara (Tyto furcata) e Coruja-buraqueira (Athene cunicularia) (Figura 1).

O grupo dos Psittaciformes, incluindo todas as espécies atendidas, representou $72,4 \%$ do total de aves atendidas entre 2018 e 2019. Uma justificativa para esse grande número de Psittaciformes é por serem conhecidos e admirados pela sua beleza, inteligência, temperamento social e a capacidade de mimetizar sons, o que faz com que muitas pessoas optem por integrantes desse grupo para se criar como animal de estimação/companhia, e que consequentemente os tornam comuns nas clínicas veterinárias (GRESPAN \& RASO, 2014).

Entre o grupo de aves, os atendimentos mais frequentes foram de calopsitas, 51 no total, o que representa $52 \%$ do total de consultas feitas com aves. As calopsitas (Nymphicus hollandicus) são aves da ordem Psittaciformes, de origem australiana, que estão entre as mais procuradas e indicadas para a criação em ambiente domiciliar devido à relativa facilidade de manutenção, temperamento que tende a ser dócil e de fácil aquisição em nosso país (SICK, 1997).

Os atendimentos à répteis representaram uma menor parcela, com apenas 5 animais, sendo 4 da ordem Testudines e 1 da ordem Squamata, subordem Serpentes, sendo 
eles Jabuti-piranga (Chelonoidis carbonaria) e Corn snake (Pantherophis guttatus), respectivamente (Figura 1).

De forma geral, notou-se que muitos tutores quando iam para a consulta, não tinham informações suficientes sobre o correto manejo alimentar e/ou ambiental dos animais que mantinham como pets e também não sabiam o quanto esse quesito é importante para a manutenção da saúde de suas aves, mamíferos ou répteis, sendo inclusive uma parcela dos casos atendidos relacionados à erros de manejo. A consulta com um médico veterinário de animais silvestres logo que se adquire um pet não convencional, ou mesmo antes de adquiri-lo, pode suprir o tutor com informações acerca da espécie em questão que incluem sua alimentação ideal, o ambiente em que o animal deve viver, incluindo o tipo de substrato necessário, o tipo de gaiola, o tamanho, se pode conviver com outros da mesma espécie, horários de maior atividade da espécie, necessidade ou não de castração, material ou plantas que podem ser tóxicos, expectativa de vida, entre outros tópicos. Essas informações unidas ao atendimento clínico preventivo, diminuem consideravelmente o risco de doenças causados por erro de manejo e de acidentes com os animais.

\section{CONCLUSÃO}

A obtenção de dados que demonstrem quais as espécies mais comuns na clínica de animais silvestres são de grande importância para que o médico veterinário possa estar preparado para realizar seu atendimento, e no caso da região de Patos, na Paraíba, houve uma prevalência maior de animais pets no atendimento clínico do período estudado, com destaque para Psittaciformes e roedores.

\section{REFERÊNCIAS}

BATISTA, L. N. et al. Tratamento de abscesso em região cervical de peru (Meleagris gallopavo LINNAEUS, 1758) - Relato de caso. In: V Semana Acadêmica de Medicina Veterinária, 2019, Patos. Anais... Patos: V SAMEV, 2019.

GRESPAN, A.; RASO, T.F. Pisittaciformes (araras, papagaios, periquitos, calopsitas e cacatuas). In: CUBAS, S.Z.; SILVA, R.C.J.; DIAS, C.L.J. Tratado de animais selvagens. Medicina veterinária. 2 ed. São Paulo: Rocca, 2014.

QUESENBERRY, K. E. et al. Ferrets, rabbits and rodents: Clinical Medicine and Surgery. 4 ed. St. Louis: Elsevier, 2021. 
SANCHES, T. C.; GODOY, S.N. Passeriformes (Canário, Sabiá, Pássaro-preto, Trincaferro). In: CUBAS, S.Z.; SILVA, R.C.J.; DIAS, C.L.J. Tratado de animais selvagens. Medicina veterinária. 2 ed. São Paulo: Rocca, 2014.

SICK, H. Ornitologia brasileira. Rio de Janeiro: Nova Fronteira, 2001.

TEIXEIRA, V. N. Rodentia - Roedores Exóticos (Rato, Camundongo, Hamster, Gerbilo, Porquinho-da-índia e Chinchila). In: CUBAS, S.Z.; SILVA, R.C.J.; DIAS, C.L.J. Tratado de animais selvagens. Medicina veterinária. 2 ed. São Paulo: Rocca, 2014. 


\title{
PROLAPSO DE CÓLON E ENFISEMA SUBCUTÂNEO DECORRENTE DE RUPTURA TRAQUEAL TRAUMÁTICA EM IGUANA-VERDE (Iguana iguana, Linnaeus, 1758)
}

\author{
Aksa Ingrid Vieira Batista \\ Universidade Federal Rural do Semi-Árido (UFERSA), Mossoró - RN \\ ORCID: https://orcid.org/0000-0003-0696-7194 \\ Lattes: http://lattes.cnpq.br/6614624885083003
}

Gabriel Vinícius Carvalho de Lucena

Universidade Federal de Campina Grande (UFCG), Patos - PB

ORCID: https://orcid.org/0000-0001-9789-6066

\section{Everaldo Henrique Souza do Vale}

Universidade Federal do Oeste da Bahia (UFOB), Barreiras - BA ORCID: https://orcid.org/0000-0002-8171-4245

\section{Audisio Alves da Costa Filho}

Centro Universitário de João Pessoa (UNIPÊ), João Pessoa - PB ORCID: https://orcid.org/0000-0003-4125-0359

\section{Victoria Felinto Franco}

Universidade Federal Rural de Pernambuco (UFRPE), Recife - PE ORCID: https://orcid.org/0000-0001-8045-1028

Izabel Milena Pereira Cavalcanti

Universidade Federal da Paraíba (UFPB), Areia - PB

ORCID: https://orcid.org/0000-0002-4246-8731

Thallys Araújo da Silva

Instituto Federal da Paraíba (IFPB), Cabedelo - PB

ORCID: https://orcid.org/0000-0001-5079-365X

\section{Igor Espínola Winkeler}

Universidade Federal da Paraíba (UFPB), João Pessoa - PB

ORCID: https://orcid.org/0000-0003-1861-9509

\section{João Victor Fernandes da Silva}

Universidade Federal da Paraíba (UFPB), João Pessoa - PB

ORCID: https://orcid.org/0000-0001-7628-5151

\section{Nathalia Caroline Souza da Silva}

Parque Zoobotânico Arruda Câmara, João Pessoa - PB

ORCID: https://orcid.org/0000-0003-1043-5713

Kleber Silva de Oliveira Filho

Parque Zoobotânico Arruda Câmara, João Pessoa - PB

ORCID: https://orcid.org/0000-0001-7260-221X

Thiago Ferreira Lopes Nery

Parque Zoobotânico Arruda Câmara, João Pessoa - PB

ORCID: https://orcid.org/0000-0002-4051-428X 


\begin{tabular}{|c|c|}
\hline $\begin{array}{l}\text { Informações sobre o } \\
\text { artigo: } \\
\text { Recebido em: } \\
\text { 30/08/2021 } \\
\text { Aceito em: } \\
02 / 09 / 2021 \\
\text { Data de publicação: } \\
\text { 19/10/2021 } \\
\text { Palavras-chave: } \\
\text { Lacertidia } \\
\text { Réptil } \\
\text { Sauria } \\
\text { Squamata }\end{array}$ & $\begin{array}{l}\text { RESUMO } \\
\text { Um dos problemas mais comuns que chegam à clínica de animais } \\
\text { selvagens é o ataque destes por animais domésticos. Decorrente do } \\
\text { trauma, esses indivíduos podem apresentar diversas afecções, } \\
\text { incluindo o enfisema subcutâneo, que é a entrada de ar no tecido } \\
\text { localizado sob a pele, que pode ser decorrente da ruptura da } \\
\text { traqueia, dos pulmões ou dos sacos aéreos. Outra afecção muito } \\
\text { importante em répteis é a ocorrência dos prolapsos, e estes podem } \\
\text { ocorrer comumente em cloaca, oviduto e hemipênis, sendo mais } \\
\text { incomum em cólon e reto. As causas mais comuns de prolapsos } \\
\text { são os problemas reprodutivos, gastrintestinais, nutricionais, } \\
\text { desidratação, neoplasias e esforços idiopáticos. Dessa forma, esse } \\
\text { trabalho possui o objetivo de relatar a ocorrência de prolapso de } \\
\text { cólon e enfisema subcutâneo decorrente de ruptura traqueal de } \\
\text { origem traumática em Iguana iguana (Linnaeus, 1758). }\end{array}$ \\
\hline $\begin{array}{l}\text { Keywords: } \\
\text { Lacertidia } \\
\text { Reptile } \\
\text { Sauria } \\
\text { Squamata }\end{array}$ & $\begin{array}{l}\text { COLONIC PROLAPSE AND SUBCUTANEOUS EMPHYSEMA DUE } \\
\text { TO TRAUMATIC TRACHEAL RUPTURE IN GREEN IGUANA } \\
\text { (Iguana iguana, LINNAEUS, 1758) } \\
\text { ABSTRACT } \\
\text { One of the most common problems that come to the clinic of wild } \\
\text { animals is the attack of wild animals by domestic animals. As a } \\
\text { result of trauma, these individuals may present with a variety of } \\
\text { conditions, including subcutaneous emphysema, which is the entry } \\
\text { of air into the tissue under the skin, which may result from the } \\
\text { rupture of the trachea, lungs or air sacs. Another very important } \\
\text { condition in reptiles is the occurrence of prolapses, and these can } \\
\text { commonly occur in the cloaca, oviduct and hemipenis, being more } \\
\text { uncommon in the colon and rectum. The most common causes of } \\
\text { prolapse are reproductive, gastrointestinal, nutritional problems, } \\
\text { dehydration, cancer and idiopathic efforts. Thus, this work aims to } \\
\text { report the occurrence of colon prolapse and subcutaneous } \\
\text { emphysema resulting from tracheal rupture of traumatic origin in } \\
\text { Iguana iguana (Linnaeus, 1758). }\end{array}$ \\
\hline
\end{tabular}

\section{INTRODUÇÃO}

A iguana-verde (Iguana iguana, Linnaeus, 1758) é um réptil da ordem Squamata, da subordem Lacertidia e da família Iguanidae, que é encontrado naturalmente no Brasil e em 
outros países do continente americano. A iguana é um animal de hábitos arborícolas, além de ser herbívoro estrito, podendo se alimentar de folhas e de algumas frutas. Apesar de não estarem ameaçados de extinção, estes animais são muito importantes ecologicamente, já que servem de alimentação para diversas outras espécies de répteis, serpentes, rapinantes e mamíferos (BOCK et al. 2018).

Uma das principais causas do declínio de algumas espécies em diversas áreas no mundo é o ataque e a predação por animais domésticos, como os cães e gatos (GALETTI \& SAZIMA, 2006). Estes geram um descontrole da fauna nativa, pois há competição com os predadores da região e uma caça exacerbada devido ao grande número de animais errantes e ferais nos ambientes urbanos e rurais (CAMPOS, 2004).

Decorrente desses ataques, o enfisema subcutâneo pode ocorrer, sendo caracterizado pela condição em que o ar entra nos tecidos localizados sob a pele. Dessa forma, o gás geralmente se encontra na parede torácica ou no pescoço, mas também pode ocorrer em outras partes do corpo. As causas principais do enfisema subcutâneo incluem trauma contuso ou penetrante, fazendo com que o ar entre na pele a partir da ruptura de anel traqueal, pulmão e/ou saco aéreo, além de outras causas como pneumoceloma, pneumonia, de forma iatrogênica ou espontânea (AGHAJANZADEH et al. 2013; DIVERS; STAHL, 2019).

Uma afecção muito comum também em lagartos é a ocorrência de prolapsos, que podem ser cloacais, de oviduto, com ou sem ovos, hemipênis, vesícula urinária, e mais raramente de cólon e reto. Assim sendo, as causas mais ordinárias de prolapsos são as parasitoses, infecções bacterianas, período de postura prolongado, postura de ovo com tamanho maior do que o normal para a espécie, diarreia, constipação, fecaloma, toxemia, hipocalcemia, desidratação, neoplasias e esforços idiopáticos (GUERRERO-MENDEZ, 2010; HEDLEY \& EATWELL, 2014; MUSIC \& STRUNK, 2016; DIVERS; STAHL, 2019).

Afim de colaborar com os dados relacionados a medicina e patologia de répteis, o presente trabalho possui o objetivo de relatar a ocorrência de prolapso de cólon e enfisema subcutâneo decorrente de ruptura traqueal de origem traumática em Iguana iguana.

\section{METODOLOGIA}

No dia 26 de fevereiro de 2020, deu entrada ao ambulatório do Parque Zoobotânico Arruda Câmara uma iguana-verde (Iguana iguana, Linnaeus, 1758) de vida livre. O referido 
zoológico (CNPJ: 08.806.721/0001-03) apresenta-se cadastrado no Instituto Brasileiro do Meio Ambiente e dos Recursos Naturais Renováveis sob Registro n²36567.

O animal era fêmea, adulta, pesava 1,45kg e possuía um escore corporal 3 (na escala onde 1 refere-se a um animal caquético e 5, obeso). De acordo com terceiros, ela havia sofrido ataques de um cachorro. No exame físico, pode-se perceber que o animal estava apático e que havia um prolapso de alça intestinal que ainda estava viável e normocorada. $\mathrm{Na}$ avaliação da cavidade oral, notou-se que a mucosa do animal se apresentava hipocorada, e a saliva estava bem viscosa, sugerindo desidratação severa. Além disso, a partir da palpação, notou-se a ocorrência de duas costelas fraturadas e enfisema subcutâneo distribuído sobre todo o dorso do animal (Figura 1).

Destarte, foi instituído o tratamento utilizando-se meloxicam a $2 \%$ na dose de 0,5mg/ $\mathrm{kg}$ (BRETAS, 2019) a cada 24 horas, durante 5 dias, por via intramuscular; dipirona em dose única por via oral; e fluidoterapia utilizando-se ringer lactato e vitaminas do complexo B por via subcutânea, a cada 12 horas e durante 7 dias. Foi também realizada a limpeza do tecido exteriorizado com solução fisiológica 0,9\%. Sendo assim, utilizando-se óleo mineral e pinças anatômicas, foi feita a reposição de alça intestinal, além de drenagem subcutânea utilizando-se de cateter e seringa, com a finalidade de diminuir a quantidade de gás presente no dorso do animal.

No dia 4 de março do mesmo ano, o animal veio a óbito e foi realizada a necropsia. Com o auxílio de um bisturi e pinças anatômicas, a linha medial do ventre da iguana foi incisada com a finalidade de acesso a cavidade celomática. As alterações macroscópicas encontradas foram principalmente a ruptura de anel traqueal, a retenção de um ovo e a fratura de duas costelas, sendo que uma delas apresentava calo ósseo, sugerindo que fosse mais antiga (Figura 1). 
Figura 1 - Alterações patológicas Iguana iguana após trauma. A - Aspecto geral do animal, onde percebe-se enfisema subcutâneo; B, C - Prolapso de cólon; D - Ruptura traqueal; E

- Fratura de costela; F - Calo ósseo em costela.

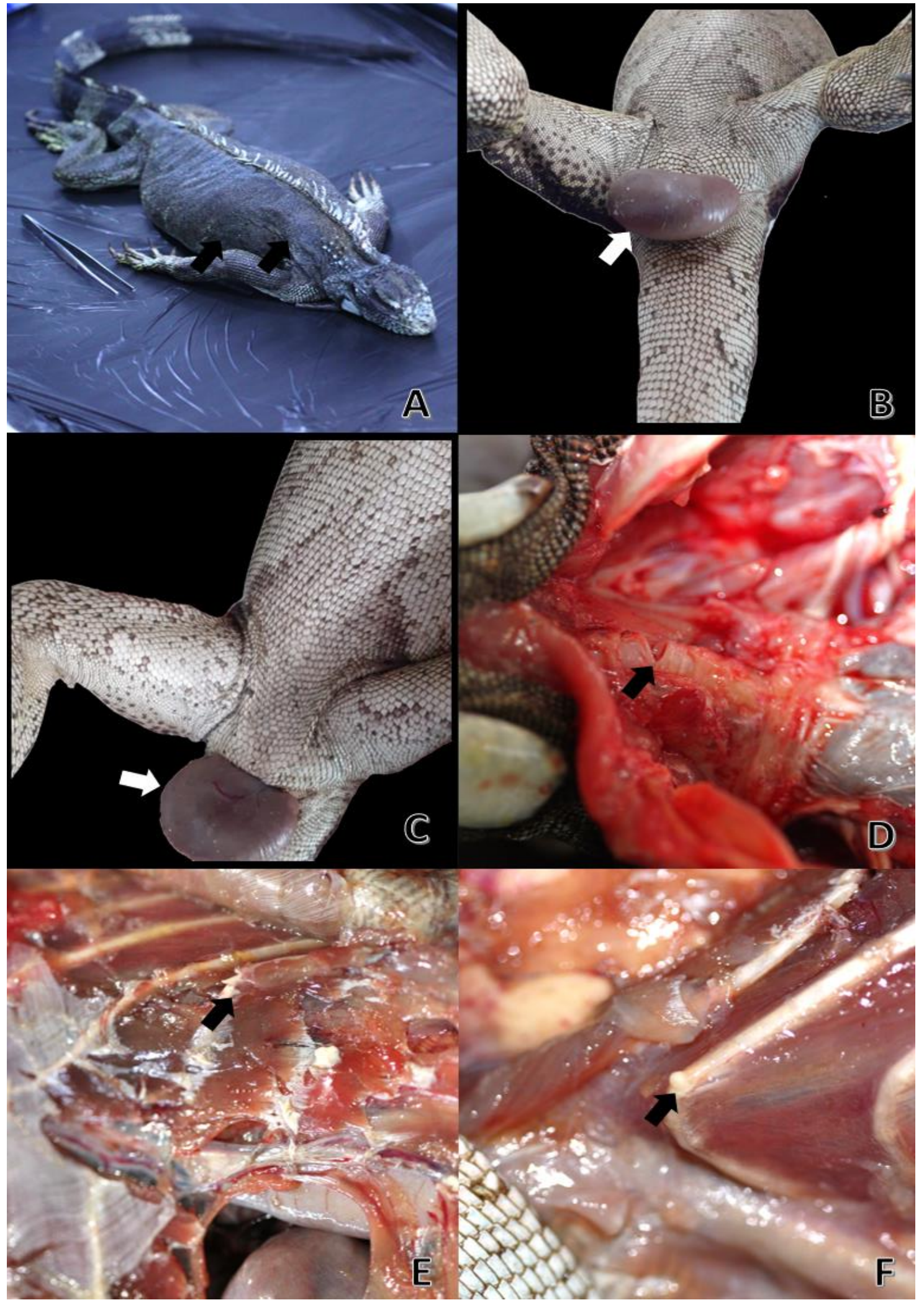

Fonte: Autores, 2021. 


\section{RESULTADOS E DISCUSSÃO}

Problemas reprodutivos como o período de postura prolongado e postura de ovo com tamanho maior do que o normal já foram demonstrados como causas para a ocorrência de prolapsos devido ao esforço que o animal faz para liberá-los. No presente caso, a iguana possuía um ovo retido e malformado, apresentando formato e mineralização deficiente. A presença do ovo sugere que o animal havia passado por postura, que somado a formação do ovo deficiente, pode ter ocasionado a formação do prolapso de cólon (GUERREROMENDEZ, 2010; MUSIC \& STRUNK, 2016; DIVERS; STAHL, 2019).

Outras causas para a formação de prolapsos são as parasitoses, diarreia, constipação, fecaloma, toxemia, hipocalcemia, desidratação, neoplasias e esforços idiopáticos. Na ocasião da necropsia não se percebeu a presença de vermes adultos alojados no trato gastrintestinal, assim como também não havia neoplasias, diarreia, constipação e fecaloma. Porém, o animal apresentava acentuada desidratação, o que pode ter colaborado com a exteriorização do tecido. Quanto as deficiências nutricionais e a intoxicação, estas não podem ser descartadas devido à falta de histórico do animal (GUERRERO-MENDEZ, 2010; MUSIC \& STRUNK, 2016; DIVERS; STAHL, 2019). De qualquer maneira, como a alça intestinal ainda estava viável, a utilização das compressas geladas para diminuir a inflamação local, e da correção manual do prolapso utilizando-se óleo mineral se mostrou eficaz para o presente caso.

Quanto ao enfisema subcutâneo, este foi causado devido ao trauma contuso, que ocasionou na ruptura do anel traqueal, e levou à presença de gás livre invadindo tecidos peritraqueais, adentrando ao longo dos feixes e das fáscias musculares, chegando até o tecido subcutâneo onde se alojou (AGHAJANZADEH et al. 2013; DIVERS; STAHL, 2019). A drenagem subcutânea se demonstrou eficaz, já que diminuiu a quantidade de ar no tecido subcutâneo, provavelmente diminuindo o desconforto do animal.

\section{CONCLUSÃO}

A ocorrência de enfisema subcutâneo decorrente de trauma ocasionado por animais domésticos, e prolapso de cólon são relatados em Iguana iguana. Apesar de prolapsos serem uma afecção comum em lagartos, o acometimento do cólon não é usual e pode ter decorrido devido a diversas causas. Além disso, há escassos relatos sobre enfisema subcutâneo em 
répteis na literatura, o que pode colaborar para a compreensão dos achados anatomopatológicos desses animais. Alerta-se também para o impacto de animais domésticos nos animais da fauna nacional, e para as consequências futuras dessa problemática.

\section{REFERÊNCIAS}

AGHAJANZADEH, Manouchehr et al. Classification andManagement of Subcutaneous Emphysema: a 10-Year Experience. Indian J Surg, out. 2013.

BOCK, B. et al. Iguana iguana. The IUCN Red List of Threatened Species 2018: e.T174481A1414646, 2018. Disponível em: http://dx.doi.org/10.2305/IUCN.UK.20181.RLTS.T174481A1414646.en. Acesso em: 18 mar. 2020.

CAMPOS, C.B.; Impacto de cães (Canis familiaris) e gatos (Felis catus) errantes sobre a fauna silvestre em ambiente periurbano. Piracicaba: Universidade de São Paulo, 2004.

GALETTI, M.; SAZIMA, I.; Impacto de cães ferais em um fragmento urbano de Floresta Atlântica no sudeste do Brasil. Natureza \& Conservação, 2006.

GUERRERO-MENDEZ, M. Cloacal organ prolapse in reptiles. Vet Times, 2013.

HEDLEY, J; EATWELL, K. Cloacal prolapses in reptiles: a retrospective study of 56 cases. Journal Of Small Animal Practice, 2014.

DIVERS, S. J.; STAHL, S. J. Mader's Reptile Medicine and Surgery. Londres: Editora Elsevier Saunders, 3 ed, 2019.

MUSIC, M.K.; STRUNK, A. Reptile Critical Care and Common Emergencies. Vet Clin Exot Anim, 2016. 


\section{IMPACTAÇÃO DO DIVERTÍCULO DO VESTÍBULO ORAL EM Phodopus campbelli- RELATO DE CASO}

Joyce Galvão de Souza

Universidade Federal do Rio Grande do Norte (UFRN), Natal - RN ORCID: https://orcid.org/0000-0001-5492-6317

Lattes: http://lattes.cnpq.br/2721275127997056

\section{Aksa Ingrid Vieira Batista}

Universidade Federal Rural do Semi-Árido (UFERSA), Mossoró - RN Lattes: http://lattes.cnpq.br/6614624885083003

\section{Gabriel Vinícius Carvalho de Lucena}

Universidade Federal de Campina Grande (UFCG), Patos - PB

Lattes: http://lattes.cnpq.br/2795820000194401

\section{Luan Nascimento Batista}

Médico Veterinário Anestesista Volante, Recife - PE

Lattes: http://lattes.cnpq.br/3431992433963298

\section{Moana Barbosa dos Santos Figuerêdo}

Médica Veterinária na Clínica Vita 24h, Recife - PE

Lattes: http://lattes.cnpq.br/8807162730434058

\section{Brunna Muniz Rodrigues Falcão}

Universidade Federal de Campina Grande (UFCG), Patos - PB

Lattes: http://lattes.cnpq.br/8069283312084930

\section{Artur da Nóbrega Carreiro}

Universidade Federal de Campina Grande (UFCG), Patos - PB http://lattes.cnpq.br/7750885373832284

\section{Raphaela Bueno Mendes Bittencourt}

Universidade Federal de Goiás (UFG), Goiânia - GO

Lattes: http://lattes.cnpq.br/7181429399410680

\section{Diego Eron Santos de Jesus}

Universidade Federal de Sergipe (UFS), Aracaju - SE

Lattes: http://lattes.cnpq.br/3042384442669627

\section{Marina Neves de Assis Aguiar}

Médica Veterinária Autônoma, Brasília - DF

Lattes: http://lattes.cnpq.br/4794338393507036

\section{Jéssica de Souza Joaquim}

Universidade Federal de Minas Gerais (UFMG), Belo Horizonte - MG Lattes: http://lattes.cnpq.br/3538676692850217

\section{Danilo José Ayres de Menezes}

Universidade Federal do Rio Grande do Norte (UFRN), Natal - RN

Lattes: http://lattes.cnpq.br/4003577127443065 


\begin{tabular}{|c|c|}
\hline Informações sobre 0 & RESUMO \\
\hline $\begin{array}{l}\text { Recebido em: } \\
30 / 08 / 2021 \\
\text { Aceito em: } \\
\text { 02/09/2021 } \\
\text { Data de publicação: } \\
\text { 19/10/2021 } \\
\text { Palavras-chave: } \\
\text { Hamster } \\
\text { Roedor } \\
\text { Silvestres }\end{array}$ & $\begin{array}{l}\text { A criação de pets não convencionais vem aumentando e com isso, } \\
\text { aumenta também a procura por atendimento médico veterinário } \\
\text { para animais como os pequenos roedores, por exemplo. Este relato } \\
\text { visa trazer informações sobre a abordagem realizada em um } \\
\text { hamster anão russo (Phodopus campbelli) que foi atendido no } \\
\text { Hospital Veterinário Universitário Professor Ivon Macêdo Tabosa } \\
\text { da Universidade Federal de Campina Grande, Patos, Paraíba (PB) } \\
\text { e que foi diagnosticado com impactação do divertículo do } \\
\text { vestíbulo oral, conhecido também como bolsa jugal. Diante das } \\
\text { informações coletadas na anamnese e no exame físico, optou-se } \\
\text { pela tentativa de retirada manual do material impactado com } \\
\text { auxílio de uma pinça de ponta pequena sem dentes e contenção } \\
\text { física do animal. O procedimento demonstrou que haviam diversas } \\
\text { sementes na bolsa jugal e uma massa maior que impedia a saída } \\
\text { dessas, sendo identificada posteriormente como sendo um pedaço } \\
\text { de pão. A retirada desse material proporcionou alívio imediato ao } \\
\text { animal e foi uma boa alternativa de resolução para este caso. }\end{array}$ \\
\hline $\begin{array}{l}\text { Keywords: } \\
\text { Hamster } \\
\text { Rodent } \\
\text { Wild }\end{array}$ & $\begin{array}{l}\text { IMPACTION OF CHEEK POUCH ON Phodopus campbelli - CASE } \\
\text { REPORT } \\
\text { ABSTRACT } \\
\text { The creation of unconventional pets has been increasing and with } \\
\text { that, the demand for veterinary medical care for animals such as } \\
\text { small rodents, for example, also increases. This report aims to } \\
\text { provide information about the approach performed on a russian } \\
\text { dwarf hamster (Phodopus campbelli) who was treated at the Professor } \\
\text { Ivon Macêdo Tabosa University Veterinary Hospital of the Federal } \\
\text { University of Campina Grande, Patos, Paraíba (PB) and who was } \\
\text { diagnosed with impaction of the diverticulum of the oral vestibule, } \\
\text { also known as the cheek pouch. In view of the information } \\
\text { collected in the anamnesis and physical examination, it was decided } \\
\text { to attempt to manually remove the impacted material with the aid } \\
\text { of small-tipped tweezers without teeth and physical restraint of the } \\
\text { animal. The procedure showed that there were several seeds in the } \\
\text { cheek pouch and a larger mass that prevented them from coming } \\
\text { out, which was later identified as a piece of bread. The removal of } \\
\text { this material provided immediate relief to the animal and was a } \\
\text { good solution for this case. }\end{array}$ \\
\hline
\end{tabular}

\section{INTRODUÇÃO}

Os pequenos roedores exóticos, assim como outras muitas espécies não convencionais, vêm sendo escolhidas como opções por quem deseja um animal pet. E esses roedores apresentam algumas características atrativas como pequeno porte, beleza e 
docilidade (TEIXEIRA, 2014). Dentre eles, estão os hamsters anão russo (Phodopus campbelli), que pertencem a ordem Rodentia, subordem Myomorpha e família Cricetidae. Esses animais são noturnos e ocorrem naturalmente em pastagens, locais semi-desertos ou desertos, se alimentando principalmente de plantas, misturas de sementes e alguns insetos na natureza, sendo nativos da China, Cazaquistão, Mongólia e Federação Russa (CASSOLA, 2016; BISPO; NUNES, 2020).

Roedores apresentam adaptações anatômicas que os distinguem dos demais mamíferos, sendo muitas encontradas no crânio (TEIXEIRA, 2014). Os hamsters possuem uma estrutura conhecida como bolsa jugal (divertículo do vestíbulo oral) que são bilaterais e localizam-se nas bochechas, formando sacos musculares que se estendem até a região de escápula destes animais. Esta estrutura é utilizada com a função de armazenar alimentos, podendo também ser usadas em alguns casos para transportar filhotes recém-nascidos ou material para formação de ninho (DE SOUZA PINTO, 2019; QUESENBERRY et al., 2021), além de terem também função imunológica e linfática (TEIXEIRA, 2014; DE SOUZA PINTO, 2019).

Alguns processos patológicos envolvendo a bolsa jugal podem acometer esses animais, assim como impactação, inversão, prolapso, neoplasia ou retenção de corpo estranho. No caso de impactações, caso não tratado, podem ocorrer autólise do tecido e/ou infecção secundária (JEPSON, 2009), e para a retirada do material impactado, pode ser utilizada uma pinça fina. Má oclusão dentária pode ser uma das causas de impactação e após a resolução do caso, deve também ser investigada (QUESENBERRY et al., 2021).

Diante do exposto, o presente relato tem como objetivo trazer a descrição dos procedimentos realizados no atendimento clínico, diagnóstico e tratamento de um hamster anão russo (Phodopus campbelli) que apresentou impactação do divertículo do vestíbulo oral.

\section{METODOLOGIA}

Um hamster anão russo de 1 ano e 3 meses de idade, pesando 48 gramas, da espécie Phodopus campbelli, foi levado ao Hospital Veterinário Universitário Professor Ivon Macêdo Tabosa, da Universidade Federal de Campina Grande (UFCG), em Patos, Paraíba (PB), para atendimento com a queixa de estar há aproximadamente 2 semanas com aumento de volume na face. Sua dieta consistia em alface e ração à base de mistura de sementes para roedores. Ao exame físico o aumento de volume se mostrou localizado na região de bochecha direita 
e o animal se locomovia em círculos voltados para esse mesmo lado. À palpação desta massa notou-se irregularidades, inconsistente com quadro de abscesso e que exalava odor forte. A pele desta área não apresentava lesões. Ao se examinar a cavidade oral do hamster, foi observado conteúdo de coloração esverdeada no divertículo do vestíbulo oral direito (Figura 1).

O animal foi contido fisicamente e realizou-se procedimento de retirada do material com auxílio de uma pinça anatômica com ponta fina, tendo o cuidado para não o estressar ou causar lesões caso isso acontecesse. Foi explicado aos tutores que caso não fosse possível a retirada desta forma, o animal seria encaminhado ao setor de anestesiologia para que fosse sedado e permitisse o procedimento. Contudo, foi possível retirar uma massa de aproximadamente $1 \mathrm{~cm} \times 1 \mathrm{~cm}$ de aspecto esverdeado e bordas arredondadas, que os tutores indicaram que poderia ser pão, que havia sido oferecido ao animal antes do início dos sinais, como petisco. Após a retirada deste material maior, outros foram retirados com a pinça, que consistiam principalmente em sementes. Ao se fazer uma pausa, o próprio hamster começou a expelir voluntariamente algumas sementes (Figura 1)

Figura 1 - A, B: Hamster anão russo apresentando impactação do divertículo oral. C:

Conteúdo impactado após retirada
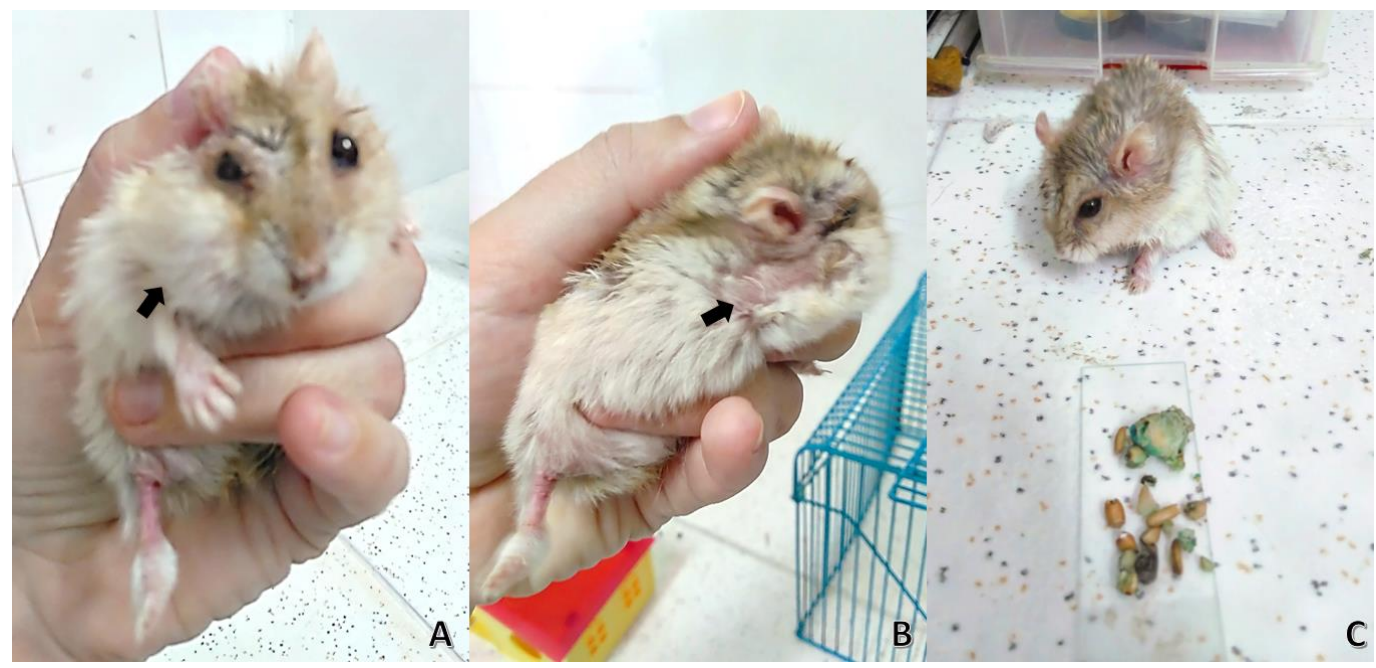

Fonte: Autores, 2021.

Após a retirada, imediatamente o animal demonstrou alívio, ficando mais ativo e começando a se limpar, além de se locomover normalmente pela mesa de procedimento.

Além do problema de impactação da bolsa jugal, foi identificado também uma infecção na pele do hamster, sem relação com este primeiro problema, para o qual foi 
instaurado tratamento adequado que incluía antibioticoterapia. Após a limpeza da bolsa, não foram observadas lesões e, devido ao tratamento que já seria feito para o problema dermatológico, não se viu necessidade de medicações para a bolsa, que estava integra. Até o último contato com os tutores, o animal não apresentou novamente impactação.

\section{RESULTADOS E DISCUSSÃO}

Os tutores receberam recomendações sobre as correções que deveriam ser feitas em relação à alimentação do animal. Além disso, alertou-se para que observassem se ele conseguia retirar o alimento sozinho da bolsa jugal ou se estava novamente impactado, devendo-se nesse caso levar para atendimento médico veterinário a fim de evitar possíveis lesões caso se realizasse o procedimento em casa.

Apesar de uma das causas da impactação do divertículo oral ser a má oclusão dentária, por levar a uma mastigação errada (QUESENBERRY et al., 2021), foram observados também o tamanho e posicionamento dos dentes do hamster descartando quaisquer anomalias na dentição. Devido não haver recidiva do quadro, sugere-se que este caso isolado provavelmente ocorreu devido ao tamanho do alimento que ele tentou guardar na bolsa jugal, e que impediu sua própria saída e dos demais alimentos já acumulados.

A limitação da abertura da boca dos roedores se dá pela presença de pregas mucosas, que são extensões dos lábios inferior e superior, que adentram a cavidade oral quando estes abrem a boca (TEIXEIRA, 2014), e esta característica se mostra como um fator que pode gerar dificuldade na avaliação da cavidade oral desses animais. Apesar disto, o conhecimento prévio da presença das bolsas jugais e quais as patologias que mais acometem essa estrutura, juntamente com a anamnese e a avaliação física do animal, permitem que seja feito o diagnóstico e o tratamento.

Outra possibilidade de diagnóstico desta afecção é através do uso de imagem obtida por radiografia, o que possibilita uma melhor visualização da extensão da impactação (QUESENBERRY et al., 2021). Ao se optar pelo diagnóstico por imagem para os pequenos redores, deve ser também levado em consideração se eles estão em condições físicas de serem submetidos ao estresse da contenção ou sedação, além da limitação da própria técnica pelo reduzido tamanho do paciente (TEIXEIRA, 2014).

Com base nesse conhecimento e na avaliação física do paciente, considerando também o pequeno porte (o qual exigiria uma contenção física mais delicada ou uma sedação 
para a obtenção de uma boa imagem), optou-se por não fazer o exame radiográfico, sendo o diagnóstico baseado nas características irregulares da massa à palpação (que ajudaram a identificar a presença de sementes que faziam parte da dieta), o histórico do animal e o resultado após a tentativa de retirada do conteúdo.

\section{CONCLUSÃO}

A abordagem realizada para retirada do conteúdo do divertículo do vestíbulo oral se mostrou adequada à situação, e o animal apresentou boa recuperação. É de suma importância, para evitar uma recidiva, que seja feito o aconselhamento aos tutores quanto ao manejo alimentar correto e também, caso necessário, a procura novamente por tratamento médico veterinário.

\section{REFERÊNCIAS}

BISPO, A. J.; NUNES, C. Proliferação fibroblástica reativa benigna em hamster Anão Russo (Phodopus campbelli)-Relato de caso. Brazilian Journal of Animal and Environmental Research, v. 3, n. 3, p. 1544-1547, 2020.

DE SOUZA PINTO, J. L. P. et al. Descrição das réplicas vasculares de bolsas jugais da Hamster sírio dourado (Mesocricetus Auratus). Brazilian Journal of Development, v. 5, n. 7 , p. 9250-9258, 2019.

CASSOLA, F. Phodopus campbelli (errata version published in 2017). The IUCN Red List of Threatened Species, 2016.

JEPSON, L. Clínica de animais exóticos: Referência rápida. Elsevier: Rio de Janeiro. 2009.

QUESENBERRY, K. E. et al. Ferrets, rabbits and rodents: Clinical Medicine and Surgery. 4 ed. St. Louis: Elsevier, 2021.

TEIXEIRA, V.N. Rodentia - Roedores Exóticos (Rato, Camundongo, Hamster, Gerbilo, Porquinho-da-índia e Chinchila). In: CUBAS, S.Z.; SILVA, R.C.J.; DIAS, C.L.J. Tratado de animais selvagens. Medicina veterinária. 2 ed. São Paulo: Rocca, 2014. 


\section{Capítulo 9}

\section{MANEJO, REABILITAÇÃO E SOLTURA DE ANIMAIS SILVESTRES}

\section{Maria Flaviane Almeida Silva}

Universidade Federal de Sergipe, Núcleo de Medicina Veterinária, Nossa Senhora da Glória- SE ORCID: https://orcid.org/0000-0001-5110-9485

Lattes: http://lattes.cnpq.br/7276739267506207

\section{Camenas Vieira Barata}

Universidade Federal de Sergipe, Núcleo de Medicina Veterinária, Nossa Senhora da Glória- SE Lattes: http://lattes.cnpq.br/3753872871256727

\section{Allan Costa Gomes}

Universidade Federal de Sergipe, Núcleo de Medicina Veterinária, Nossa Senhora da Glória- SE Lattes: http://lattes.cnpq.br/6542226186166115

\section{Lórena Maciel Santos Silva}

Universidade Federal de Sergipe, Núcleo de Medicina Veterinária, Nossa Senhora da Glória- SE Lattes: http://lattes.cnpq.br/0766419381359796

\section{Taynara Alessandra de Matos Santos}

Universidade Federal de Sergipe, Núcleo de Medicina Veterinária, Nossa Senhora da Glória- SE Lattes: http://lattes.cnpq.br/4807858146979413

\section{Weslania Souza Inacio da Silva}

Universidade Federal de Sergipe, Núcleo de Medicina Veterinária, Nossa Senhora da Glória - SE Lattes: http://lattes.cnpq.br/2096023399078864

\section{Igo Gonçalves dos Santos}

Universidade Federal de Sergipe, Núcleo de Medicina Veterinária, Nossa Senhora da Glória - SE Lattes: http://lattes.cnpq.br/3048876638161878

\section{Manuel Benicio Oliveira Neto}

Universidade Federal de Sergipe, Núcleo de Medicina Veterinária, Nossa Senhora da Glória - SE Lattes: http://lattes.cnpq.br/6372287958265880

\section{Danilo Santos de Jesus}

Universidade Federal de Sergipe, Núcleo de Medicina Veterinária, Nossa Senhora da Glória - SE Lattes: http://lattes.cnpq.br/0030697599240620

\section{Matheus Resende Oliveira}

Universidade Federal de Sergipe, Núcleo de Medicina Veterinária, Nossa Senhora da Glória - SE Lattes: http://lattes.cnpq.br/3822150058285111

\section{Victor Fernando Santana Lima}

Universidade Federal de Sergipe, Núcleo de Medicina Veterinária, Nossa Senhora da Glória - SE Lattes: http://lattes.cnpq.br/7265386741392623 
Informações sobre o

artigo:

Recebido em:

02/09/2021

Aceito em:

06/09/2021

Data de publicação:

$19 / 10 / 2021$

Palavras-chave:

Aves

Répteis

Doenças

Tratamento

\section{RESUMO}

O Brasil possui uma das maiores biodiversidades do mundo, no entanto, ações antrópicas como a expansão agropecuária e urbana, queimadas, turismo, caça e/ou captura colocam em risco populações de animais silvestres. Pensando na redução desses eventos, o trabalho a seguir traz os desafios e progressos encontrados em um centro de manejo de animais silvestres. Para esse estudo foi avaliado a casuística dos animais silvestres atendidos no período de janeiro a julho de 2021 no Centro de Aprendizagem e Manejo de Animais Silvestres (CAMASE) da Universidade Federal de Sergipe (UFS), campus do Sertão. Todos os dados foram analisados estatisticamente através do software InStat (GraphPad Software). No geral foram atendidos 495 animais silvestres, dos quais 46,06\% foram aves, 44,65\% répteis, 7,48\% mamíferos, $1,20 \%$ anfíbios e $0,61 \%$ artrópodes. 84,6\% dos animais foram reintroduzidos na natureza e passaram pelas seguintes etapas: manejo alimentar, enriquecimento ambiental, acompanhamento clínico, reabilitação e soltura. Com isso, podemos destacar que os protocolos de manejo e reabilitação utilizados em centros de manejo, podem garantir saúde e bem-estar para animais silvestres vítimas de ações antrópicas.

\section{MANAGEMENT, REHABILITATION AND RELEASE OF WILD}

ANIMALS

\section{ABSTRACT}

Brazil has one of the greatest biodiversity in the world, however, anthropic actions such as agricultural and urban expansion, fires, tourism, hunting and/or capture put wild animal populations at risk. Thinking about reducing these events, the work that follows brings the challenges and progress found in a wild animal management center. For this study, the sample of wild animals attended from January to July 2021 at the Wild Animal Learning and Management Center of the Federal University of Sergipe, was evaluated. All data were statistically analyzed using InStat software (GraphPad Software). Overall, 495 wild animals were attended, of which $46.06 \%$ were birds, $44.65 \%$ reptiles, $7.48 \%$ mammals, $1.20 \%$ amphibians and $0.61 \%$ arthropods. $84.6 \%$ of the animals were

Keywords:

Birds

Reptiles

Diseases

Treatment reintroduced into nature and went through the following stages: feeding management, environmental enrichment, clinical followup, rehabilitation and release. Thus, we can highlight that the management and rehabilitation protocols used in management centers can guarantee health and well-being for wild animals that are victims of anthropic actions. 


\section{INTRODUÇÃO}

O Brasil é um dos países com maior biodiversidade do mundo, no entanto, devido ao crescimento populacional, a diversidade biológica tem sofrido com a pressão oriunda da intensificação das atividades antrópicas, que impacta negativamente e coloca em risco muitas espécies da fauna silvestre (ICMBIO, 2018; SCANES, 2018). Para redução dos danos à fauna, os profissionais da biologia e medicina da conservação do país e também de outras partes do mundo têm se redobrado buscando implantar técnicas de manejo, reabilitação e soltura desses animais.

Os principais elementos vetores de ameaça à fauna silvestre estão relacionados com as atividades que contribuem para destruição e fragmentação de habitat como a agropecuária, a expansão urbana, a produção de energia, a poluição, as queimadas, a mineração, o turismo desordenado e caça e/ou captura. A caça que tem principal finalidade o consumo de aves e mamíferos. E a captura de animais vivos para destinação ao tráfico (PRIMACK e ROGRIGUES, 2001; ICMBIO, 2018). No bioma Caatinga, o tatu-bola (Tolypeutes tricinctus) (MARINHO FILHO e REIS, 2008) e o mocó (Kerodon rupestris) são exemplos de mamíferos que têm sofrido prejuízo em razão do seu consumo excessivo pelo homem (SANTOS, 2018).

Os Centros de Triagem de Animais Silvestres (CETAS), os Centros de Recuperação de Animais Silvestres (CRAS) e outras instituições são locais responsáveis por receber, triar, tratar, reabilitar e destinar animais silvestres feridos, órfãos e/ou oriundos do tráfico e/ou cativeiro ilegal (BRASIL, 2021). Em relação ao manejo da fauna silvestre em cativeiro RochaMendes et al. (2006) destacam a importância da construção de planilha de alimentação, características e biologia da espécie, avaliação médica veterinária, acompanhamento sanitário, contato mínimo do espécime com fontes emissoras de sons e/ou pessoas, ambientação e enriquecimento do recinto a fim de reduzir os efeitos negativos do cativeiro.

O processo de reabilitação consiste em uma ação planejada que visa a preparação e treinamento do animal que será destinado para soltura e/ou cativeiro. A soltura imediata, é realizada quando o animal após avaliação não apresenta problemas que afetem a sua sobrevivência na natureza. Por outro lado, os animais destinados para o cativeiro, são aqueles que não tem condições de retornar à natureza, apesar de existir a possibilidade de destinação mediata (soltura experimental, revigoramento populacional, reintrodução, cativeiro entre outros) (BRASIL, 2014). Pensando nisso, esse trabalho traz os desafios e progressos encontrados em um centro de manejo de animais silvestres. 


\section{METODOLOGIA}

Para esse trabalho foi realizado um estudo retrospectivo da casuística de animais silvestres encaminhados por órgãos ambientais do estado de Sergipe para o Centro de Aprendizagem e Manejo de Animais Silvestres (CAMASE) da Universidade Federal de Sergipe (UFS), Campus do Sertão, no período de janeiro a julho de 2021.

Todos os dados referentes ao registro, espécie, idade, sexo, procedência, estado de saúde, prognóstico e status do animal: 1) soltura, 2) em reabilitação, 3) entrou em óbito, e 4) destinados para CETAS ou CRAS, foram colhidas das fichas de entrada, prontuários e laudos de óbitos (Figura 1).

Para análise estatística foi utilizado o software InStat (GraphPad Software), calculando-se frequência absoluta $(\mathrm{n} / \mathrm{N})$ e relativa (\%). O Teste de Qui-quadrado (X2) foi utilizado para verificar se há significância entre as alterações clínicas e status atual do animal. As variáveis independentes consideradas no modelo foram aquelas com significância estatística menor que 0,20. EpiInfoTM7, sendo utilizado para realizar os cálculos estatísticos, com nível de significância estabelecido de $p<0,05$.

Figura 1 - Procedimentos operacionais do CAMASE/UFS

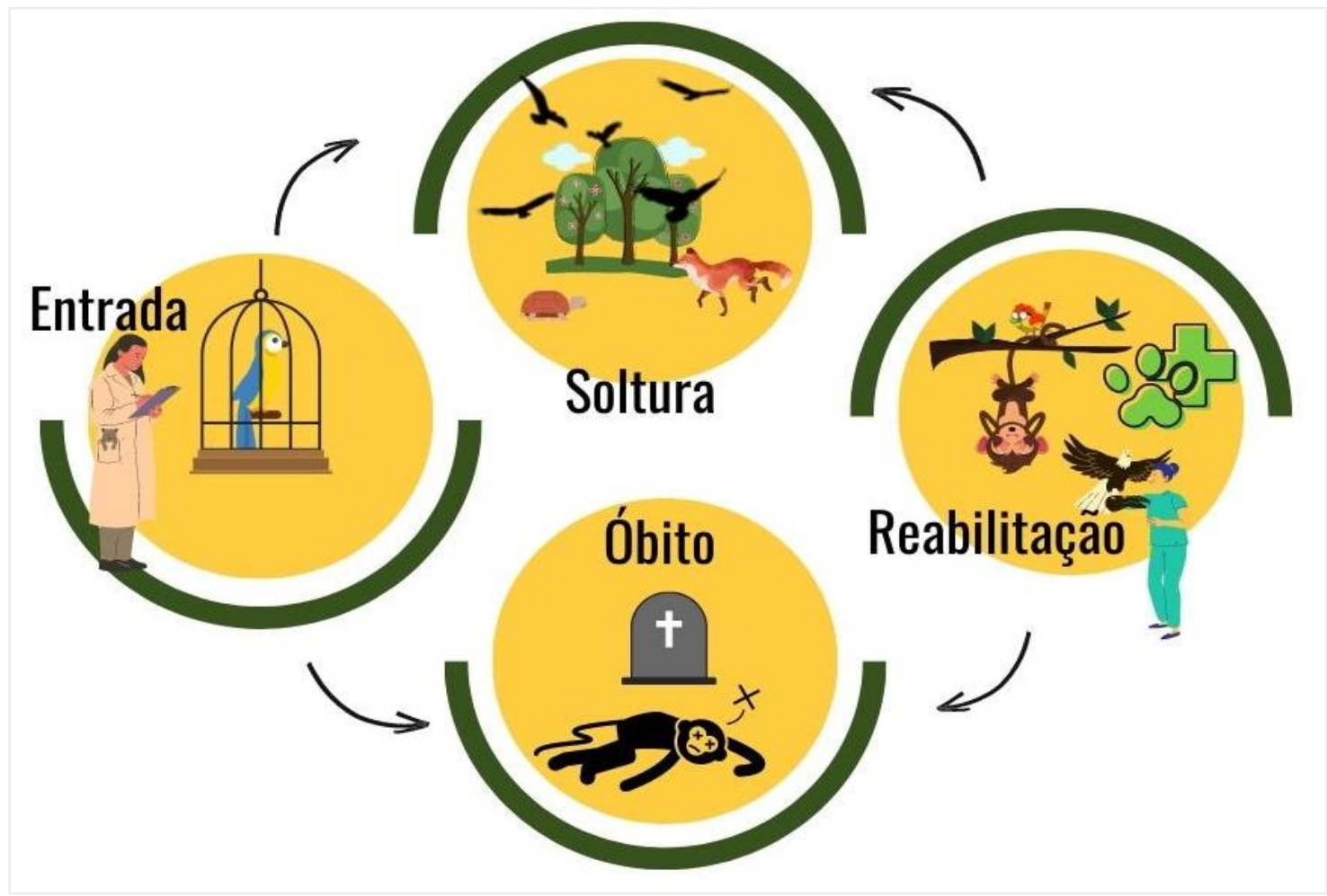

Fonte: Autores, 2021. 


\section{RESULTADOS E DISCUSSÃO}

Dentre os animais reabilitados no CAMASE/UFS, as aves apresentaram maior percentual, seguido dos répteis, mamíferos, anfíbios e artrópodes. Ribeiro (2017) destaca que aves e répteis são os animais que mais sofrem com comportamento estereotipado e manejo ambiental e nutricional inadequado.

Os resultados ilustrados na figura 2 corroboram com resultados obtidos em estudos realizados em CRAS e CETAS na região Nordeste do Brasil, que destacam a casuística de aves e répteis como as mais frequentes e predominantes (MOURA et al., 2012; SILVA, 2015). Provavelmente devido ao fato de estarem entre os grupos de animais silvestres mais traficados no Brasil, a exemplo dos Passeriformes e Psittaciformes (RECTAS, 2001; SILVA, 2015; FARIAS et al., 2019).

Figura 2 - Percentual de animais silvestres que deram entrada no CAMASE/UFS no período de janeiro a julho de 2021

\section{Percentual de animais silvestres - janeiro a julho de 2021}

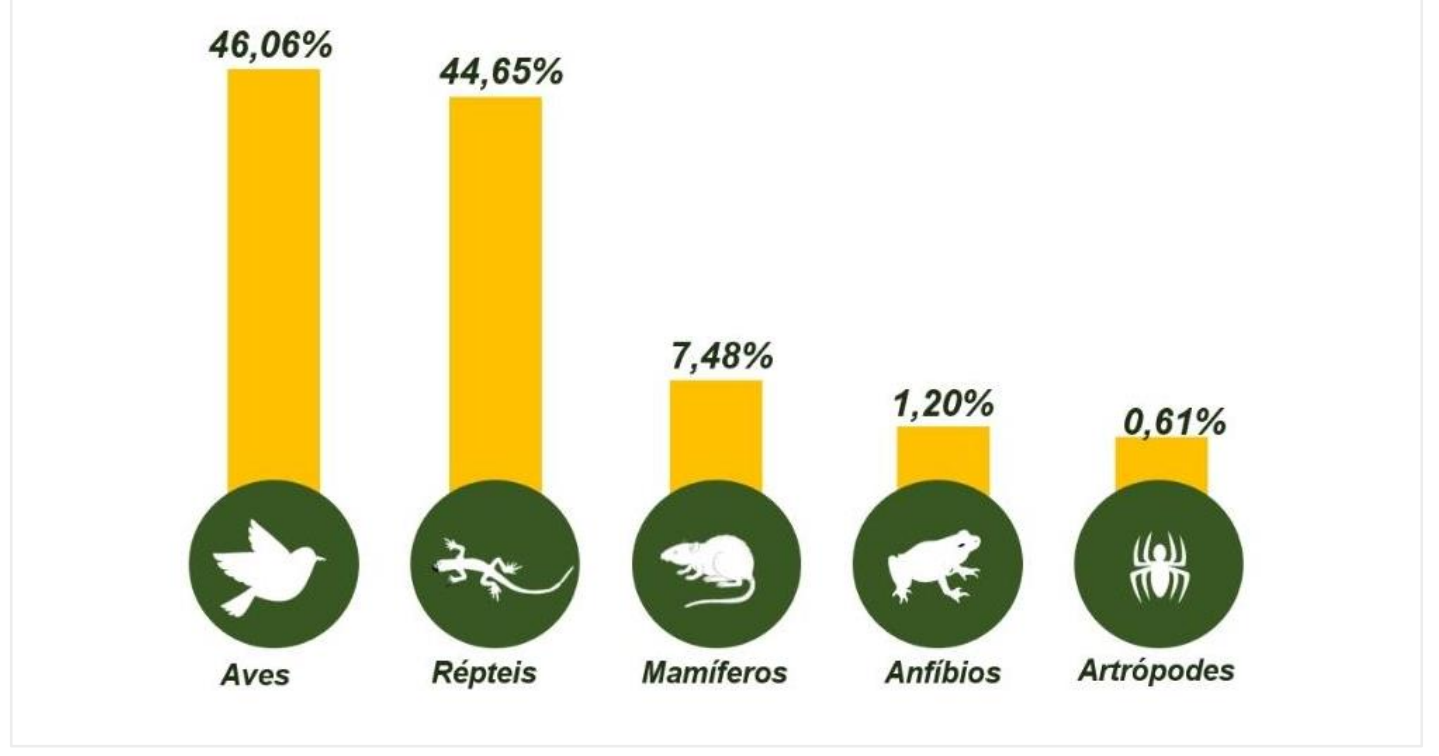

Fonte: Autores, 2021.

Em relação aos animais recebidos $84,6 \%$ obtiveram sucesso na reabilitação e seguiram para a soltura, após finalização do treinamento de busca, captura e/ou forrageamento dos alimentos (Figura 3 A), boa capacidade de locomoção, baixa tolerância à 
presença de humanos (fuga), expressando o comportamento natural da espécie (Figura 3 C, D, E e F).

Vale a pena destacar que a identificação da espécie e seu habitat natural é essencial na reintrodução do animal em seu ambiente natural (MENDONÇA, 2020). Além disso, o animal que foi capturado recentemente do seu ambiente natural e manifesta sua característica selvagem, é indicada a soltura imediata pós-avaliação clínica (BARRIENTO, 2012). É importante ressaltar que os animais reintroduzidos, devem ser monitorados, com o objetivo de avaliar a progressão da população na área e consequentemente o equilíbrio ambiental (MILANELO e FITORRA, 2012).

Apesar da reintrodução e soltura estarem entre os principais objetivos dos CRAS e CETAS, em alguns casos as sequelas e traumas (Figura 3B) do tráfico levam esses animais a um estado irreversível e assim, os índices de mortalidade podem chegar a 90\% (ROCHA, 1995; PAGANO, et al., 2009). Nesse contexto, os nossos resultados apontaram uma taxa de 9,1\% de óbitos de animais silvestres no CAMASE, sendo esse percentual considerado abaixo da média, quando comparado ao de outros centros de manejo. Fato este pode ser justificado ao curto período contabilizado nesse estudo, quando comparado ao de Vilela (2012) que em um estudo no período de janeiro de 2008 a dezembro de 2010 no CETAS de Minas gerais constatou $24 \%$ de óbitos dos animais recebidos.

Os animais que não atenderam aos critérios de soltura, corresponderam a 1,8\% dos animais (56\% mamíferos), os quais foram destinados por parte dos órgãos ambientais a instituições e entidades que trabalham em programas de conservação de espécies em cativeiro. Rocha-Mendes et al. (2006) destacam a dificuldade de soltura e reintrodução de mamíferos silvestres, pois apresentam uma facilidade de imprinting com os humanos.

Ainda que o Brasil passe por dificuldades de lidar com os impactos e consequências do tráfico de animais silvestres e da ação antrópica (BASTOS, 2008). É de suma importância destacar, os impactos positivos dos CRAS, CETAS e centros de manejo de animais silvestres na reabilitação da fauna (MORITA, 2009; ZAMBOM, 2018). Tendo um valor imensurável em relação a reintrodução e soltura desses animais, constituindo assim, um dos grandes pilares para a conservação e reintrodução da fauna silvestre ao meio ambiente. 
Figura 3 - Pacientes em tratamento, reabilitação e soltura. Nota-se em A - Alimentação de Ara ararauna e Ara chloropterus. B - Galea spixii em tratamento. C - Soltura de um Caiman latirostris. D - Reintrodução de um grupo de Chelonoidis carbonaria. E e F - Soltura de Micrurus spp. e de um bando de Amaz̧ona amazônica.

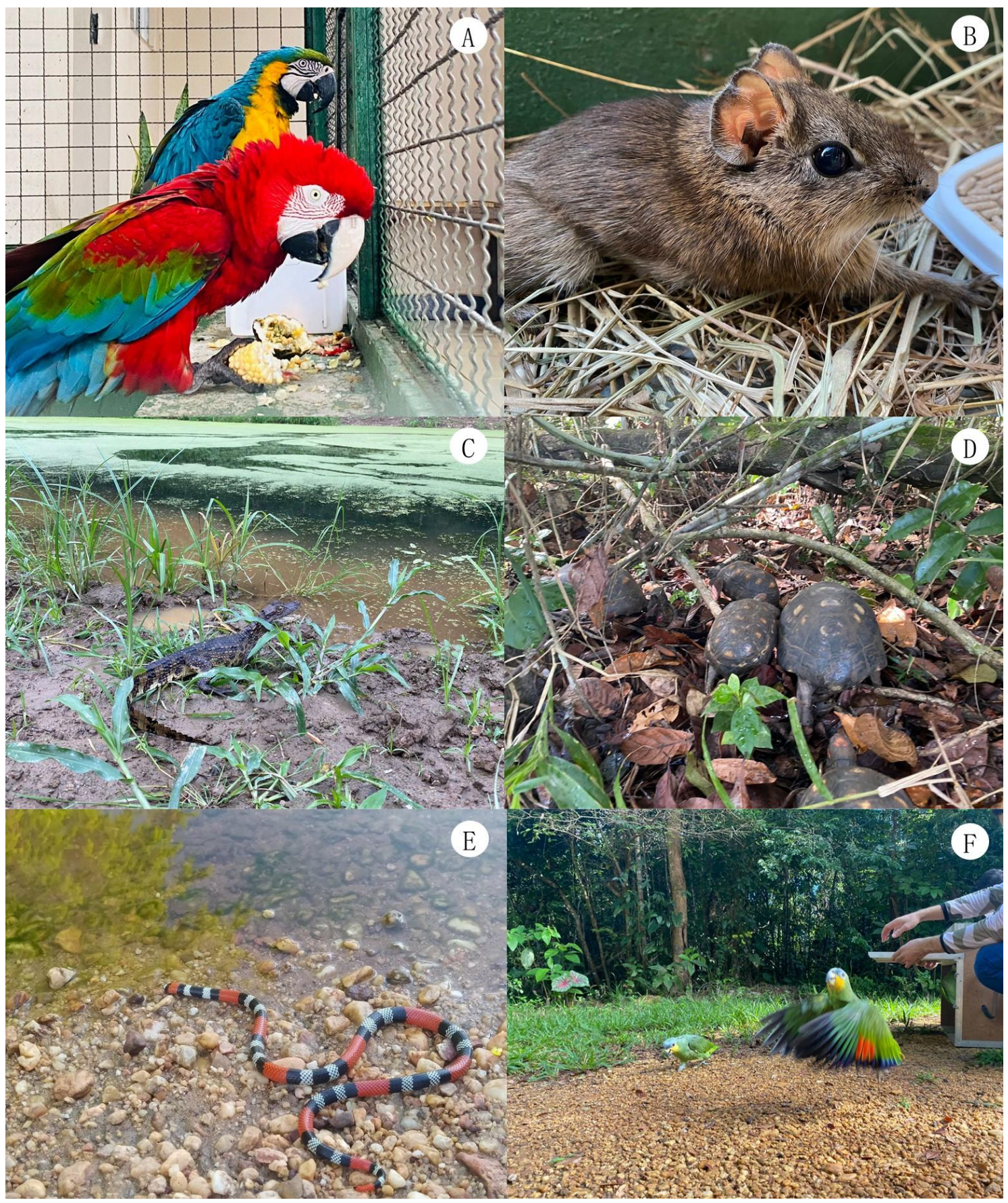

Fonte: Autores, 2021. 


\section{CONCLUSÕES}

Conclui-se que os centros de triagem e reabilitação de animais silvestres desempenham um papel crucial na saúde e bem-estar de centenas de espécies vítimas de ações antrópicas. Além disso, graças aos programas de reintrodução e manejo, as comunidades/populações locais acabam sendo conscientizadas sobre os impactos e prejuízos do tráfico e cativeiro ilegal para fauna silvestre.

\section{REFERÊNCIAS}

BASTOS, L.F. et al. Apreensão de espécimes da fauna silvestre em Goiás - situação e destinação. Revista Biologia Neotropical, v.5, n.2, p.51-63, 2008.

BRASIL- Ministério do Meio Ambiente. Os Centros de Triagem de Animais Silvestres (Cetas). Disponível em:< http://www.ibama.gov.br/fauna-silvestre/cetas/o-que-sao-oscetas $>$ Acesso em 14 de agosto de 2021.

BARRIENTO, C.; DUARTE, S. A conscientização para educação e planejamento de soltura de aves silvestres aplicados à população do bairro do Jardim Cumbica, município de Guarulhos-SP. Revista Monografias Ambientais, v. 6, n. 6, p. 1244-1247, 2012.

BRITO, M. Diagnóstico, Registro e Destinação da Avifauna Recebida no Pró-Arara Centro de Reabilitação de Animais Silvestres, Araras- SP. 2017. 68 f. Dissertação (Mestrado em Conservação da Fauna) - Universidade Federal de São Carlos, São Carlos, 2017.

CALAIS JÚNIOR, A.; MORAIS, G. C.; NUNES, L. C. Intoxicação criminal por carbamato em aves da fauna silvestre. Arquivos de Ciências Veterinárias. Suplemento de 2013, v. 18, n.3, p.459- 461, 2013.

FARIAS, T.C; BELO, R.P; SILVA, S.R; JÚNIOR, P.C. Comércio ilegal de aves silvestres em Feiras Livres da Amazônia: um estudo de caso no Município de Abaetetuba, Pará, Brasil. Biota Amazônia, Macapá, v. 9, n. 4, p. 24-28, 2019.

BRASIL. Instituto Brasileiro do Meio Ambiente e dos Recursos Naturais Renováveis. (IBAMA). Instrução Normativa No 23, 31 de dezembro de 2014. Diário Oficial da União, Brasília, DF, seção 01, n.1 p.115, 02 de janeiro 2015. Disponível em:<https://www.in.gov.br/materia//asset_publisher/Kujrw0TZC2Mb/content/id/3209 4529/do1-2015-01-02-instrucao-normativa-n-23-de-31-de-dezembro-de-2014-32094512> Acessado em: 13 de agosto de 2021.

BRASIL. Instituto Brasileiro do Meio Ambiente e dos Recursos Naturais Renováveis. (IBAMA) Instrução Normativa $\mathrm{N}^{\circ}$ 5, 13 de maio de 2021. Diário Oficial da União, Brasília, DF, Seção 01 - Ed. 187, p. 187, 26 de maio 2021. Disponível em < https://www.in.gov.br/web/dou/-/instrucao-normativa-n-5-de-13-de-maio-de-2021322106813> Acessado em: 15 de agosto de 2021. 
ICMBIO - Instituto Chico Mendes de Conservação da Biodiversidade. Livro Vermelho da Fauna Brasileira Ameaçada de Extinção: Volume 1. $1^{\text {a }}$ ed. 492 p. Brasília, DF: ICMBio/MMA, 2018.

MARINHO FILHO, J.S.; REIS, M.L. Tolypeutes tricinctus Linnaeus 1758. In: Machado, A.B.M. Drummond, G.M. \& Paglia, A.P (eds.). Livro Vermelho da Fauna Brasileira Ameaçada de Extinção, Vol. II. Ministério do Meio Ambiente, Brasília. p. 709-710.2008.

MENDONÇA, R.; AMARAL, A. A. N.; VOLTOLINI, J.C. Recepção, triagem e soltura de psitacídeos no Centro de Triagem de Animais 54 Silvestres (CETAS) IBAMA Lorena, SP. Revista Biociências, v. 26, n. 1, p. 70-79, 2020.

MILANELO, L.; FITORRA, L, S. Centro de Recuperação de Animais Silvestres "Orlando Vilas Boas" - Parque Ecológico do Tietê (CRAS-PET-DAEE). In: IBAMA, Centros de Triagem e Áreas de Soltura de Animais Silvestres no Estado de São Paulo. Revista CETAS e ASMs no Estado de São Paulo - Relatório de Atividades 2012. IBAMA/São Paulo, p.23- 27, 2012.

MORITA, C.H.C. Caracterização da Fauna Recebida e Avaliação dos Procedimentos em Centros de triagem de animais silvestres (CETAS). 2009. 70 f. Trabalho de conclusão de curso (Ecologia). Universidade Estadual Paulista, Instituto de Biociências de Rio Claro, Rio Claro, 2009.

MOURA, S. V. G.; PESSOA, F. B.; OLIVEIRA, F. F.; LUSTOSA, A. H. M.; SOARES, C. B. Animais Silvestres recebidos pelo Centro de Triagem do IBAMA. Enciclopédia Biosfera, Goiânia, v.8, n.15; p. 1748- 1761, 2012.

NASCIMENTO, C. J.; GOMES, B.M.S.; GARCIA, A. D.; NETTO, V.D. COSTA, D.I. JUNGER,R.B. Enxerto de Penas na Asa Direita de um Gavião-Carijó. Ciência Animal, v.28, n.4, p.47-49, 2018. Edição Especial (V CESMEV).

PAGANO, I. S. A.; SOUSA, A.E.B.A. ; WAGNER, P.G.C. ; RAMOS, R.T.C. Aves depositadas no Centro de Triagem de Animais Silvestres do IBAMA na Paraíba: uma amostra do tráfico de aves silvestres no estado. Ornithologia, v.3, n.2, p. 132-144, 2009.

PRIMACK, R. B.; RODRIGUES, E. Biologia da Conservação. 9a ed. Editora Planta. Londrina, 2001.

RENCTAS (REDE NACIONAL DE COMBATE AO TRÁFICO DE ANIMAIS SILVESTRES). $1^{\circ}$ Relatório Nacional sobre o tráfico de fauna silvestre. Brasília: RENCTAS. 108 p. 2001.

RIBEIRO, J.M. Consequências do manejo nutricional e ambiental inadequados para a saúde dos animais selvagens de estimação. 2017.25 f. Trabalho de Especialização (Programa de Aprimoramento Profissional - SES-SP), Universidade Estadual Paulista, Faculdade de Ciências Agrárias e Veterinárias, 2017.

ROCHA, F. M. 1995. Tráfico de animais silvestres no Brasil - Fundo Mundial para a Natureza (WWF). Documento para discussão. 
ROCHA-MENDES, F.; NAPOLI, R. P.; MIKICH, S. B. Manejo, reabilitação e soltura de mamíferos selvagens. Arq. Ciênc. Vet. Zool. Unipar, Umuarama, v. 9, n. 2, p. 105-109, 2006.

SANTOS, S.S. Conhecimento, uso e manejo de Galea spixii (wagler, 1831) e Kerodon rupestris (wied - Neuwied, 1820) no semiárido do Rio Grande do Norte Nordeste do Brasil.2018. 61p. Dissertação (Mestrado em Desenvolvimento e Meio ambiente) Universidade Federal da Paraíba, Paraíba, 2018.

SCANES, C. G. Human activity and habitat loss: Destruction, Fragmentation, and Degradation. Animals ans Human Society, p. 451-482. 2018.

SILVA, N. S. Espécimes recebidos no centro de triagem de animais silvestres de Salvador/BA durante os anos de 2012 a 2014. 2015. p. 47. Trabalho de conclusão de curso. (Graduação em Medicina Veterinária). Escola de Medicina veterinária e zootecnia, Departamento de Anatomia, patologia e clínicas veterinárias, Universidade Federal da Bahia, Salvador, 2015.

VILELA, D. A. R. Diagnóstico de situação dos animais silvestres recebidos nos CETAS brasileiros e Chlamydophila psittaci em papagaios (Amazona aestiva) no CETAS de Belo Horizonte. 2012. 107 f. Tese (Doutorado em Ciência animal). Universidade Federal de Minas Gerais, Escola de veterinária, Belo Horizonte, Minas Gerais, Brasil, 2012.

ZAMBOM, M, L. A. Políticas públicas municipais e gestão de fauna silvestre vitimada pelo comércio ilegal de animais: análise dos municípios paulistas que possuem CETAS e CRAS. 2018. 173 f. Dissertação (Mestrado em Ciências ambientais). Universidade Federal de São Carlos, Campus São Carlos, São Carlos, 2018. 


\section{ATROPELAMENTO DE FAUNA SILVESTRE EM RODOVIAS}

\section{Weslania Souza Inácio da Silva}

Universidade Federal de Sergipe, Núcleo de Medicina Veterinária, Nossa Senhora da Glória - SE ORCID:https://orcid.org/0000-0003-4393-544X

Lattes: http://lattes.cnpq.br/2096023399078864

\section{Igo Gonçalves dos Santos}

Universidade Federal de Sergipe, Núcleo de Medicina Veterinária, Nossa Senhora da Glória - SE Lattes: http://lattes.cnpq.br/3048876638161878

\section{Matheus Resende Oliveira}

Universidade Federal de Sergipe, Núcleo de Medicina Veterinária, Nossa Senhora da Glória - SE Lattes: http://lattes.cnpq.br/3822150058285111

\section{Manuel Benicio Oliveira Neto}

Universidade Federal de Sergipe, Núcleo de Medicina Veterinária, Nossa Senhora da Glória - SE Lattes: http://lattes.cnpq.br/6372287958265880

\section{Camenas Vieira Barata}

Universidade Federal de Sergipe, Núcleo de Medicina Veterinária, Nossa Senhora da Glória - SE Lattes: http://lattes.cnpq.br/3753872871256727

\section{Danilo Santos de Jesus}

Universidade Federal de Sergipe, Núcleo de Medicina Veterinária, Nossa Senhora da Glória - SE Lattes: http://lattes.cnpq.br/0030697599240620

\section{Allan Costa Gomes}

Universidade Federal de Sergipe, Núcleo de Medicina Veterinária, Nossa Senhora da Glória - SE Lattes: http://lattes.cnpq.br/6542226186166115

\section{Lórena Maciel Santos Silva}

Universidade Federal de Sergipe, Núcleo de Medicina Veterinária, Nossa Senhora da Glória - SE Lattes: http://lattes.cnpq.br/0766419381359796

\section{Maria Flaviane Almeida Silva}

Universidade Federal de Sergipe, Núcleo de Medicina Veterinária, Nossa Senhora da Glória - SE Lattes: http:/ / lattes.cnpq.br/7276739267506207

\section{Taynara Alessandra de Matos Santos}

Universidade Federal de Sergipe, Núcleo de Medicina Veterinária, Nossa Senhora da Glória - SE Lattes: http://lattes.cnpq.br/4807858146979413

\section{Victor Fernando Santana Lima}

Universidade Federal de Sergipe, Núcleo de Medicina Veterinária, Nossa Senhora da Glória - SE Lattes: http://lattes.cnpq.br/7265386741392623 


\begin{tabular}{|c|c|}
\hline $\begin{array}{l}\text { Informações sobre o } \\
\text { artigo: } \\
\text { Recebido em: } \\
\text { 10/09/2021 } \\
\text { Aceito em: } \\
\text { 13/09/2021 } \\
\text { Data de publicação: } \\
\text { 19/10/2021 } \\
\text { Palavras-chave: } \\
\text { Animais Silvestres } \\
\text { Ação Antrópica } \\
\text { Nordeste } \\
\text { Óbitos }\end{array}$ & $\begin{array}{l}\text { RESUMO } \\
\text { Atualmente os atropelamentos de animais silvestres em rodovias } \\
\text { brasileiras têm tornado-se frequente em diferentes localidades e } \\
\text { regiões do país. Uma vez que essas ações podem provocar } \\
\text { impactos em populações de animais, o trabalho a seguir, demonstra } \\
\text { essa problemática através da exposição de dados obtidos por meio } \\
\text { de um levantamento de espécies da fauna silvestre vertebrada } \\
\text { atropelada em trechos na rodovia BR-175, no estado de Sergipe, } \\
\text { Nordeste do Brasil. Ao final do estudo foram registrados } 110 \\
\text { animais silvestres vítimas de atropelamento, distribuídas em } 17 \\
\text { espécies, entre mamíferos ( } 47,06 \% \text { ), aves ( } 29,41 \%) \text { e répteis } \\
\text { (23,53\%). O espécime com o maior registro de óbitos por } \\
\text { atropelamento foi o cachorro-do-mato (Cerdocyon thous; } 36,36 \%) \text {, } \\
\text { provavelmente pelo fato de se locomover em busca de alimentos e } \\
\text { parceiros. Sendo de suma importância a implementação de } \\
\text { estratégias para a prevenção de mais atropelamentos da fauna } \\
\text { silvestres nativa. }\end{array}$ \\
\hline $\begin{array}{l}\text { Keywords: } \\
\text { Wild Animals } \\
\text { Anthropic Action } \\
\text { Northeast } \\
\text { Deaths }\end{array}$ & $\begin{array}{l}\text { RULING OF SILVESTRE FAUNA ON HIGHWAYS } \\
\text { ABSTRACT } \\
\text { Currently, the running over of wild animals on Brazilian highways } \\
\text { has become frequent in different locations and regions of the } \\
\text { country. Since these actions can cause impacts on animal } \\
\text { populations, the work below demonstrates this problem through } \\
\text { the exposure of data obtained through a survey of vertebrate } \\
\text { wildlife species run over in stretches of the BR-175 highway, in the } \\
\text { state of Sergipe, Northeast of Brazil. At the end of the study, } 110 \\
\text { wild animals victims of roadkill were registered, distributed in } 17 \\
\text { species, including mammals ( } 47.06 \%) \text {, birds ( } 29.41 \% \text { ) and reptiles } \\
\text { ( } 23.53 \% \text { ). The specimen with the highest number of deaths from } \\
\text { being run over was the crab-eating fox (Cerdocyon thous; } 36.36 \%) \text {, } \\
\text { probably due to the fact that they move in search of food and } \\
\text { partners. It is of paramount importance to implement strategies to } \\
\text { prevent further trampling of native wild fauna. }\end{array}$ \\
\hline
\end{tabular}

\section{INTRODUÇÃO}

Desde os primórdios, humanos e animais coabitam e interagem no mesmo ambiente (SILVIUS et al., 2004). Diante disso, esse tipo de interação é favorável para os humanos, uma vez que mantêm relações com os recursos faunísticos, mas por outro lado, vem procando grandes impactos nas populações de animais silvestres (KALTENBORN et 
al., 2006). Alguns países a exemplo do Brasil, possui uma das maiores biodiversidades do mundo, com mais de 8930 espécies vertebrados dentre, aves, répteis, mamíferos e anfíbios, no qual vem sofrendo perdas ecológicas, devido ao crescimento de cidades, rodovias e rotas públicas (ZANINI, 2000; PEREIRA et al., 2006; NASCIMENTO e CAMPOS, 2011).

Não é novidade que as construções de rodovias dispõem de um papel econômico importante no país, através da mesma, realiza-se o tráfego de produtos e insumos, além de transportar animais e humanos, facilitando o acesso a serviços básicos de saúde (PERZ et al., 2008).

Devido a expansão rodoviária, houve modificações no paisagismo nativo, ocasionando assim, mudanças nos aspectos ambientais e da fauna local (SIMONETTI, 2010; VAN DER REE et al., 2015). Expondo os animais a fatores de risco, por meio da delimitação de alimentos e deslocamento das espécies, aumentando os índices de atropelamentos. Por isso, muitos estudos têm destacado o aumento de colisões entre veículos e animais (FORMAN et al., 2003; VAN DER REE et al., 2011).

Segundo algumas pesquisas conservacionistas, no Brasil, estima-se que 14,7 milhões de vertebrados são atropelados anualmente, variando conforme às estações do ano (ROE et al., 2006; SANTOS et al., 2012; DORNAS et al., 2012).

O levantamento e a identificação da fauna silvestre atropelada em diversas regiões do Brasil é fundamental para definir medidas eficientes (DEFFACI et al., 2016). Devido a essa importância, o presente estudo, verifica a incidência de atropelamento de fauna silvestre vertebrada em trechos na rodovia BR-175, em Sergipe.

\section{METODOLOGIA}

O estudo foi realizado ao longo da BR-175, rodovia brasileira que interliga os municípios de Nossa Senhora da Glória e Nossa Senhora Aparecida, situada na transição entre o Agreste e Sertão do estado de Sergipe, Brasil. O trecho estudado possui cerca de 31 Km, na extensão do percurso da BR-175, sendo banhados pelos Rios Sergipe e Campanha.

Os registros dos atropelamentos da fauna silvestre foram realizados aos domingos, no periodo que compreende fevereiro a julho de 2021, entre 7 h às 9 horas da manhã, segundo Moreira et. al. (2006), os atropelamentos ocorrem principalmente no período noturno, portanto, no horário do referido estudo as carcaças ainda permaneceriam na rodovia, totalizando 44 horas de monitoramento. Porém, nem todos os atropelamentos 
foram registrados, pois muitos dados são interferidos pelo fato de alguns animais detritívoros ingerirem animais vítimas de atropelamento, levando-os para outras áreas inacessíveis, sem deixar rastros das carcaças (DORNAS et al., 2012).

Com isso, quando um animal silvestre atropelado era encontrado, realizava-se a parada do automóvel, seguindo algumas etapas e preenchimento de alguns dados, tais como: data, horário, espécie, clima, localização do trecho e registro fotográfico.

Durante o período que compreende a pesquisa, os registros obtidos foram tabulados em planilhas de Microsoft Excele posterior agrupamento conforme a individualidade dos espécimes, classificando-os em diferentes grupos: mamíferos, anfíbios, aves e répteis, em seguida, realizou-se a análise estatística, no qual calcula-se a taxa média de animais atropelados e os grupos de vertebrados (TURCI e BERNARDE, 2009). Todos os dados foram analisados utilizando o software InStat (GraphPad Software), com nível de significância estabelecido de $p<0,05$.

\section{RESULTADOS E DISCUSSÃO}

Em nosso estudo, 110 animais silvestres foram vítimas de atropelamento no trecho de rodovia, sendo catalogado 17 espécies distribuídas entre três grupos: mamíferos (47,06\%), aves $(29,41 \%)$ e répteis $(23,53 \%)$ (Figura 01$)$.

No táxon dos mamíferos, as espécies identificadas foram Cerdocyon thous (36,36\%), Didelphis albiventris (16,36\%), Galictis cuja (2,73\%), Galea spixii (2,73\%), Procyon cancrivorus (0,91\%), Puma yagouaroundi (0,91\%), Tamandua tetradactyla (2,73\%) e Thrichomys apereoides $(2,73 \%)$. Ao longo do trecho estudado, foi observado a presença de mamíferos de médio e pequeno porte atropelados em locais próximos a áreas de rios e fragmentos de matas, conforme pode ser observado nas figuras 02 e 03. 
Figura 01 - Animais silvestres vítimas de atropelamentos em rodovias. Nota-se em A Tamandua tetradactyla, B - Puma yagouaroundi, C - Galea spixii, D - Didelphis albiventris, E Athene cunicularia e $\mathbf{F}$ - Boa constrictor.
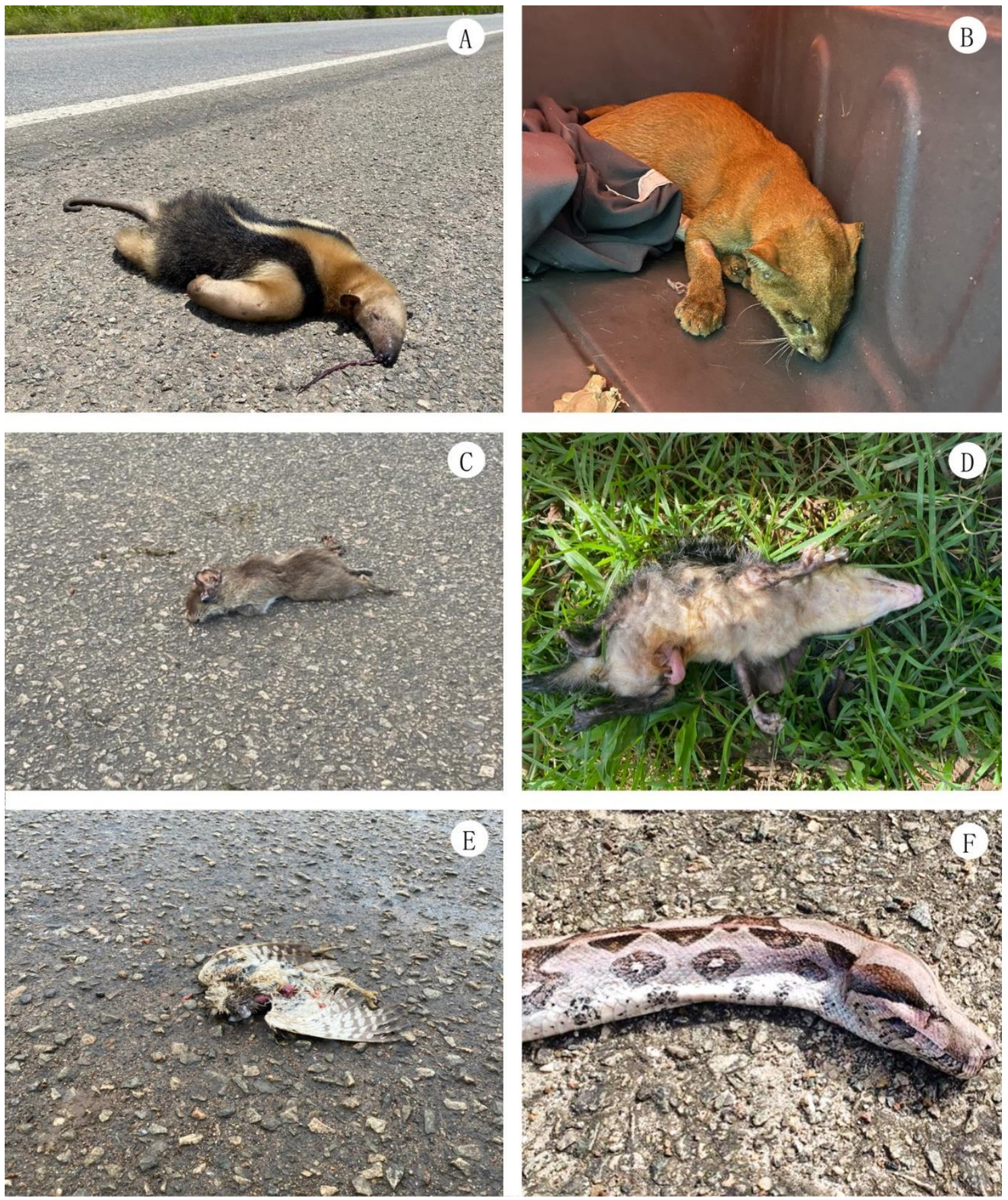

Fonte: Autores, 2021. 
Figura 02 - Mapa do trecho da BR-175 entre os municípios de Nossa Senhora da Glória e Nossa Senhora Aparecida, Sergipe, demonstrando áreas de atropelamento de animais silvestres vertebrados, no ponto georreferenciado do Rio Sergipe. Nota-se em branco tamandúas (Tamandua tetradactyla); vermelho cachorros-do-mato (Cerdocyon thous) e em amarelo gambá-de-orelha-branca (Didelphis albiventris)

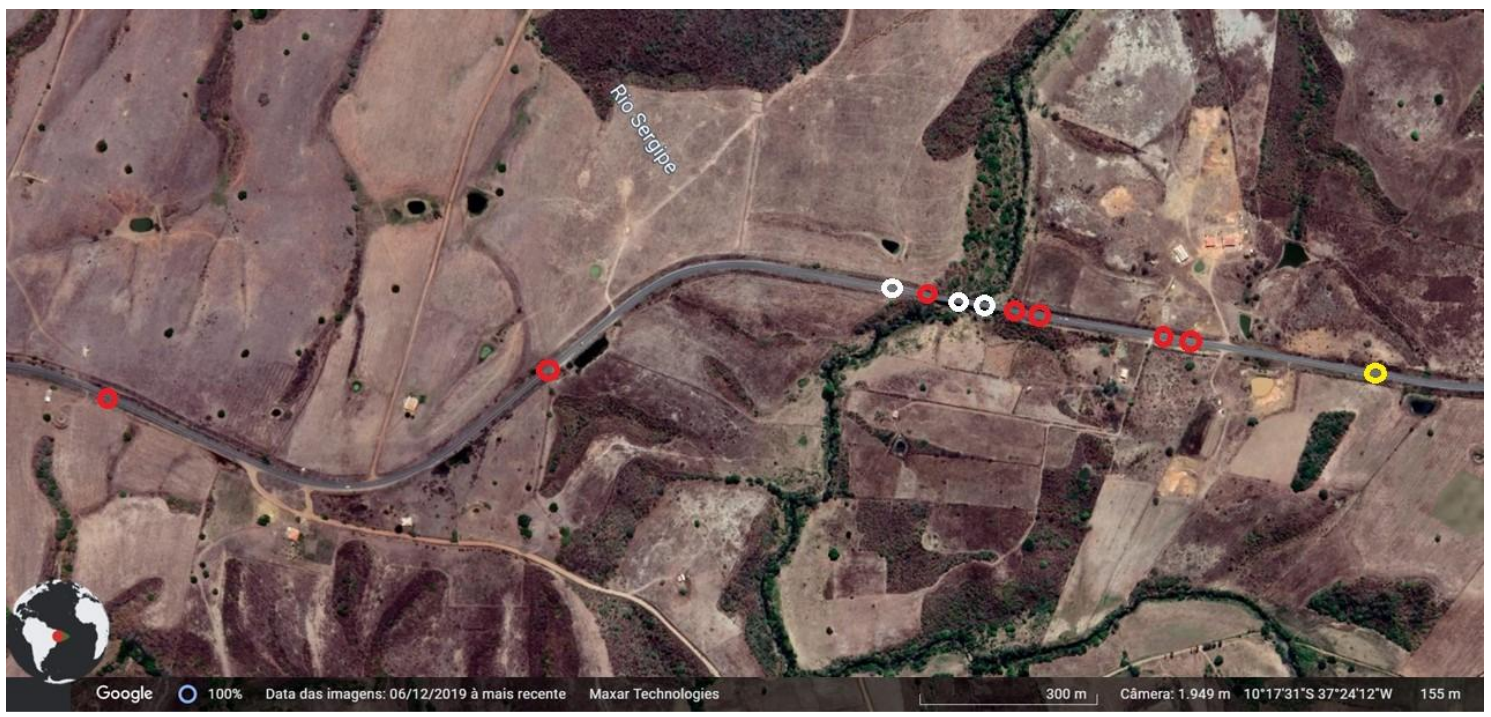

Fonte: Autores, 2021. Adaptado do Google Earth (2021).

Figura 03 - Mapa demonstrando áreas de atropelamento de animais silvestres vertebrados, no ponto georreferenciado do açude público de Nossa Senhora da Glória-SE. Nota-se em vermelho cachorros-do-mato (C. thous), em amarelo gambá-de-orelha-branca (D. albiventris), azul tiziu (Volatinia jacarina) e verde Jiboia-constritora (Boa constrictor)

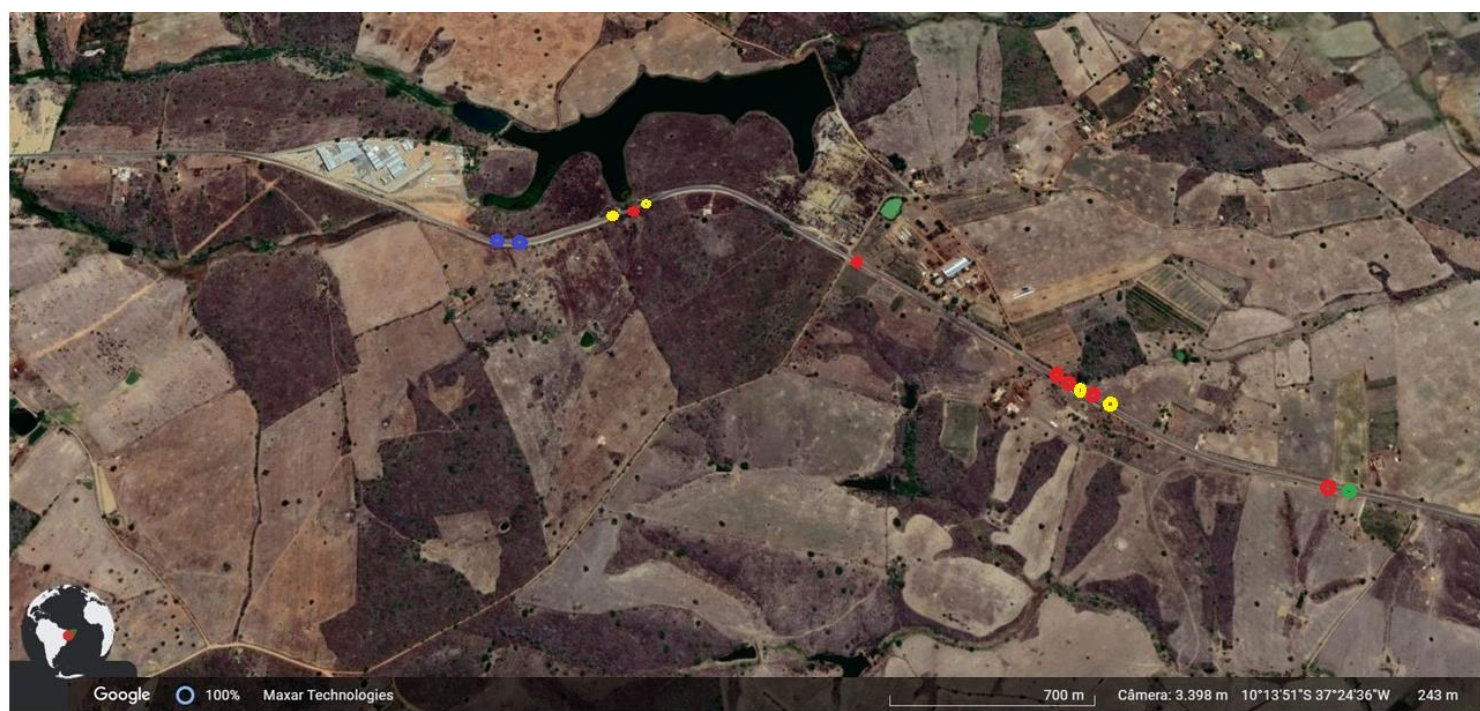

Fonte: Autores, 2021. Adaptado do Google Earth (2021). 
Segundo BRUM et al., (2011) a presença de rios na área do estudo, e a alta temperatura em dias secos aumentam os riscos de atropelamentos, no qual os animais acabam procurando fonte de água, e consequentemente são vítimas de atropelamentos. Além disso, os estudos realizados por (GUMIER e SPERBER, 2009; TURCI e BERNARDE, 2009) são semelhantes com os resultados do presente estudo, no qual os cachorros-do-mato (Cerdocyon thous), apresentam os maiores índices de atropelamentos, este fato pode ser explicado, devido ao ato de se locomoverem frequentemente em busca de alimentos, por possuirem porte médio, e pelas buscas excessivas por parceiros (TEIXEIRA et al., 2013).

No grupo das aves, foram catalogadas cinco espécies: Urubu-de-cabeça-preta (Coragyps atratus; 4,55\%), Coruja-buraqueira (Athene cunicularia; 1,82\%), Tiziu (Volatinia jacarina; 6,39\%), Carcará (Caracara plancus; 4,55\%) e Anu-preto (Crotophaga ani; 2,73\%). As aves são atraídas para as rodovias devido a disponibilidade de arbustos nos acostamentos das estradas, e pela procura de alimentos nas rodovias (LIMA e OBARA, 2004).

Segundo as pesquisas realizadas por Clevenger et al., (2003) e Prada (2004) os voos rasos são um dos fatores predisponente que expõem as aves a colidirem com os veículos. Além disso, seus hábitos alimentares colocam-os em risco de atropelamento, por exemplo, os urubus (Coragyps atratus) e os carcarás (Caracara plancus) que são detritívos e consomem os cadáveres de animais nas rodovias (FISCHER, 1997).

Já no grupo dos répteis as espécies: Cobra-corredeira (Philodryas nattereri; 5,45\%), Jiboia-constritora (Boa constrictor, 0,91\%); Iguana-verde (Iguana iguana, 2,73\%) e cobra-cipó (Chironius sp.; 5,45\%) os índices de atropelamentos desses espécimes estão associados ao fato de serem animais ectotérmicos, no qual utilizam as estradas ou rios para realizar a regulação térmica (LIMA e OBARA, 2004).

\section{CONCLUSÕES}

Os resultados desse estudo demonstram que diversos grupos de animais silvestres, principalmente os mamíferos, estão sendo atropelamentos em áreas de rodovias que ligam o Agreste e Sertão de Sergipe. Sendo de suma importância a implementação de estratégias para a prevenção de mais atropelamentos da fauna silvestres nativa, tais como: instalação, construção de passagens, barreiras, e cercas ao longo dos trechos. 


\section{REFERÊNCIAS}

BRUM, T. R. et al. Comparações de mortalidade de mamíferos atropelados em rodovias em área antropizada (MT-358) e Terra Indígena Paresi (MT-235). Anais do Road Ecology, Brasil, p. 173-174, 2011.

CLEVENGER, A. P.; CHRUSZCZ, B.; GUNSON; K. E. Spatial Patterns and Factors Influencing Small Vertebrate Fauna Road-Kill Aggregations. Biological Conservation, v. 109, p.15-26, 2003.

DEFFACI, A. G.; SILVA, V. P.; HARTMANN, M. T. et al. Diversidade de aves, mamíferos e répteis atropelados em região de floresta subtropical no sul do Brasil. Ciência e Natura, Rio Grande do Sul, v. 38, n. 3, p.1205 - 1216, 2016.

DORNAS, R. A. P.; KINDEL, A.; BAGER, A.; FREITAS, S. R. Avaliação da mortalidade de vertebrados em rodovias no Brasil. In: Bager, A. (Ed.). Ecologia de Estradas: tendências e pesquisas. Lavras: Ed. UFLA, p.139-152, 2012.

FISHER, W. Efeitos da BR-262 na mortalidade de vertebrados silvestres: síntese naturalística para conservação da região do Pantanal, MS. 1997. Dissertação Mestrado. Universidade Federal do Mato Grosso do Sul, Campo Grande, MS, 1997.

FORMAN, R. T. T. Road ecology: science and solutions. Washington: Island Press, p. 481, 2003.

GUMIER, F. C.; SPERBER, C. F. Atropelamentos de vertebrados na Floresta Nacional de Carajás, Pará, Brasil. Acta Amazonica, n. 39, p. 459-466, 2009.

KALTENBORN, T.; BJERKE, B. T. \& NYAHONGO, J. Living with problem animals selfreported fear of potentially dangerous species in the Serengeti region, Tanzania. Human Dimensions of Wildlife, v. 11, p. 397-409, 2006.

LIMA, S, F.; OBARA, A, T. Levantamento de animais silvestres atropelados na BR-277 às margens do parque nacional do Iguaçu: subsídios ao programa multidisciplinar de proteção à fauna. Fauna nativa. 2004.

MOREIRA, F. G. A.; SILVA, S. S.; CUNHA, H. F.. Impacto do atropelamento de animais silvestres na rodovia GO 060, Trecho Goiânia - Iporá. Xlll Seminário de Iniciação Científica, Goiânia: UFG, 2005.

NASCIMENTO, L. J.; CAMPOS, I. B. Atlas da fauna brasileira ameaçada de extinção em unidades de conservação federais, Brasília: Instituto Chico Mendes de Conservação da Biodiversidade, ICMBIO, p. 276, 2011.

PEREIRA, A. P. F. G.; ANDRADE, F. A. G.; FERNANDES, M. E. B. Dois Anos de monitoramento dos atropelamentos de mamíferos na rodovia PA-458, Bragança, Pará. Ciências Naturais, Belém, v.1, n. 3, p. 77-83, set-dez, 2006. 
PERZ, S. G., WARREN, J. W., DAVID P. \& KENNEDY, D. P. Contributions of racialethnic reclassification and demographic processes to indigenous population resurgence: the case of Brazil. Latin American Research Review, v.42, n.3, p. 7-33, 2008.

PRADA, Cristiana de Santis. Atropelamento de vertebrados silvestres em uma região fragmentada do nordeste do estado de São Paulo: quantificação do impacto e análise de fatores envolvidos. 2004. p. 147 Dissertação (Mestrado em Ciências Biológicas) Universidade Federal de São Carlos, São Carlos, 2004.

ROE, J. H., GIBSON, J., KINGSBURY, B.A. Beyond the wetland border: estimating the impact of roads for two species of water snakes. Biological Conservation, v. 130, p. 161168, 2006.

SANTOS, A. L. P. G.; ROSA, C. A.; BAGER, A..Variação sazonal da fauna selvagem atropelada na rodovia MG 354, Sul de Minas Gerais - Brasil. Universidade Federal de Lavras, Biotemas, v. 25, n.1, p. 73-79, mar. 2012.

SILVIUS, K. M.; BODMER, R. E. \& FRAGOSO, J. M. V. People in Nature: wildlife conservation in South and Central America. Columbia University Press, New York, 2004.

SIMONETTI, H. Estudo de impactos ambientais gerados pelas rodovias: sistematização do processo ded elaboração de EIA/RIMA. Trabalho de diplomação apresentado ao Dept. de Engenharia Civil da UFRGS para obtenção do título de engenheiro civil, 2010.

TEIXEIRA, FERNANDA ZIMMERMANN et al. Vertebrate road mortality estimates: effects of sampling methods and carcass removal. Biological Conservation, v. 157, p. $317-$ 323, 2013.

TURCI, L. C. B. \& BERNARDE, P. S. Vertebrados atropelados na rodovia estadual $383 \mathrm{em}$ Rondônia, Brasil. Biotemas, v. 22, p. 121 - 127, 2009.

VAN DER REE, R.; SMITH, D. J.; GRILO, C. Handbook of Road Ecology. Chichester: John Wiley \& Sons, p. 522, 2015.

ZANINI, A. C. S. Fauna Silvestre. Lavras: UFLA/FAEPE, P. 80, 2000. 


\section{Capítulo 11}

\section{ENXERTIA CUTÂNEA EM CROCODILIANO}

\section{Igo Gonçalves dos Santos}

Universidade Federal de Sergipe, Núcleo de Medicina Veterinária, Nossa Senhora da Glória - SE ORCID: https://orcid.org/0000-0003-2318-8053

Lattes: http://lattes.cnpq.br/3048876638161878

\section{Weslania Souza Inacio da Silva}

Universidade Federal de Sergipe, Núcleo de Medicina Veterinária, Nossa Senhora da Glória - SE Lattes: http://lattes.cnpq.br/2096023399078864

\section{Allan Costa Gomes}

Universidade Federal de Sergipe, Núcleo de Medicina Veterinária, Nossa Senhora da Glória - SE Lattes: http://lattes.cnpq.br/6542226186166115

\section{Camenas Vieira Barata}

Universidade Federal de Sergipe, Núcleo de Medicina Veterinária, Nossa Senhora da Glória - SE Lattes: http://lattes.cnpq.br/3753872871256727

\section{Danilo Santos de Jesus}

Universidade Federal de Sergipe, Núcleo de Medicina Veterinária, Nossa Senhora da Glória - SE Lattes: http://lattes.cnpq.br/0030697599240620

\section{Manuel Benicio Oliveira Neto}

Universidade Federal de Sergipe, Núcleo de Medicina Veterinária, Nossa Senhora da Glória - SE Lattes: http:/ / lattes.cnpq.br/6372287958265880

\section{Lórena Maciel Santos Silva}

Universidade Federal de Sergipe, Núcleo de Medicina Veterinária, Nossa Senhora da Glória - SE Lattes: http://lattes.cnpq.br/0766419381359796

\section{Maria Flaviane Almeida Silva}

Universidade Federal de Sergipe, Núcleo de Medicina Veterinária, Nossa Senhora da Glória - SE Lattes: http://lattes.cnpq.br/7276739267506207

\section{Matheus Resende Oliveira}

Universidade Federal de Sergipe, Núcleo de Medicina Veterinária, Nossa Senhora da Glória - SE Lattes: http://lattes.cnpq.br/3822150058285111

\section{Taynara Alessandra de Matos Santos}

Universidade Federal de Sergipe, Núcleo de Medicina Veterinária, Nossa Senhora da Glória - SE Lattes: http://lattes.cnpq.br/4807858146979413

\section{Aline Monteiro Silveira}

Faculdade Pio Décimo, Departamento de Medicina Veterinária, Aracaju - SE Lattes: http://lattes.cnpq.br/8435735980526988

\section{Victor Fernando Santana Lima}

Universidade Federal de Sergipe, Núcleo de Medicina Veterinária, Nossa Senhora da Glória - SE Lattes: http:/ / lattes.cnpq.br/7265386741392623 


\begin{tabular}{|c|c|}
\hline Informações sobre o & RESUMO \\
\hline $\begin{array}{l}\text { Palavras-chave: } \\
\text { Pele-de-tilápia } \\
\text { Crocodiliano } \\
\text { Medicina reconstrutiva } \\
\text { Enxertia cutânea }\end{array}$ & $\begin{array}{l}\text { Há muitos anos surgiram os primeiros enxertos de pele utilizados } \\
\text { na medicina como curativo biológico, desde o século IXX até os } \\
\text { dias atuais, grandes conquistas ocorreram devido a sua utilização } \\
\text { em casos de feridas por queimaduras. Atualmente, na medicina } \\
\text { veterinária a pele de tilápia-do-Nilo tem sido utilizada como } \\
\text { enxerto biológico para o tratamento de animais vítimas de } \\
\text { queimadura, por proporcionar proteção, rápida epitelização, } \\
\text { diminuir o tempo de cura e promover alívio da dor. Em animais } \\
\text { silvestres, o enxerto tem demonstrado excelentes resultados na } \\
\text { recuperação de pacientes vítimas de queimadura, além de oferecer } \\
\text { um prognóstico favorável e diminuir riscos de morte em cativeiro. } \\
\text { Nos répteis a cirurgia em tegumento é indicada para o tratamento } \\
\text { de feridas, abcessos e a remoção de massas neoplásicas. Diante } \\
\text { disso, o nosso trabalho apresenta uma alternativa biológica usando } \\
\text { a pele de tilápia-do-Nilo como curativo de ferida cirúrgica em } \\
\text { répteis, após procedimentos de remoção de neoformação. Para } \\
\text { esse estudo, foram obtidos fragmentos de pele de tilápia o qual } \\
\text { passaram por processos de limpeza, recorte e esterilização, seguido } \\
\text { de aplicação em um Jacaré-de-papo-amarelo. Previamente, o } \\
\text { animal foi submetido a mensuração da neoformação na base da } \\
\text { cauda para o recorte ideal do enxerto a ser implantado. Logo após } \\
\text { a excerese, a massa foi acondicionada e encaminhada para exame } \\
\text { anatomopatológico. Devido a similaridade fisiológica de pele de } \\
\text { ambos animais, o enxerto biológico demonstrou ser uma excelente } \\
\text { alternativa para auxiliar na cicatrização da ferida cirúrgica, não } \\
\text { necessitando da troca diária de curativo, acelerando o processo de } \\
\text { cicatrização, formação do tecido de granulação e a diminuição do } \\
\text { tempo em cativeiro. Nesse trabalho conclui-se que a enxertia de } \\
\text { tilápia-do-Nilo é uma alternativa para o tratamento de crocodiliano } \\
\text { após remoção de massa cutânea. }\end{array}$ \\
\hline
\end{tabular}

SKIN GRAFT IN CROCODILIAN

\section{ABSTRACT}

The first skin grafts used in medicine as a biological dressing appeared many years ago, from the 19th century to the present day, great achievements occurred due to its use in cases of burn wounds. Currently, in veterinary medicine, Nile tilapia skin has been used as a biological graft for the treatment of animals suffering from burns, as it provides protection, rapid epithelialization, reduces healing time and promotes pain relief. In wild animals, grafting has shown excellent results in the recovery of burn victims, in addition to offering a favorable prognosis and reducing the risk of death in captivity. In reptiles, tegument surgery is indicated for the treatment of wounds, abscesses and the removal of neoplastic masses. Therefore, our work presents a 
Keywords:

Tilapia skin

Crocodilian

Reconstructive

medicine

Skin grafting biological alternative using Nile tilapia skin as a surgical wound dressing in reptiles, after neoformation removal procedures. For this study, tilapia skin fragments were obtained, which underwent cleaning, trimming and sterilization processes, followed by application to an alligator-growing-yellow alligator. Previously, the animal was submitted to measurement of neoformation at the base of the tail for the ideal cut of the graft to be implanted. Soon after exceresis, the mass was packaged and sent for anatomopathological examination. Due to the physiological similarity of the skin of both animals, the biological graft proved to be an excellent alternative to aid in the healing of the surgical wound, not requiring a daily dressing change, allowing for a fast healing process, formation of granulation tissue and reduction of time in captivity. In this work, it is concluded that Nile tilapia grafting is an alternative for the treatment of crocodilian after skin mass removal.

\section{INTRODUÇÃO}

Por volta de 3500 anos, surgiram os primeiros enxertos de pele utilizados, até então, na medicina contemporânea e, diante disso, grandes conquistas ocorreram durante o século IXX e XX após a utilização em casos de queimaduras de pele, tornando-se padrão ouro para essa apresentação clínica (KOHLHAUSER et al., 2021; OZHATHIL et al., 2021). Recentemente o enxerto de pele tem sido uma das técnicas reconstrutivas utilizadas por cirurgiões plásticos como alternativa biológica para auxiliar na cicatrização de feridas em pacientes humanos e em animais (SHIMIZU-HAYASHI e KISHI, 2012; IBRAHIM et al., 2020).

Atualmente, a pele-de-tilápia-do-Nilo (Oreochromis niloticus) é cada vez mais utilizada como enxerto biológico que contribui na recuperação de animais vítimas de queimaduras, por promover rápida epitelização de forma eficiente, além de diminuir o tempo de cura, promover o alívio da dor e proteger as estruturas dérmicas e tecidos adjacentes contra microrganismos (TOGNETTI et al., 2017; PASSINI e AIUB, 2019). Composta de ômega 3 e colágeno, esta apresenta características histológicas semelhantes a pele de outras espécies, e tem sido considerado como o xenoenxerto de escolha para auxiliar no tratamento de queimaduras e na cicatrização de feridas cirúrgicas (LIMA-JUNIOR et al., 2017; MACHADO et al., 2021).

$\mathrm{Na}$ medicina de silvestres, o enxerto de pele-de-tilápia tem demonstrado excelente alternativa que auxiliar na recuperação de animais silvestres e exóticos vítimas de queimaduras, pois reduz o tempo de animais selvagens em cativeiro, diminuindo os riscos de 
mortes e proporciona um prognóstico favorável, assim como o animal do presente estudo (GONZÁLEZ e MAYER, 2019; PASSINI e AIUB, 2019).

Em répteis, devido as particularidades anatômicas da pele por ser composta de escamas epidérmicas e dérmicas, a cirurgia é indicada para o tratamento de feridas, abcessos cutâneos, subcutâneos e remoção de neoplasias (DI GIROLAMO e MANS, 2016; RUTLAND et al., 2019). Tendo como função a proteção contra patógenos externos, retenção e perda de fluidos corporais, a pele é um órgão fundamental nessas espécies (LONG, 2016). Dessa forma, pensando na função exercida pelo tegumento nesses animais, o nosso trabalho apresenta uma alternativa biológica para o tratamento de ferida cirúrgica utilizando pele de tilápia-do-Nilo como curativo em répteis, após excerese de neoformação na base da calda.

\section{METODOLOGIA}

Para esse estudo foram utilizadas peles de tilápia-do-Nilo (O. niloticus), as quais foram obtidos fragmentos de $10 \mathrm{~cm}$ de largura X $27 \mathrm{~cm}$ de comprimento fornecidos por um abatedouro frigorífico, passando então por um processo rigoroso de esterilização para aplicação no animal.

Esse material foi preparado seguindo os protocolos descritos por LIMA-JUNIOR et al., 2017, que consistem em: 1) remoção das escamas utilizando alicate de bico fino; 2) lavagem da pele em água corrente para remoção de sangue e sujidades; 3) remoção do excesso de musculatura utilizando lâmina de bisturi (nº 23); 4) reidratação e resfriamento em solução salina $(\mathrm{NaCl} 0,9 \%)$ estéril a $4^{\circ} \mathrm{C}$. Em seguida a pele de tilápia passou por dois processos de esterilização em solução de gluconato de clorexidrina à $20 \%$, duas lavagens em solução $\mathrm{NaCl}$ $0,9 \%$ e por fim foram depositadas em um recipiente hermético e refrigerado por 24 horas sobre imersão na solução $\mathrm{NaCl}$ 0,9\%.

Nesse estudo, o enxerto biológico de pele de tilápia-do-Nilo, foi utilizada em um jacaré-de-papo-amarelo (Caiman latirostris), macho de 12 anos de idade, pesando 12,3 kg, medindo $132 \mathrm{~cm}$, apresentando uma neoformação na base da cauda.

Previamente a implantação da pele, o animal foi submetido a mensuração da neoformação para a escolha do tamanho ideal do enxerto a ser implantado (Figura 1, $A$ e $B$ ). Em seguida, foi aplicado a anestesia dissociativa no animal, seguindo de assepsia da neoformação e posterior excisão da estrutura. 
Após a remoção da massa, a neoformação foi depositada em formol a $10 \%$ e encaminhada ao laboratório para realizar o exame anatomopatológico. Devido o espaço de pele removida no procedimento, optou-se pela utilização do enxerto biológico de tilápia no animal (Figura 1, C). A pele foi fixada sobre a musculatura com auxílio do cianoacrilato e após o final do procedimento, foi utilizado a bandagem Vetrap sobre o enxerto de pele para aderir sobre a ferida cirúrgica (Figura 1, D e E). Após o procedimento o animal ficou em observação, o qual foi monitorado até a sua completa recuperação.

Figura 1 - Aplicação da pele de tilápia-do-Nilo (O. niloticus) em crocodiliano. A - Observase a mensuração da neoformação. B - Observa-se a massa tumoral excisada. C - Observase o enxerto sobre o animal. D - Observa-se a fixação da pele sobre a ferida cirúrgica. E -

Observa-se a bandagem Vetrap sobre o enxerto biológico. F - Microscopia de lipoma infiltrativo, observa-se proliferação neoplásica de adipócitos com infiltração ao tecido muscular adjacente.
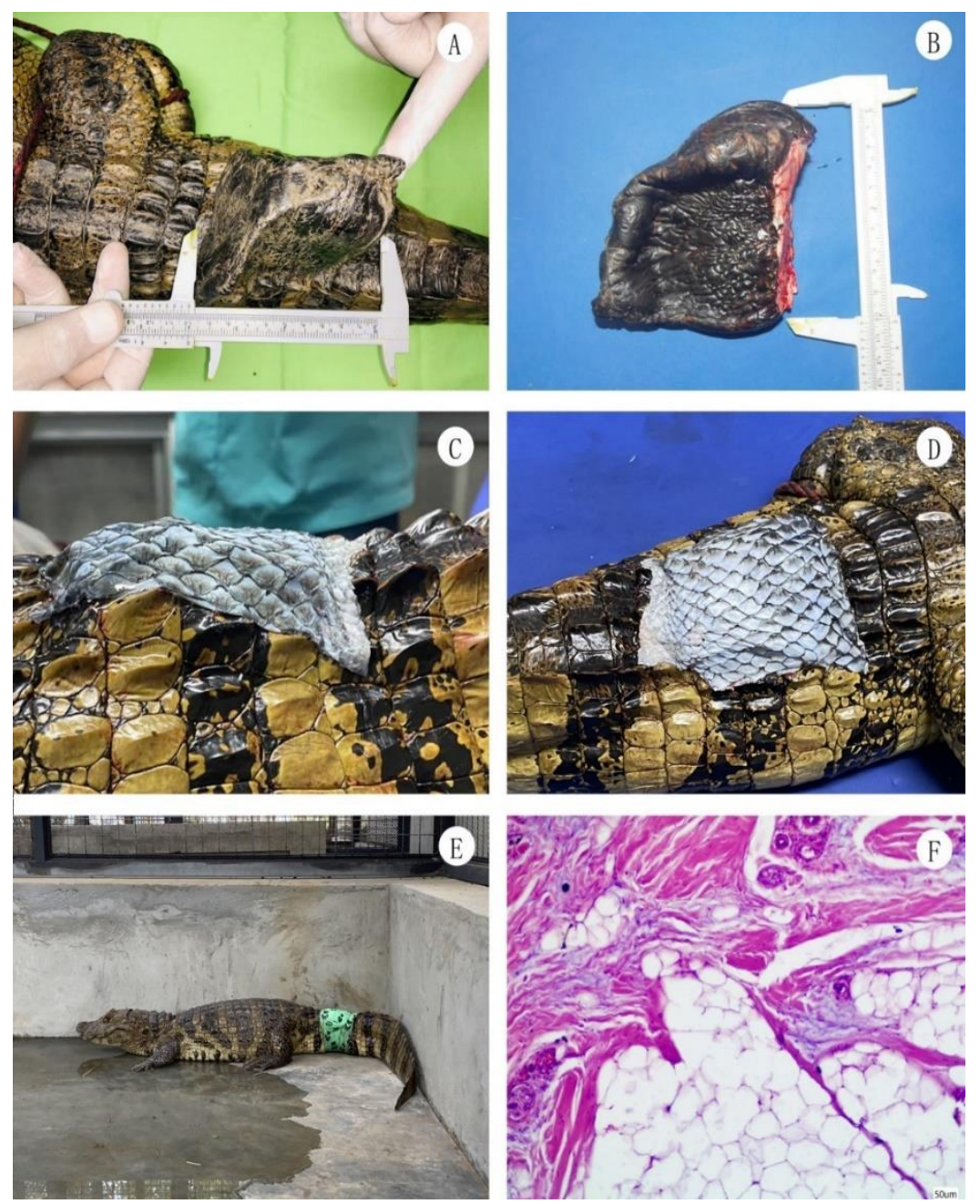

Fonte: Autores, 2021. 


\section{RESULTADOS E DISCUSSÃO}

Em nosso estudo, foram utilizadas a pele de tilápia-do-Nilo (O. niloticus) como enxerto biológico em um exemplar de crocodiliano, Jacaré-de-papo-amarelo (Caiman latirostris), após a remoção cirúrgica de uma neoformação. Essa técnica tem sido aplicada como curativo biológico que auxilia na recuperação de pacientes animais e humanos vítimas de queimadura, por prevenir perdas de fluidos corporais, evitar contaminação microbiana e promover rápida epitelização e formação de tecido de granulação (LONG, 2016; MIRANDA, 2018).

Devido à similaridade fisiológica da pele de tilápia com a de outras espécies, esta, microscopicamente, possui fibras de colágeno organizadas e diferentes tipos de queratina que promovem resistência mecânica contra mecanismos físicos e biológicos (ALVES et al., 2015; DUBANSKY e CLOSE, 2018; RUTLAND et al., 2019; NASCIMENTO et al., 2020). Diante disso, optou-se pela utilização desse enxerto biológico como tratamento de ferida após a remoção cirúrgica de uma neoformação, o qual estudos comprovam que materiais a base de colágeno aceleram o processo de cicatrização em tecido cutâneo, assim como ocorreu no animal do presente estudo (BAOSHENG et al., 2020).

Nesse trabalho o protocolo de preparação do curativo biológico seguiu etapas das metodologias citadas por outros autores como o processo de limpeza, recorte e esterilização (MIRANDA, 2018; IBRAHIM et al., 2020). Entretanto, baseando-se no trabalho descrito por Lima-Junior et al. (2017), optou-se pela aplicação das etapas de preparo da pele, devido a praticidade, eficácia e por utilizar materiais de baixo custo.

Para a fixação da pele de tilápia-do-Nilo sobre o ferimento cirúrgico no jacaré, utilizou-se o cianoacrilato, o qual já vem sendo utilizado na medicina em procedimentos cirúrgicos e odontológicos devido a facilidade de aplicação, diminuição dos riscos de contaminação e aumento da aderência e eficácia na cicatrização. Além disso, promove resultados estéticos e funcionais incomparáveis aos métodos tradicionais de sutura, considerando suas complicações aceitáveis (OLIVEIRA et al., 2010; CASTRO DIP e CAMPOS, 2010; DAVIS e DERLET, 2013; VALENTIN FILHO et al., 2021).

Para o paciente em questão, optou-se pela utilização do enxerto biológico em função da presença da neoformação na base da calda. Após o resultado dos achados anatomopatológico e histopatológico, possibilitou-se a conclusão diagnóstica de lipoma (Fig. 
1, F). Essa afeção de carater benigno ocorre devido o acúmulo de gordura nos adipócitos do tecido subcutâneo e, pode acometer animais de todas as espécies, incluindo mamíferos, répteis e anfíbios (BUKERT et al., 2002; BAQIR et al., 2014; BORTEIRO et al., 2017).

Apesar da complexidade relacionada a medicina de crocodilianos (CUBAS et al., 2014), os novos avanços tecnológicos relacionados a cicatrização de feridas podem ser aplicados não somente em animais de estimação, assim como os silvestres (GONZÁLES e MAYER, 2019). Dessa forma, no $30^{\circ}$ dia, foi observado a diminuição da cicatriz na ferida cirúrgica, presença de tecido de granulação róseo e formação de placa córnea. Ao $45^{\circ}$ após remoção do enxerto de pele de tilápia, notou-se cura clínica completa da ferida cirúrgica e expressão do comportamento natural da espécie, sendo posteriormente o animal encaminhado para soltura em seu habitat natural.

\section{CONCLUSÕES}

O uso de enxerto biológico com pele de tilápia, demonstrou ser uma excelente alternativa no tratamento de ferida cirúrgica devido exérese de neoplasia cutânea em crocodiliano, sendo de grande importância o planejamento dos materiais utilizados antecedendo o procedimento nesses pacientes, submetidos a enxertia de pele.

\section{REFERÊNCIAS}

ALVES, A. P. N. N.; LIMA VERDE, M. E. Q.; FERREIRA JÚNIOR, A. E. C.; SILVA, P. G. B., FEITOSA, V. P.; LIMA JÚNIOR, E. M.; MIRANDA, M. J. B.; MORAES FILHO, M. O. Avaliação microscópica, estudo histoquímico e análise de propriedades tensiométricas da pele de tilápia do Nilo. Revista Brasileira de Queimaduras, v. 14, n. 3, p. 203-210, 2015.

BAOSHENG, G.; WANG, H.; LI, J.; LIU, H.; YIN, Y.; ZHANG, N.; QIN, S. Comprehensive Assessment of Nile Tilapia Skin (Oreochromis niloticus) Collagen Hydrogels for Wound Dressings. Marine drugs, v. 18, n. 4, p. 178, 2020.

BAQIR, S.; AZRI, H. A.; RASBI, K. A.; MASTROMONACO, G.; GARTLEY, C. Skin Lipoma in na Arabian Leopard (Panthera paradus nimr). Acta Scientiae Veterinarie, v. 42, n. 1, p. 1-6, 2014.

BORTEIRO, C.; KOLENC, F.; UBILLA, M. Subcutaneous lipoma in the toad Melanophryniscus sanmartini, third case in amphibians. Herpetology Notes, v. 10, p. 709-711, 2017.

BUKERT, B. A.; TUlLY, T. N.; NAVAREZ, J.; MITCHELL, M. A.; CAMUS, A. C. Infiltrative Lipoma in a Corn Snake, Elaphe guttata guttata. Journal of Herpelogical Medicine and Surgery, v. 12, n. 3, p. 33-35, 2002. 
CASSALI, G. D. et al. Cytological and histopathological aspects of lipoma in Botbrops moojeni. Arquivo Brasileiro de Medicina Veterinária e Zootecnia, v. 56, n. 6, p. 799-801, 2004.

CASTRO DIP, E.; CAMPOS, Á. L. F. Ester de cianoacrilato (Super Bonder ${ }^{\circledR}$ ) e suturas tradicional na implantodontia: Relato de casos. Innovations Implant Journal, v. 5, n. 1, p. 60-65, 2010.

CUBAS, Z. S.; SILVA, J. C. R.; CATÃO DIAS, J. L. Tratado de Animais Selvagens. In: BASSETTI, L. A. B.; VERDADE, L. M. Crocodyla (Jacarés e Crocodilos). 2ed. São Paulo: Roca, 2014. p. 2470.

DAVIS, K. P.; DERLET, R. W. Cyanoacrylate Glues for Wilderness and Remote Travel Medical Care. Wilderness e Environmental medicine, v. 24, n. 1, p. 67-74, 2013.

DI GIROLAMO, N.; MANS, C. Reptile Soft Tissue Surgery. Veterinary Clinics of North America: Exotic Animal Practice, v. 19, n. 1, p. 97-131, 2016.

DUBANSKY, B. H.; CLOSE. M. A review of alligator and snake skin morphology and histotechnical preparations. Journal of Histotechnology, v. 42, n. 1, p. 1-2, 2018.

GONZÁLEZ, M. S.; MAYER, J. Technological Advences in Wound Treatment of Exotic Pets. Veterinary Clinics: Exotic Animal Practice, v. 22, n. 3, p. 541-470, 2019.

IBRAHIM, A.; SOLIMAN, M.; KOTB, S.; ALI, M. M. Evaluation of fish skin as a biological dressing for metacarpal wounds in donkeys. BMC Veterinary Research, v. 16, n. 1, p. 1 $10,2020$.

KOHLHAUSER, M.; LUZE, H.; NISCHWITZ, S. P.; KAMOLZ, L. P. Historical Evolution of Skin Grafting-A Journey through Time. Medicina, v. 57, n. 4, p. 1-14, 2021.

LIMA-JUNIOR, E.; PICOLLO, N. S.; MIRANDA, M. J. B.; RIBEIRO, W. L. C.; ALVES, A. P. N. N.; FERREIRA, G. E.; PARENTE, E. A.; MORAES FILHO, M. O. Uso da pele de tilápia (Oreochromis niloticus), como curativo biológico oclusivo, no tratamento de queimaduras. Revista Brasileira de Queimaduras, v. 16, n.1, 2017.

LONG, S. Y. Approach to Reptile Emergency Medicine. Veterinary Clinics of North America: Exotic Animal Practice, v. 19, n. 2, p. 567-590, 2016.

MACHADO, F. L.; SILVA, D. C. B.; TAVEIRA, C. S.; SOUSA, F. A. Uso de pele de tilápia em disjunção de sínfise mandibular em felino: Relato de caso. Publicação em Medicina Veterinária e Zootecnia, v. 15, n. 05, p. 188, 2021.

MIRANDA, M. J. B. Viabilidade da pele de Tilápia do Nilo (Oreochromis niloticus) como curativo biológico no tratamento de queimaduras: revisão da literatura. Faculdade de Medicina de Olinda, v. 1, n. 1, p. 49-52, 2018.

NASCIMENTO, A. B.; MORAIS, F. S.; BEZERRA, J. S.; SILVA, M. L.; OLIVEIRA, G. S.; BEZERRA, Y. C. P. O Uso da Pele de Tilápia no Tratamento de Queimaduras. Temas em Saúde, p. 128-143, 2020. 
OLIVEIRA, C. L.; SANTOS, C. H. M.; BEZERRA, F. M. M.; BEZERRA, M. M.; RODRIGUES, L. L. Utilização de adesivo de cianoacrilato em suturas de pele. Revista Brasileira de Cirurgia Plástica, v. 25, n. 3, p. 573-576, 2010.

OZHATHIL, D. K.; TAY, M. W.; BRANSKI, L. K. A Narrative Review of the History of Skin Grafting. Medicina, v. 57, n. 4, p. 380, 2021.

PASSINI, Y.; AIUB, P. B. Uso de pele de tilápia (Oreochromis niloticus) em acidentes por queimadura em animais selvagens. APAMVET, v. 10, n. 2, p. 29-31, 2019.

RUTLAND, C. S.; CIGLER, P.; KUBALE, V. Reptilen Skin and Special Histological Structures. In: RUTLAND, C. S.; CIGLER, P.; KUBALE, V. Veterinary Anatomy and Physiology. p. 1-21, 2019.

SHIMIZU-HAYASHI; R.; KISHI, K. Skin Graft. Pastic Surgery International, v. 2012, n. 3, p. 1-5, 2012.

TOGNETTI, L.; PIANIGIANI, E.; LERARDI, F.; MARIOTTI, G. Current insights into skin banking: storage, preservation and clinical importance of skin allografts. Journal of Biorepository Science for Applied Medicine, v. 5, p. 41-46, 2017.

VALENTIN FILHO, J. M.; PARDINHO, L.; AVENA, K. M.; FELZEMBURGH, V. A. Uso da cola de cianoacrilato como alternativa em procedimentos cirúrgicos: uma revisão integrativa. Research Society and Development, v. 10, n. 2, p. 1-9, 2021. 


\section{SOBRE OS ORGANIZADORES}

\section{AKSA INGRID VIEIRA BATISTA}

Discente de Medicina Veterinária da Universidade Federal Rural do Semi-Árido (UFERSA) e presidente do Grupo de Estudos de Animais Selvagens da mesma universidade (GEASUFERSA). Pesquisadora (Iniciação Científica - PICI) do Laboratório de Parasitologia Animal da UFERSA (LPA-UFERSA) com o projeto intitulado "Ecto e endoparasitos em animais silvestres e exóticos cativos e atendidos no Parque Zoobotânico Getúlio Vargas, SalvadorBA". Monitora da disciplina de Parasitologia Animal, orientada pela Prof ${ }^{a}$ Dr $^{a}$ Josivania Soares Pereira. Possuiu e possui linhas de pesquisa relacionadas a Animais Silvestres e Exóticos, com ênfase em Parasitologia e Patologia.

CV Lattes: http://lattes.cnpq.br/ 6614624885083003

\section{VICTOR FERNANDO SANTANA LIMA}

Médico Veterinário graduado pela Universidade Federal de Sergipe (2015). Mestre e Doutor em Ciência Animal Tropical pela Universidade Federal Rural de Pernambuco/ Recife-PE (2016 - 2018). Foi Professor Substituto de Parasitologia, Doenças Parasitárias e Clínica Médica de Animais Silvestres no Departamento de Medicina Veterinária da UFS/São Cristóvão-SE, e Coordenador do Setor de Animais Silvestres do Zoológico Boa Luz/Laranjeiras-SE. Atuou como pesquisador colaborador no Oceanário de Aracaju (Fundação Pró-TAMAR) e no Grupo de Estudos Espeleológicos de Sergipe. Membro da Comissão Regional de Meio Ambiente e Animais Silvestres do Conselho Regional de Medicina Veterinária de Sergipe (CRMV-SE); Professor Adjunto do Núcleo de Graduação em Medicina Veterinária da Universidade Federal de Sergipe campus do Sertão; Professor do Programa de Pós-Graduação em Biologia Parasitária (PROBP) da Universidade Federal de Sergipe/Aracaju-SE; Têm experiência na área de Doenças Parasitárias, Parasitologia clínica e laboratorial, Análises Clínicas Veterinária, Medicina Veterinária Preventiva e Clínica Médica de Animais Silvestres e Exóticos.

CV Lattes: http://lattes.cnpq.br/7265386741392623 


\section{ÍNDICE REMISSIVO}

\section{A}

animais, 2, 3, 7, 8, 9, 10, 12, 13, 14, 15, 17, 20, 24, 27, $28,30,31,34,35,36,40,43,44,48,49,50,52,53$, $54,57,58,59,60,61,62,63,65,66,69,72,73,75$, $76,78,79,80,81,82,84,85,86,88,89,90,92,93$, 94, 96, 98, 99, 100, 101, 103, 104

Animais Silvestres, 8, 9, 14, 59, 60, 78, 79, 80, 84, 85, 88,105

atropelamentos, 88, 89, 91, 93, 94

aves silvestres, $19,20,34,41,84,85$

B

biodiversidades, 78,89

C

carapaças de quelônios, 9, 14

crocodiliano, 97, 100, 102

curar, 8

curativos, 7, 9, 10

D

Diptera, 19, 20, 22, 23, 24, 25, 53, 54

$\mathbf{E}$

ectoparasitoses, 19, 20

endoparasitose, 37

enxertos, 7, 10, 96, 98

exames, 29, 34, 38

\section{F}

fauna, 3, 31, 51, 66, 70, 79, 82, 84, 85, 86, 88, 89, 93, 94, 95

fotogrametria, 7, 9

$\mathbf{H}$

habitats, 44 hospedeiros, 20, 27, 32, 40, 50

$\mathbf{L}$

larvas, 20, 21, 22, 24, 28

\section{$\mathbf{M}$}

Medicina, 2, 3, 6, 7, 8, 9, 14, 15, 16, 32, 40, 42, 51, 52, $54,62,63,76,77,86,87,95,96,102,103,104,105$

\section{$\mathbf{N}$}

Nordeste, 10, 17, 19, 20, 23, 45, 54, 81, 86, 88

\section{$\mathbf{P}$}

parasitos, 20, 27, 28, 32, 39, 40, 53

patógenos, 43, 50, 52, 98

pequenos roedores, $58,60,72$

pneumonia, 66

\section{$\mathbf{R}$}

répteis, $10,57,58,59,61,62,65,66,70,78,81,88,89$, $90,93,94,97,98,101$

restauração, $7,9,12,13,14$

S

selvagens, 40, 50, 52, 62, 63, 65, 76, 85, 86, 98, 103

$\mathbf{T}$

tecido, 7, 14, 65, 67, 69, 73, 97, 100, 101

tecnologia, 9, 13, 14

tilápia, 96, 98, 99, 100, 101, 102, 103

tratamento, 7, 8, 9, 12, 13, 14, 38, 40, 49, 67, 73, 75, 76, $83,96,98,101,102,103$

tutores, 59, 62, 74, 75, 76

\section{$\mathbf{Z}$}

zoonose, $27,31,43,44,50,54$ 


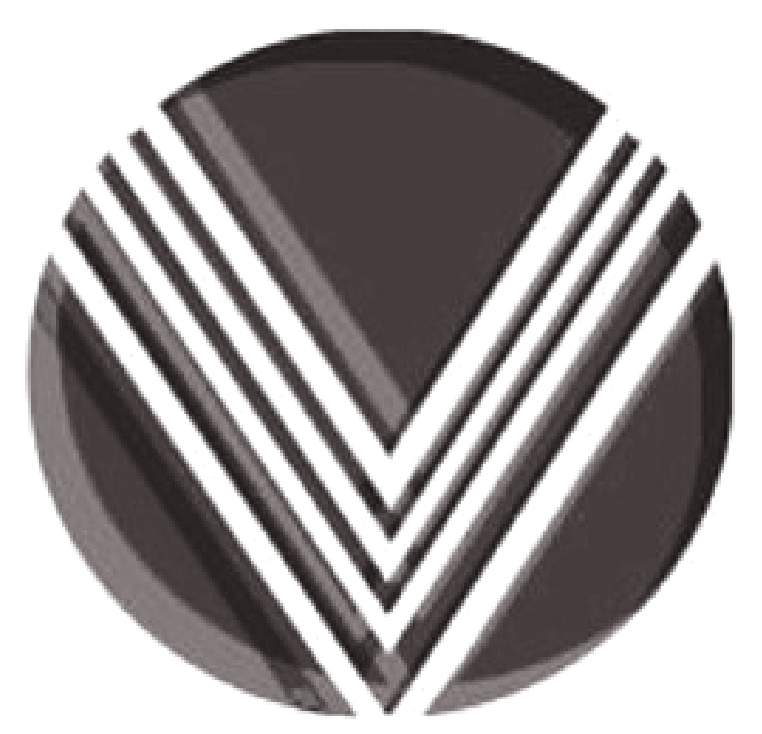

EDITORA
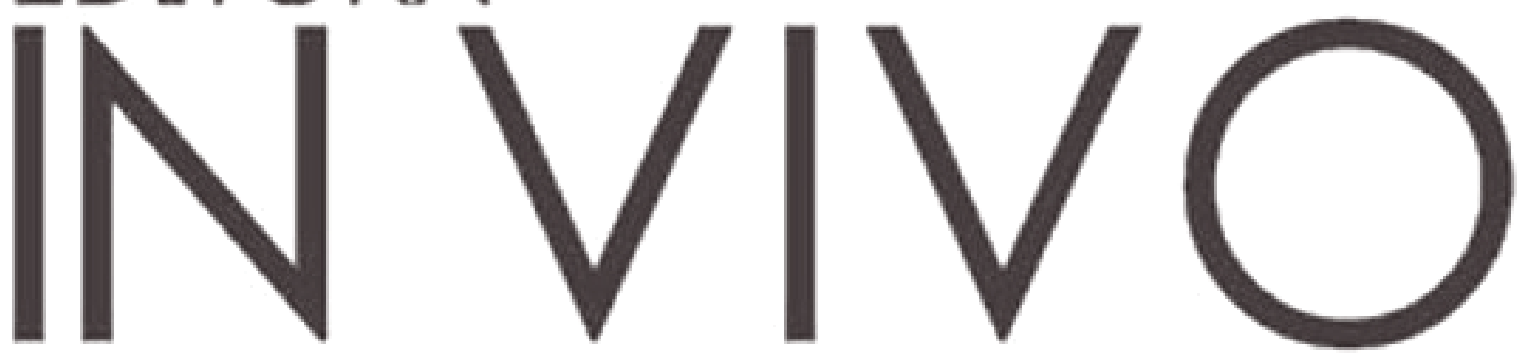

ACESSE:

www.editorainvivo.com

Avance na ciência! Venha ser In Vivo! 